\title{
INVESTIGATING THE MECHANICAL BEHAVIOUR AND DAMAGE RESPONSE OF FLAX FIBRES HYBRIDIZED WITH ARAMIDS
}

\author{
by \\ Ahmed Sarwar \\ Hon. Bachelor of Science (BSc) Physics \\ University of Toronto, 2014 \\ A thesis \\ presented to Ryerson University \\ in partial fulfillment of the requirements \\ for the degree of \\ Master of Applied Science \\ in the program of \\ Mechanical and Industrial Engineering
}

Toronto, Ontario, Canada, 2018

(C) Ahmed Sarwar, 2018 


\section{Author's Declaration}

I hereby declare that I am the sole author of this thesis. This is a true copy of the thesis, including any required final revisions, as accepted by my examiners.

I authorize Ryerson University to lend this thesis to other institutions or individuals for the purpose of scholarly research.

I further authorize Ryerson University to reproduce this thesis by photocopying or by other means, in total or in part, at the request of other institutions or individuals for the purpose of scholarly research.

I understand that my thesis may be made electronically available to the public. 
Investigating the Mechanical Behaviour and Damage Response of Flax fibres Hybridized with Aramids

\author{
Ahmed Sarwar \\ Master of Applied Science (MASc) \\ Mechanical and Industrial Engineering \\ Ryerson University
}

2018

\begin{abstract}
Natural fibers are replacing traditional materials in many industrial applications, though, their use is limited due to their high moisture uptake and complex structure. This study aims at characterizing and analyzing the mechanical and damage response of a hybrid Woven Kevlar/Flax/Epoxy composites in a sandwich structure consisting of a 12 ply Flax core and 2-layer Kevlar skin. Three ply orientations for the flax core([0],[0/90],[ \pm 45$])$, were manufactured. To evaluate the mechanical properties of the hybrid composites, tensile, compressive, flexural and torsional loading tests were performed. Fractured regions were analyzed using optical microscopy to evaluate fracture mechanics. Test specimens were subjected to loadunload sequences at progressively increasing loads until failure to evaluate damage response. SEM analysis was performed to characterize dominant damage mechanisms. Reported data shows that hybridization offers significant improvements in mechanical performance and noticeable reductions in damage accumulation, thus, can be further implemented into the industry for general engineering applications.
\end{abstract}




\section{Acknowledgements}

This dissertation would not have been possible without the unwavering support and guidance of my advisor, Dr. Habiba Bougherara. Her feedback and constructive criticism greatly impacted my research capabilities, and her persistence and optimism is the reason I was able to achieve my goal. I owe much, if not all to her.

I would like to thank Dr. Zouheir Fawaz of the Department of Aerospace Engineering at Ryerson University, for opening his doors to me and providing support without any expectations. I am also grateful to Mr. Alan Machin and Dr. Hamid Ghaemi, for indulging in my every inquiry and providing their expertise whenever required.

I am deeply indebted to my friend and mentor, Dr. Zia Mahboob, who helped me every step of the way. His insight and knowledge regarding material mechanics is bar none, and I can say with absolute certainty that he's taught me everything I know.

I also thank my friends (especially Daniel) and colleagues Ms. Zainab Al-Hajaj, Mr. Benedict Sy, and Mr. Saeed Manteghi for their assistance and friendship throughout the years.

Finally, I am grateful to Natural Sciences and Engineering Research Council of Canada - Discovery Grants program (NSERC-DG), Hunstman Corporation (The Woodlands, TX, USA) and LECO Instruments ULC (Mississauga, ON, Canada) for supplying funding and materials essential to this work. 


\section{Dedication}

I dedicate this thesis to my parents, who have endured my shenanigans ever since I was born, and without whom, I would be nothing. 


\section{Table of Contents}

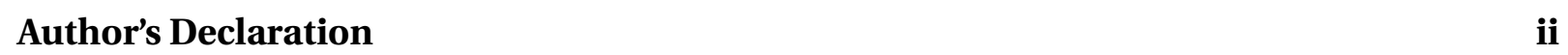

$\begin{array}{ll}\text { Abstract } & \text { iii }\end{array}$

$\begin{array}{ll}\text { Acknowledgements } & \text { iv }\end{array}$

Dedication $\quad$ v

List of Tables $\quad$ viii

List of Figures $\quad$ ix

List of Appendices $\quad$ xii

1 Introduction $\quad 1$

1.1 Research Motivation and Objectives . . . . . . . . . . . . . 3

2 Literature Review $\quad 5$

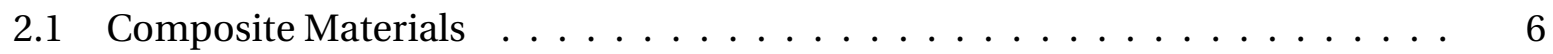

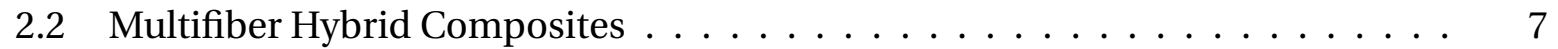

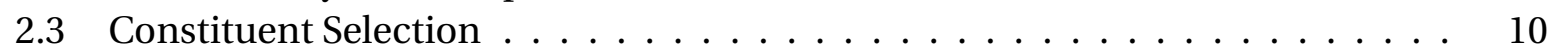

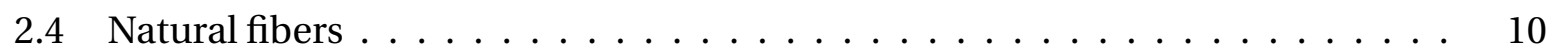

2.4 .1 Flax fibers . . . . . . . . . . . . . . . . . . 12

2.5 Aramid $/$ Kevlar Fibers . . . . . . . . . . . . . . . . . . . . . . 14

2.6 Polymer Matrices $\ldots \ldots \ldots \ldots \ldots \ldots \ldots$

3 Manufacturing of Composites 21

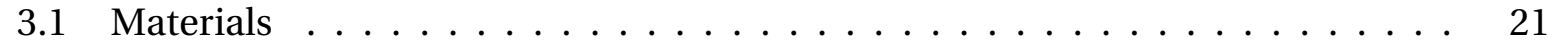

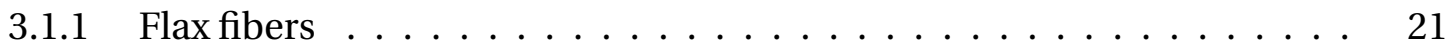

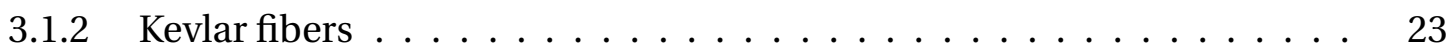

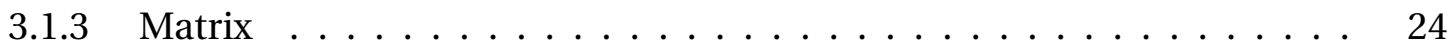

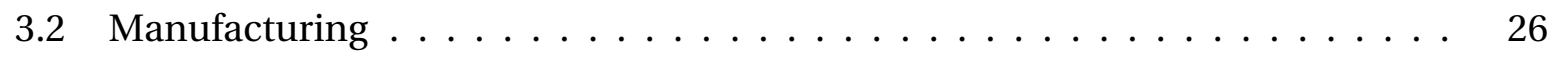

3.2.1 Stacking Sequence and Ply Orientations . . . . . . . . . . . . 26

3.2 .2 Fiber Volume Fractions . . . . . . . . . . . . . . . . 28

3.2 .3 Manufacturing Procedure . . . . . . . . . . . . . . . 28

3.2 .4 Specimen Preparation $\ldots \ldots \ldots \ldots \ldots \ldots \ldots$ 
3.2.5 Volume Fraction Validation and Porosity . . . . . . . . . . . . 33

3.2 .6 Density Measurements . . . . . . . . . . . . . . . . . 35

4 Static Behaviour of Kevlar/Flax/Epoxy Composites 37

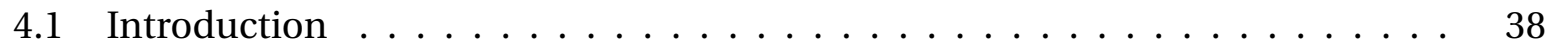

4.1.1 Digital Image Correlation (DIC) $\ldots \ldots \ldots \ldots \ldots \ldots$

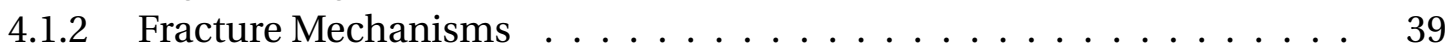

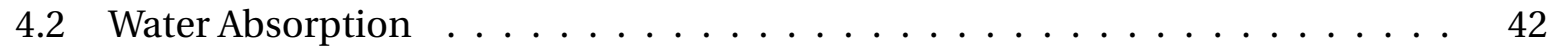

4.3 Rockwell Hardness . . . . . . . . . . . . . . . . . . . . . . . . . . . . . . 44

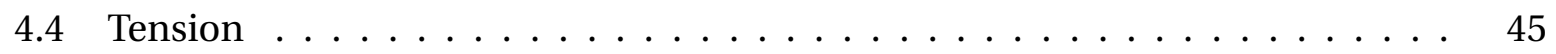

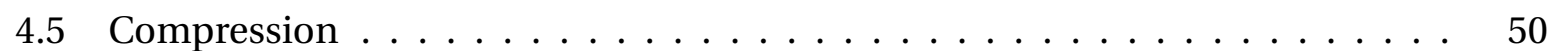

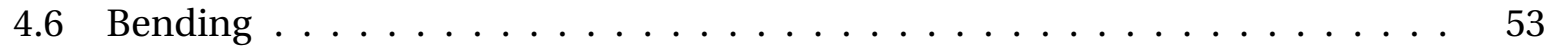

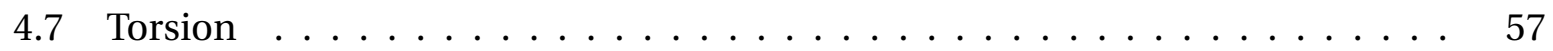

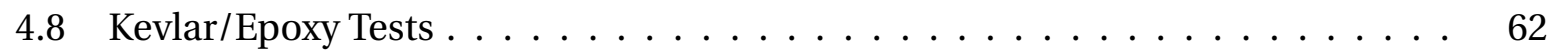

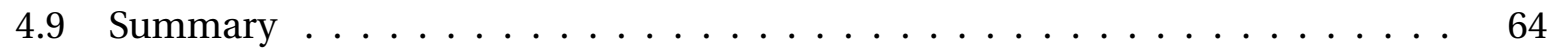

5 Quasi-static behaviour of Kevlar/Flax/epoxy composites 65

5.1 Continuum Damage Mechanics . . . . . . . . . . . . . . . . . . 65

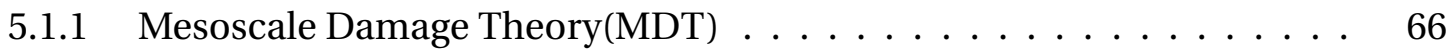

5.2 Damage in Flax and Kevlar Composites _ . . . . . . . . . . . . . . . . 70

5.3 Damage Response of Kevlar/Flax/Epoxy Composites . . . . . . . . . . . . 72

5.3.1 Unidirectional fiber Direction $\left[W_{K 2} / 0_{F 6}\right]_{S} \ldots \ldots \ldots \ldots \ldots \ldots$

5.3.2 Unidirectional Transverse $\left[W_{K 2} / 0_{F 6}\right]_{S} \ldots \ldots \ldots \ldots \ldots \ldots \ldots . \ldots \ldots$

5.3.3 Crossply $\left[W_{K 2} /(0 / 90)_{F 3}\right]_{S} \ldots \ldots \ldots \ldots \ldots \ldots \ldots \ldots \ldots$

5.3.4 Angleply $\left[W_{K 2} / \pm 45_{F 3}\right]_{S} \ldots \ldots \ldots \ldots \ldots \ldots \ldots \ldots \ldots \ldots$

5.3.5 Kevlar/Epoxy $\left[W_{K}\right]_{16} \ldots \ldots \ldots \ldots \ldots \ldots$

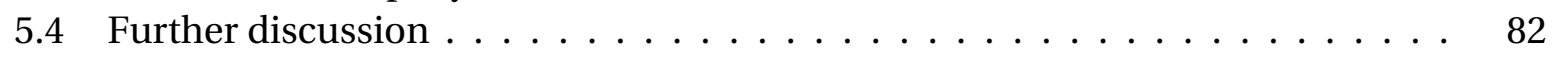

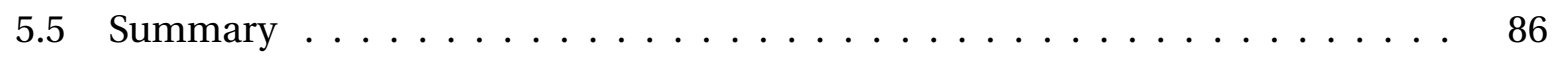

$\begin{array}{ll}\text { Conclusion } & 87\end{array}$

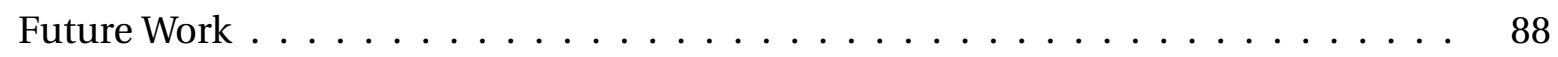

$\begin{array}{lr}\text { Appendices } & 90\end{array}$

$\begin{array}{lr}\text { References } & 95\end{array}$ 


\section{List of Tables}

3.1 Physical Properties of Lineo FlaxPly UD $150[100] \ldots \ldots . \ldots 22$

3.2 Physical and Mechanical Properties of Kevlar 49(BFG Industries) . . . . . . . . 24

3.3 Physical and Mechanical Properties of Araldite ${ }^{\circledR}$ LY 1564 and Aradur ${ }^{\circledR} 22962$ Resin System(Huntsman Advanced Materials, The Woodlands, TX, USA)) . . . . . . 25

3.4 Fiber Volume Fractions and Porosities of UD, Cross-Ply, Angle-Ply and Pure Kevlar ......................... 35

3.5 Comparison between measured and calculated densities and porosities . . . 36

4.1 Moisture Uptake of UD, Crossply and Angleply Hybrid, along with Flax and Kevlar results reported in the literature . . . . . . . . . . . . . . . 43

4.2 Surface Hardness results for Hybrid UD, Crossply and Angleply . . . . . . . . 44

4.3 Mechanical properties of UD, Crossply and Angleply laminates in Tension, compared to their constituents . . . . . . . . . . . . . . . 45

4.4 Mechanical properties of UD, Crossply and Angleply laminates in Compres-

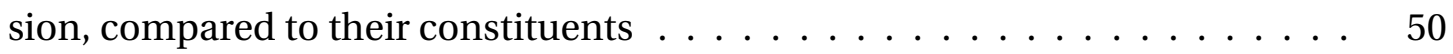

4.5 Mechanical properties of UD, Crossply and Angleply laminates in Bending, compared to their constituents . . . . . . . . . . . . . . . . 54

4.6 Mechanical properties of UD, Crossply and Angleply laminates in Torsion, compared to their constituents . . . . . . . . . . . . . . . 58

4.7 Mechanical properties of Kevlar/Epoxy laminates tested and extracted from lit-

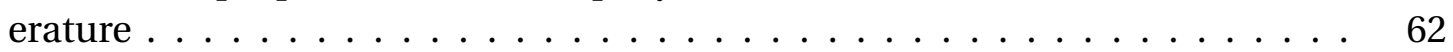

5.1 Comparison of damage and inelasticity evolution in tension ( $\mathrm{T}$ ) and compression (C) for Kevlar/Flax/Epoxy (KFE), Flax/Epoxy (FE) and Kevlar/Epoxy (KE) . 


\section{List of Figures}

2.1 Stress Strain curves for PMCs with constituents [Pilling, 2006] (left), Strength to density ratio comparison between numerous materials [ASHBY, 2017] (right) . 7

2.2 Natural Materials that can be used as fiber reinforcements [ASHBY, 2017] . . . 11

2.3 Environmental Impact of the productions of $1 \mathrm{~kg}$ of Flax and Glass Fibers [10] . 13

2.4 (a) Structure of Flax Stem, (b) Structure of elemenetary Flax fiber [82] . . . . 14

2.5 Structure (right) and Stacking (left) of Kevlar fibers (Dupont, 2017) . . . . . . 15

2.6 Solar Electromagnetic Absorption Spectrum of Kevlar fibers (Dupont, 2017) 16

2.7 Kevlar 29 (left) and Kevlar 49 (right) both with Over Under bidirectional Weav-

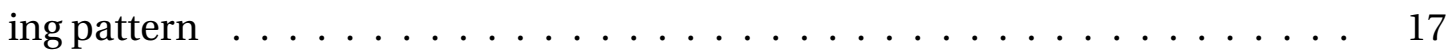

2.8 Comparion of properties between Kevlar and other synthetic polymer fibers (Dupont, 2017) . . . . . . . . . . . . . . . . . . . 17

3.1 UD FlaxPly ${ }^{\circledR}$ fabric roll from Lineo NV, Belgium, shown prepared for cutting on

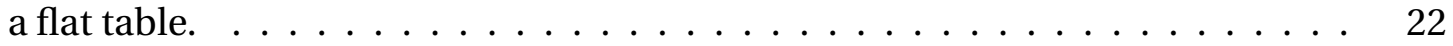

3.2 Kevlar $^{\circledR} 49$, (BFG Industries) $\ldots \ldots \ldots \ldots \ldots \ldots$

3.3 Manufacturing Assembly for KFE Composites . . . . . . . . . . . . . 26

3.4 Three Flax ply orientations visualized $\ldots \ldots \ldots \ldots \ldots \ldots$

3.5 Carver Auto Series Hydraulic Press . . . . . . . . . . . . . . . . . . . . 29

3.6 High temperature plastic membrane Vacuum sealed base aluminum plate with 12 " x 12 " silicon rubber border to prevent resin leakage . . . . . . . . . 30

3.7 Using a laminate brush to spread resin (left), Using a roller to compress plies and extract trapped air $($ right $) \ldots \ldots \ldots \ldots \ldots \ldots \ldots \ldots$

3.8 Plate assembly vacuum sealed in High temperature plastic membrane bag, and inserted in to Carver Press . . . . . . . . . . . . . . . . . . . . . . 31

3.9 Temperature and Pressure curing Cycle used for Huntsman Resin System . . . 32

3.10 Dimensions for Torsion, Bending and Tension Specimens (left $t$ ), all compression specimens $($ right $) \ldots \ldots \ldots \ldots \ldots \ldots \ldots \ldots$

3.11 Sample SEM cross-section image taken at 100x magnification to show fibers, matrix and different flaws present $\ldots \ldots \ldots \ldots \ldots \ldots$

3.12 Example 100x SEM image of KFE UD hybrid cross-section in 8-bit greyscale $(l e f t)$, and the same image processed into black and white (right) to get a $\mathrm{b} / \mathrm{w}$ ratio of the fiber vs. the matrix, which corresponds to the area fraction. . .

3.13 Example 100x SEM image of KFE Crossply hybrid cross-section in 8-bit greyscale $(l e f t)$, and the same image reduced in brightness and contrast to make the

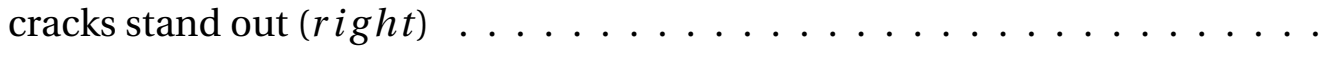


4.1 (a) Digital Image Correlation Imaging setup alongside the Testing Frame, (b) Speckled pattern sprayed on the surface of the sample . . . . . . . . . .

4.2 Different microdamage modes that lead to fracture in long fiber tension loading [Eitzenberger, 2007] . . . . . . . . . . . . . . . . . 40

4.3 Compressive failure (buckling) (left) and Matrix cracking and Delamination (right) $[$ Lesko, 2004] . . . . . . . . . . . . . . . . . . . 41

4.4 Water Absorption rate of UD, Crossply and Angleply KFE Hybrid _ . . . . . . 42

4.5 (a) fiber-direction and (b) Transverse Profile in Tension for UD - $\left[W_{K 2} / 0_{F 6}\right]_{S}$ Hybrid Composite . . . . . . . . . . . . . . . . . . . 46

4.6 (a) Crossply $\left[W_{K 2} /(0 / 90)_{F 6}\right]_{S}$ and (b) Angleply $\left[W_{K 2} /( \pm 45)_{F 6}\right]_{S}$ Profile in Tension for KFE Hybrid Composites . . . . . . . . . . . . . . . . . .

4.7 fiber-direction (left) and Transverse (right) Fracture Side Profile in Tension for UD Hybrid Composite . . . . . . . . . . . . . . . . . . . . 48

4.8 fiber-direction (left) and Transverse (right) Fracture Face in Tension for UD Hybrid Composite . . . . . . . . . . . . . . . . . . . . 48

4.9 Crossply (left) and Angleply (right) Fracture Side Profile in Tension . . . . . . . 49

4.10 Crossply (left) and Angleply (right) Fracture Face Profile in Tension . . . . . . . 49

4.11 (a) fiber-direction and (b) Transverse Profile in Compression for UD - $\left[W_{K 2} / 0_{F 6}\right]_{S}$ Hybrid Composite . . . . . . . . . . . . . . . . . 51

4.12 (a) Crossply $\left[W_{K 2} /(0 / 90)_{F 6}\right]_{S}$ and (b) Angleply $\left[W_{K 2} /( \pm 45)_{F 6}\right]_{S}$ Profile in Compression for KFE Hybrid Composites . . . . . . . . . . . . . . . .

4.13 fibers buckling occurring in Kevlar skin for UD KFE Hybrid (left) and Fracture Side Profile in Compression (right) _ . . . . . . . . . . . . . . 52

4.14 fibers buckling occurring in Kevlar skin for Crossply KFE Hybrid (left) and Fracture Side Profile in Compression (right) . . . . . . . . . . . . . . 52

4.15 fibers buckling occurring in Kevlar skin for Angleply KFE Hybrid (left) and Fracture Side Profile in Compression (right) $\ldots \ldots \ldots \ldots \ldots$

4.16 Three point Bending test Setup . . . . . . . . . . . . . . . . . . 53

4.17 (a) UD - $\left[W_{K 2} / 0_{F 6}\right]_{S}$, (b) Crossply $\left[W_{K 2} /(0 / 90)_{F 6}\right]_{S}$ and (c) Angleply $\left[W_{K 2} /( \pm 45)_{F 6}\right]_{S}$ Profile in Bending . . . . . . . . . . . . . . . . . . . 55

4.18 Side Fracture for UD (left), Crossply (middle) and Angleply (right) Hybrid in Bend-

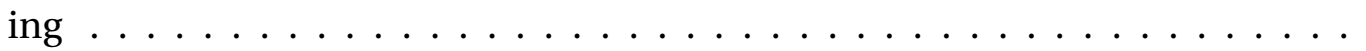

4.19 Fracture face for UD Hybrid in Bending (left) and fibers displaying clean breakage $(r i g h t) \ldots \ldots \ldots \ldots \ldots \ldots \ldots \ldots \ldots \ldots \ldots \ldots \ldots \ldots \ldots \ldots \ldots \ldots \ldots$

4.20 Fracture face for Crossply Hybrid in Bending (left) and fibers displaying clean breakage and pullout $(r i g h t) \ldots \ldots \ldots \ldots$

4.21 Fracture face for Angleply Hybrid in Bending (left) and fibers showing fracture along fiber axis (right) . . . . . . . . . . . . . .

4.22 (a) fiber-direction and (b) Transverse Profile in Shear for UD - $\left[W_{K 2} / 0_{F 6}\right]_{S}$ Hybrid Composite . . . . . . . . . . . . . . . . . . .

4.23 (a) Crossply $\left[W_{K 2} /(0 / 90)_{F 6}\right]_{S}$ and (b) Angleply $\left[W_{K 2} /( \pm 45)_{F 6}\right]_{S}$ Profile in Shear for KFE Hybrid Composites . . . . . . . . . . . . . . . .

4.24 Fracture face for UD Hybrid in Torsion (left) and fibers showing delamination and fiber breakage $(r i g h t) \ldots \ldots \ldots \ldots$ 
4.25 Fracture face for Crossply Hybrid in Torsion (left) and fibers showing delamination and fiber breakage $($ right $) \ldots \ldots \ldots \ldots$

4.26 Fracture face for Angleply Hybrid in Torsion (left) and fibers showing delamination and fiber breakage along fiber axis (right) $\ldots \ldots \ldots \ldots$

4.27 (a) Tension, (b) Compression and (c) Torsion Profile for 16-layer Kevlar/Epoxy

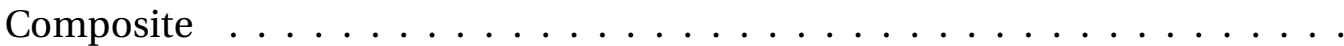

5.1 Visual Representation of a volume element, showing damage as cavities and cracks [Kondo, 2013] . . . . . . . . . . . . . . . . . . . . 67

5.2 General hysteretic response curve generated during quasi-static loading [[78]

5.3 Load Unload Plot for (a) Unidirectional KFE Hybrid and (b) Kevlar/Epoxy showing hysteresis . . . . . . . . . . . . . . . . . . . .

5.4 Damage [(a),(c)] and Inelasticity [(b),(d)] for Tension and Compression in Unidirectional KFE Hybrid . . . . . . . . . . . . . . . . . . .

5.5 SEM Images at 100x for damage in Fiber direction for $\left[W_{K 2} / 0_{F 6}\right]_{S}$ (a)Tension at $0.2 \sigma_{11}^{t}$, (b) Tension at $0.8 \sigma_{11}^{t}$, (c) Compression at $0.2 \sigma_{11}^{c}$, and (d) Compression at $0.8 \sigma_{11}^{c}$. Arrows show intra-bundle cracks. Load applied parallel to fiber direction. ............................. 73

5.6 Damage [(a),(c)] and Inelasticity [(b),(d)] for Tension and Compression in $\left[W_{K 2} / 0_{F 6}\right]_{S} 74$

5.7 Transverse Damage [(a),(c)] and Inelasticity [(b),(d)] for Tension and Compression in Unidirectional KFE Hybrid . . . . . . . . . . . . . . . . . .

5.8 SEM Images at 100x for transverse damage for $\left[W_{K 2} / 0_{F 6}\right]_{S}$ (a)Tension at $0.8 \sigma_{22}^{t}$, and (b) Compression at $\sigma_{22}^{c}$. Small arrows show intra-bundle cracks. Load applied perpendicular to fiber direction. . . . . . . . . . . . . .

5.9 Transverse Damage [(a),(c)] and Inelasticity [(b),(d)] for Tension and Compression in Unidirectional KFE Hybrid . . . . . . . . . . . . . . . . 76

5.10 Damage [(a),(c)] and Inelasticity $[(\mathrm{b}),(\mathrm{d})]$ for Tension and Compression in Crossply KFE Hybrid . . . . . . . . . . . . . . . . . . . . . 77

5.11 SEM Images at 100x for damage for $\left[W_{K 2} /(0 / 90)_{F 3}\right]_{S}$ (a)Tension at $0.2 \sigma_{11}^{t}$, (b) Tension at $0.8 \sigma_{11}^{t}$, (c) Compression at $0.2 \sigma_{11}^{c}$, and (d) Compression at $0.8 \sigma_{11}^{c}$. Arrows show intra-bundle cracks. Load applied parallel to fiber direction. . . . 78

5.12 Damage [(a),(c)] and Inelasticity [(b),(d)] for Tension and Compression in Crossply KFE Hybrid . . . . . . . . . . . . . . . . . . . . . 79

5.13 Damage $[(a),(c)]$ and Inelasticity $[(b),(d)]$ for Tension and Compression in Angle ply KFE hybrid . . . . . . . . . . . . . . . . . . . .

5.14 SEM Images at $100 \mathrm{x}$ for damage for $\left[W_{K 2} / \pm 45_{F 3}\right]_{S}$ (a)Tension at $0.2 \sigma_{11}^{t}$, (b,e) Tension at $0.8 \sigma_{11}^{t}$, (c) Compression at $0.2 \sigma_{11}^{c}$, and (d,g,f) Compression at $0.8 \sigma_{11}^{c}$. Arrows show intra-bundle cracks. Load applied parallel to fiber direction. . . .

5.15 Damage [(a),(c)] and Inelasticity [(b),(d)] for Tension and Compression in Angle ply KFE hybrid . . . . . . . . . . . . . . . . . . . .

5.16 Damage and Inelasticity for Tension [(a),(b)] and Compression [(c),(d)] in Pure

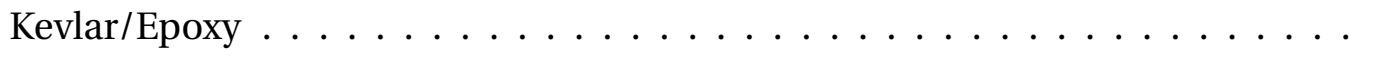




\section{List of Appendices}

A.1 Sartorius Lab 2000 Series (Sartorius Inc., NY, USA) … . . . . . . . . . . 91

A.2 LR300TD Rockwell Hardness tester (LECO Corporation, St. Joseph, MI, USA) . 92

A.3 MTS 322 (Eden Prairie, MN, USA) Hydraulic Test Frame . . . . . . . . . . . . . . 93

A.4 CTT series torque testing machine (Shenzhen Sans Testing Machine Co. Ltd., Shenzhen, China $\ldots \ldots \ldots \ldots \ldots \ldots$ 


\section{Chapter 1}

\section{Introduction}

Composites have been used since time immemorial to enhance the properties of their constituent materials. History has extensive evidence that different fibers have been used by many civilizations to augment and improve materials and structures in many facets of life. Nowadays, fiber reinforced polymer composites are known to provide better strength to weight ratios than metals and have been constantly overtaking metals in industries ranging from biomedical, aerospace, automotive to civil and structural engineering applications. While fiber-based composites are projected to remain popular in engineering applications, their sustainability and end of life disposal still require meaningful research and implementation. Synthetic fibers such as Carbon, Glass and Aramid are still massively used in current industries [1; 2], however, due to their high energy production, hazardous environmental impact and low relative renewability, natural fibers have been rising steadily in the ranks. [1;3-6].

In recent times, interest in natural fibers has picked up significantly as an alternative to commercially available synthetic fibers such as glass and carbon. Due to the race against global warming, governments have started investing readily in high sustainability and recyclability, promoting the use of alternative environmentally friendly materials as alternatives. [7; 8]. Generally, natural fibers offer easier recyclability [5], higher sustainability, [4; 9], low cost to weight ratio [3], lower energy requirements for production [10], and low toxicity [10; 11], while exhibiting similar mechanical properties to some conventional fibers. $[3 ; 4 ; 7 ; 8 ; 12]$.

Natural alternatives to synthetic fibers can be found in plants such as kenaf, Flax, jute, hemp, sisal, bamboo, etc. [13-17] and in animals (wool, hair, silk, etc.) [18; 19] . While used, fibers derived from animals offer comparatively low mechanical properties in comparison to the production and environmental costs [6]. In this context, current natural fiber research has been directed towards the readily available and inexpensive plant-based fiber. In fact, natural 
fibers are now widely used in the automotive industry, with an annual growth rate of above $20 \%[20]$.

While natural fibers have numerous advantages, their disadvantages cannot be discounted. Compared to synthetic fibers, natural fibers show a higher moisture absorption rate rendering them incapable of handling hydrophobic applications. Natural fibers also tend to degrade at relatively low temperatures (around $200^{\circ} \mathrm{C}$ )) which eliminates high temperature applications as well as the use of high temperature thermoset resins [12;21]. Due to their bio-compatibility, they are susceptible to microorganisms, and exhibit poor fire resistance [12; 20]. Depending on the fibers, their mechanical properties can vary largely [21] and due to natural decay, they are susceptible to wear and tear [12]. Structurally, natural fibers do not exhibit uniform monofilament cylindrical behaviour, similar to carbon and glass fibers, they are instead bundles of non-uniform elementary fibers that are inherently flawed and contains defects. [13].

Mixing different varieties of fibers can offer a hybrid solution, as one can compensate for the disadvantages of the other [22]. Hybridization has been a staple in the manufacturing industry with vast adaptation across various applications. Most commonly, synthetic fibers such as Carbon fiber, glass and Aramid fibers are mixed and matched to improve mechanical performance[23-25].

In this research, different orientations of Flax and aramid (Kevlar 49) fiber-reinforced polymer composites are manufactured and extensively tested. The effective hybridization potentially creates a material that uses combines the strengths of Kevlar and Flax, while complimenting their inherent weaknesses. This novel research enhances the existing understanding of natural and synthetic fiber composites, their mechanical behaviour, progression of damage, failure modes and damage response. 


\subsection{Research Motivation and Objectives}

Natural fibers offer many desirable properties for engineering applications. Despite research increasingly leaning in favour of plant-based fibers [3; 26-31], industries have been reluctant to adapt them. Usually found in non-structural applications such as sporting equipment $[1 ; 6]$, one is hard pressed to find them being utilized in load bearing mechanical and civil engineering applications.

Natural plant fibres are hydrophilic by nature. Their inherent cellulosic structure is built to move water through a plant. This makes them prone to up-taking much more water compared to synthetic fibres. Natural fibers are also susceptible to harvesting times and locations. Consistent natural growth is dependent on many factors, such as the soil content, watering schedules, types of fertilizer etc. Therefore, the mechanical properties of plant fibres are highly variable, even for the same type and breed. Extensive sorting and quality checks are needed to maintain consistent mechanical performance.

With governments moving towards sustainability and recyclability, natural fibers offer a sustainable and cost effective solution. However, extensive adaption requires extensive testing, and it is here that natural fibers are at a disadvantage. The current research and data available on their mechanical performance are lacking. Coupled with their hydrophilic and variable nature, industries are reluctant to adapt.

It is also extremely difficult to alter the current widespread use of synthetic fibers completely towards natural fibers. Changes takes time and effort, both of which are costly. It is much easier to adapt than overcome. Hybridization offers a middle ground, where natural and synthetic fibers with conflicting advantages can be combined to improve their overall performance, while still benefitting from their mutual strengths. These hybrids can be manufactured in the optimized facilities currently used for composite manufacturing, without extensive modifications. Any addition of natural fibers can reduce the carbon footprint of every industry currently using composite materials. Due to the novelty and added complexity of different material properties, research in Multifiber Hybrid composites is still in the early stages.

There are a variety of publications on Multifiber Hybrid composites, and many discussing synthetic-natural combinations. Though most of the studies published, tailor the composite for specific application and avoid an in depth analysis of the benefit of hybridization itself. Understanding the interactions between various types of fibers cannot be characterized by performing basic mechanical testing methods. Knowledge of damage initiation and progression, failure mechanics and plasticity accumulation are required to properly design hybrid 
composites for structural applications. Existing studies that study damage, focus mostly on damage within the fibers, and to the authors knowledge, no present publications characterized the damage response in Multifiber Flax Hybrid composites.

In order to fill this knowledge gap, the aim of this study is to manufacture and characterize the mechanical behaviour of Kevlar-Flax hybrid composites. Physical as well as the mechanical orthotropic properties will be determined under different loading conditions. The elastoplastic behaviour of the hybrid composite will be quantified in terms of damage and inelastic strain accumulation under quasi-static loading. This study will provide the necessary basis to define and validate the behaviour and mechanical response of Flax-Kevlar composites, hopefully, leading to increased adaption. 
Chapter 2

Literature Review 


\subsection{Composite Materials}

A composite combines multiple materials of varying properties, in an effort to benefit from their combined strengths and dampen their respective weaknesses. Generally, they consist of a material reinforced with a matrix. The reinforced material contributes mechanical properties, and acts as the load bearing medium while the matrix adhesively binds to the material, transfers loads between fibers and offers environmental protection to the reinforcements.

Composite materials are categorized into three subsets, varying in the type of reinforced material. Metal-matrix composites, include powdered metals and electroplating. Ceramicmatrix composites (CMCs) are used in extreme applications in aerospace and automotive industries, as they retain their mechanical properties at high temperatures. Lastly, Polymermatrix composites (PMCs) are some of the most commonly used composites, due to their ease of manufacturing and relatively low cost. They contain fiber reinforcements, along with a polymer-based matrix.

PMCs typically contain materials such as Glass, Carbon, Graphite, Aramid etc. The fiber

reinforcements typically have excellent mechanical properties, however, due to the miniscule diameters of the individual fibers, they cannot be fully utilized[32]. They require something to bind them, in order to collectively exploit their high strengths and stiffness. Polymer-based matrices are easily mouldable and versatile; however, their low material strengths keep them from being used extensively. Combining the two into a single composite material, reinforces the weak individual fibers together, increasing their capacity to bear load much more efficiently. Fiber-Polymer Matrix composites exhibit higher strength to density ratios than most metals and can be tailored to suit the application. Figure 2.1 shows the general loading contributions of PMCs and its constituents, along with a comparison between composites and other materials.

Due to the combinatory nature of PMCs, their properties can vary depending on the amount of fibers and matrix used. The volume difference between the fibers and matrix, make or break a composite. Therefore, an optimized ratio has to be decided upon, whenever creating a new composite material. This diversity is represented by volume fractions, whose relation to the strength and stiffness is represented in the following equations (Eq. 2.1, 2.2).

$$
\begin{gathered}
E_{c t}=E_{f} v_{f}+E_{m} v_{m} \\
\sigma_{c t}=\sigma_{f} v_{f}+\sigma_{m} v_{m}
\end{gathered}
$$




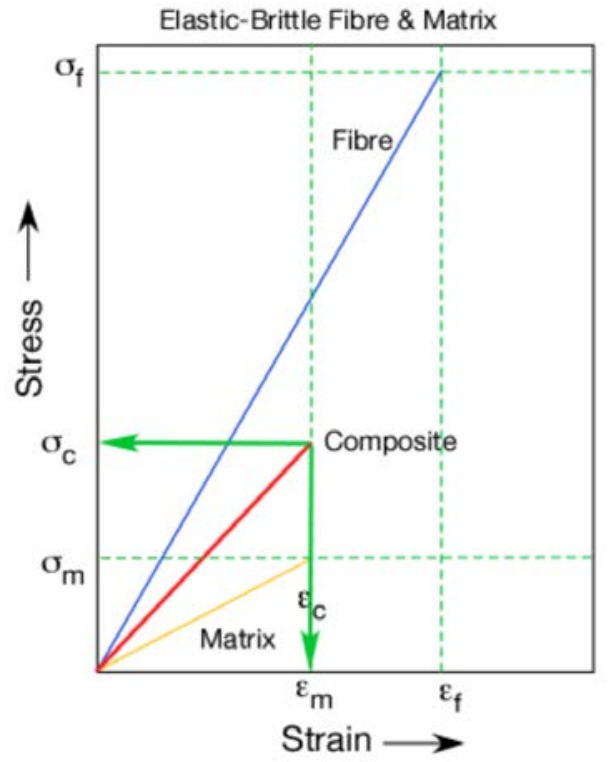

(a)

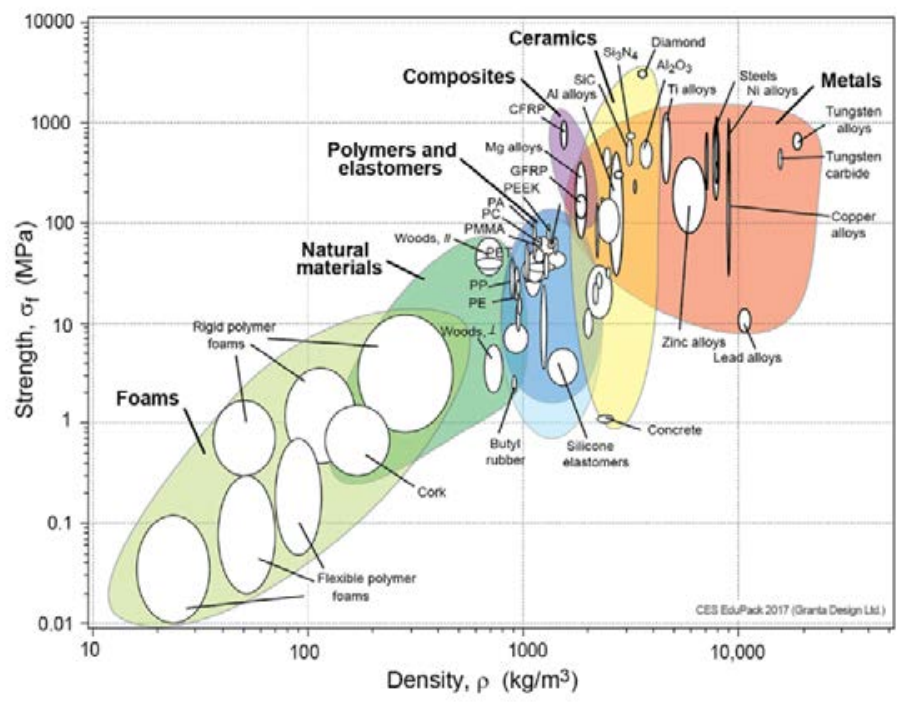

(b)

Figure 2.1: Stress Strain curves for PMCs with constituents [Pilling, 2006] (left), Strength to density ratio comparison between numerous materials [ASHBY, 2017] (right)

While most PMCs consist of one type of fiber and matrix, this research focuses on two different fibers combined within a matrix, also known as hybrid composites. While the same volume fraction rules can be used, due to the difference in the fiber properties, it is more complicated to predict their behaviour, and there haven't been many studies that investigate the interaction of different fibers, bonded together.

\subsection{Multifiber Hybrid Composites}

Multifiber Hybrid composites (MHCs) combine two or more fibers as reinforcements with the same matrix. They are known for their versatility and are desired when a single type of fiber cannot fulfill the design requirements. MHCs also have the ability to be tailored to exhibit different mechanical properties in multiple directions. as needed, or when longitudinal as well as lateral mechanical performances are required. Multiple fibers can be layered in multiple orientations for different fibers, resulting in varying mechanical behaviour dependent on the loading axis. This gives MHCs a significant advantage over regular isotropic materials, allowing the composite to handle multidirectional and non-uniform loading conditions for the required applications. [33]. 
Due to the flexible nature of most natural and synthetic fibers, thermoset resins are the best choice for adhering fibers. Relatively hard thermosets force the fibers to remain parallel to the loading axis, utilizing their maximum potential and eliminating formation of kinks and bends. Due to the chemical nature of the curing cycles, compatible thermosets tend to adhere strongly to fibers, showing excellent resilience under torsional and bending loading. [34].

Hybridization has been a staple in the manufacturing industry with vast adaptation across various applications. Most commonly, synthetic fibers such as Carbon fiber, Glass and Aramid fibers are mixed and matched to improve mechanical performance [23-25]. Swolfs et al.[35] recommended Carbon/Glass composite for multidirectional loading applications such as wind turbine blades. Valenca et al. [23] showed that combining Glass and Kevlar highly improved mechanical strength and impact performance, when compared to plain Kevlar. Wan et al.[25] performed flexural and impact tests on Carbon/Kevlar hybrids, concluding that the hybrid retained similar flexural properties to Carbon fiber, while also increasing impact damage tolerance superior to Kevlar. Hybridization of Carbon fiber with basalt fiber and E-Glass significantly decreased fracture propagation, resulting in high impact energy absorption [36]. Sezgin et al. [37] demonstrated that incorporating Glass/Carbon fibers to the outer layers of the composites leads to higher impact resistance, while placing them in the inner layers results in higher tensile strength.

However, focus has been shifting towards hybrids between synthetic and natural fibers, with studies corroborating their mechanical and environmental advantage. Synthetic MHCs are light weight and have excellent mechanical properties, however, they have a huge negative impact on the environment. While synthetic fibers are stronger, they are often non-recyclable and their production emits greenhouse gases. Combining them with natural fibers, can lead to less waste and a lower environmental impact[38]. Dhakal et al.[39] did a complete characterization on Carbon/Flax hybrids and confirmed their viability in structural applications. Bagheri et al.[40], tested and simulated Carbon/Flax hybrids for bone fracture plate applications. Similarly, Manteghi et al.[41], proposed Glass/Flax hybrids as a potential solution for similar biomedical uses. Yahaya et al.[42] combined Kevlar with kenaf to improve impact properties. Nisini et al.[43] showed that combining Flax and basalt with Carbon made the Flax fibers rigid, increasing their flexural tolerance. Many other studies corroborated the superiority of hybridizing natural fibers with synthetic ones [44-48]. MHCs have also been implemented in the industrial manufacturing. Recently, CARBIO developed a Carbon/Flax hybrid for automotive structural applications [49]. Cicala et al.[50] used hybrid Glass/natural fiber composites in curved pipes to achieve a $20 \%$ cost reduction while saving $23 \%$ in weight, in comparison to currently implemented solutions. 
While the selection of the constituent materials is important, the properties of MHCs also depend on the traditional volume fraction and ply-orientation. The volume fraction of the fibers and matrix can be tweaked to obtain optimal mechanical performance. For example, a $50 / 50$ ratio of Carbon and Flax has been shown to results in $15 \%$ cost and $7 \%$ weight reduction, along with having 58\% higher vibrational damping, all the while maintaining a similar bending stiffness to Carbon fiber laminates [49]. Similarly, the ply-orientation plays an important role in the performance of the material under different loading conditions and can be adjusted based on requirements.

There is however another property that must be taken into account for MHCs. Due to the composites having different types of fibers, it is imperative to study the placement of the fibers with respect to each other. Using the ply orientation and fiber placement, MHCs can be made to exhibit orthotropic, anisotropic and even relative isotropic properties, for the same basic fiber compositions. This freedom allows engineers to design specifically tailored variations in composite properties, extending the possible application range, based on the same fundamental fibers.

Many different structural properties can be obtained via changing the placement of the fibers. Depending on the difference in mechanical properties of the fibers, MHCs can display a wide range in behaviour. Most combinations of MHCs use a mixture of a cheaper, comparatively lower strength fibers and expensive high-performance fibers to complement each other. Generally, for MHCs, the fiber layup can be divided into two patterns: (1) similar fibers stacked together (2) different fibers stacked alternatingly. To reduce the impact of interfacial bonding between different fibers, alternating patters in fibers should be avoided. Similar fibers tend to bond much better with each other and can improve overall mechanical properties of the composite.

The most commonly used fiber layup method in MHCs is the sandwich structure due to its versatile mechanical strengths and ease of manufacturing $[24 ; 40 ; 41 ; 43 ; 51]$. The MHC is made to have a stiffer material as the outer layers that take majority of the tension and compression loads under flexural loading and absorb the most energy during impact. All the while, maintaining the same stress load during uniaxial loading as the inner plies. Fiore et al.[51] and Bagheri et al.[40] showed that the presence of Carbon fiber layers on the outside of a Flax fiber core improves the mechanical properties significantly. MHCs with a sandwich structure can simultaneously exhibit a lower axial stiffness while still having a higher bending stiffness. 


\subsection{Constituent Selection}

When creating a composite, the selection of the constituents is of utmost importance. The fibers provide the strength and stiffness required for load bearing. The matrix is required to be compatible with the fibers (to not be reactive with the fibers, to be adhesive enough to keep the fibers together) as well as efficiently transfer forces between the fibers.

When selecting fibers, one must consider both the physical and mechanical properties offered, depending on the application in mind. Fiber selection can depend on properties ranging from strength, ductility, hardness, density, corrosion to thermal conductivity, toxicity, water absorption, cost etc. Due to emphasis on environmental preservation, industries have been focusing on finding greener alternative to commonly used materials. Synthetic fibers like Carbon and Glass have allow industries to reduce material weight while maintaining highperformance, however, in the long term, synthetic-fiber PMCs are not easily recyclable, and their production contributes to increased greenhouse gas emissions.

While natural fibers may one day be the dominant in material engineering, transitioning from synthetic to natural fibers is not an easy task. Considering all these factors, a hybrid material consisting of natural and synthetic fibers offers to be a compromise that is sustainable, environmentally friendly, light-weight and exhibits excellent physical and mechanical properties.

\subsection{Natural fibers}

Natural fibers consist of fibers derived from plants, animals and minerals. Fibers from plants can be obtained from many parts including the leaf, stem or bast or even the fruit. Mineral fibers are mined from the earth and woven into fabric. Animal fibers are from either the animals its self like sinew and ligaments, or are produced by them, e.g. wool, silk, hair etc. Figure 2.2 shows the strength to stiffness ratio of natural materials than can be harvested. It can be seen that plant-based fibers offer the highest performance and are therefore used for commercial composite applications [52].

Plants consist of lignocellulosic structures [53]. The three-major organic constituent of plant cell walls are cellulose, hemicellulose and lignin [53; 54]. A plant behaves as a naturally occurring composite material, where the lignocellulose fibrils are reinforcement fibers bonded with a lignin matrix [55]. 


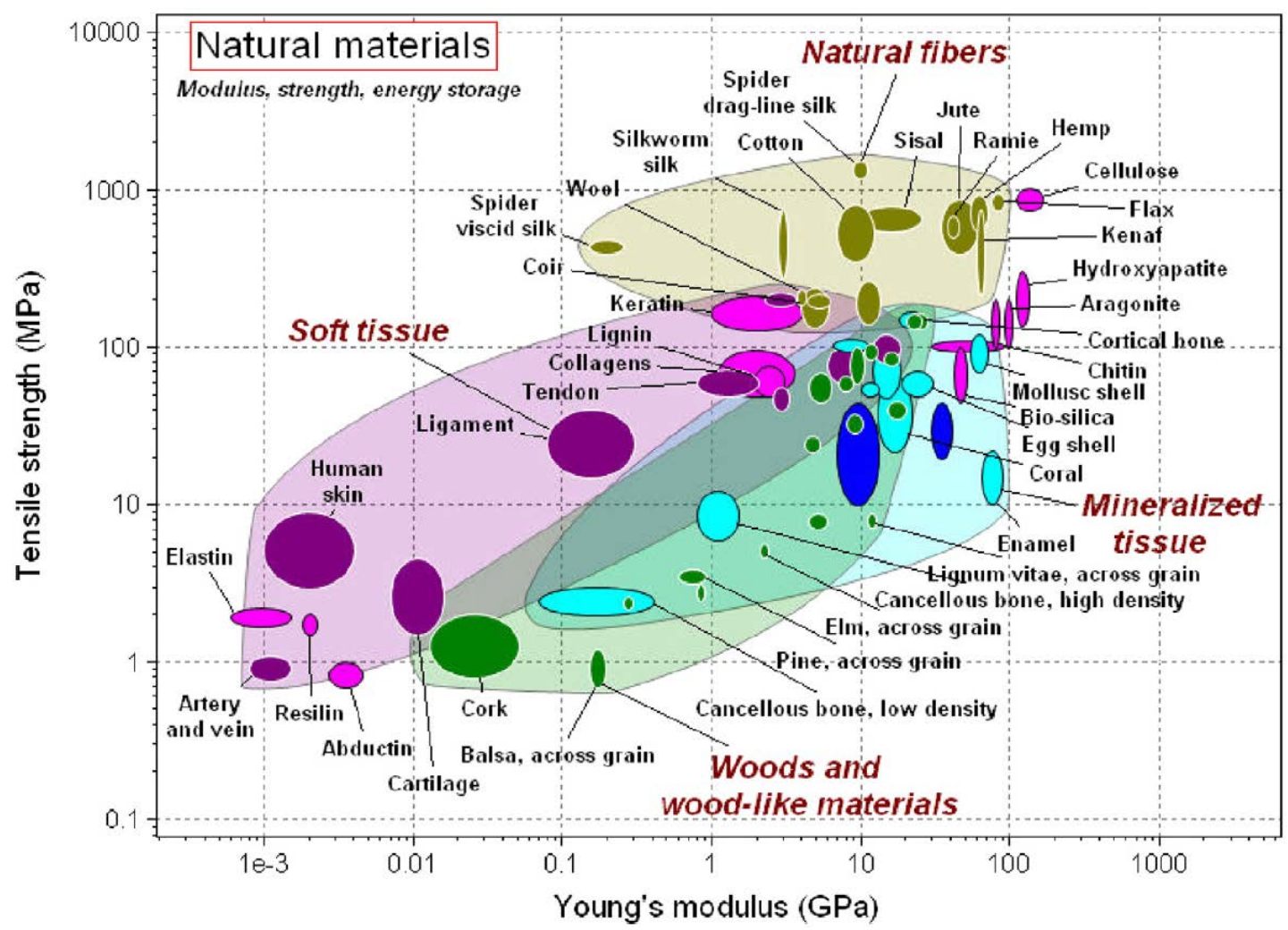

Figure 2.2: Natural Materials that can be used as fiber reinforcements [ASHBY, 2017]

The plant fibers are a collection of organic molecules that are held together by their structure and hydrogen bonds [52]. Thus, varying the amount of different sugars(cellulose) can result in different strength characteristics. The angle of the microfibrils plays an important role in the stiffness. The closer the angle is to the loading fiber axis, the stiffer the material becomes. Helically structured fibers offer more ductility but lower strength [20]. Other properties such as the absorption, thermal response and biocompatibility are decided by the amount of hemicellulose. While lignin offers protection to the internal fibers from ultraviolet radiation[52].

Natural fibers are starting to come into the limelight. They exhibit high strength to density ratio $[3 ; 4 ; 13 ; 56]$, are sustainable and renewable[5; 13], have a low cost of energy consumption and production [10; 16], offer excellent thermal insulation and vibrational damping [13], are very environmentally friendly and contribute as a Carbon sink $[4 ; 9 ; 11 ; 15 ; 57]$, absorb higher energy impacts [58] and are very biocompatible and offer low toxicity [10; 11].

However, they are not without there downsides. Due to the natural manufacturing process, they are highly dependent on the source for consistency in properties. They offer lower ultimate strengths when compared to conventional Carbon or Aramid fibers [16; 26; 59], have 
a high variability in mechanical properties and relative data due to fiber geometry and imperfections [56; 60-64], are flammable and cannot operate at extreme temperatures due to their organic nature $[11 ; 13]$. Natural fibers also exhibit complex non-linear behaviour in loading and cannot be modeled as linear elastic isotropic [65; 66], they are biologically active and vulnerable to microorganisms $[11 ; 13]$ and have high water absorption rate and retention due to intra-fiber voids [67-69].

Many surface chemical processes such as alkaline and silane treatments, acrylation etc. reduce water present within the fibers, constricting them and abrasively affect the fibers surfaces, increasing the fiber-matrix contact area for better adhesion[20; 55]. While these methods do enhance fiber properties, they cannot overcome the organic boundaries set in nature, and must require additional support.

\subsubsection{Flax fibers}

From Figure 2.2 its can be seen that Flax fibers offer a higher strength and stiffness when compared to other natural materials. They are cheap to produce, readily available, renewable and have a high strength to density ratio [21]. The density of Flax fibers is $1.473 \mathrm{~g} / \mathrm{cm}^{3}$, which makes them much lighter than Glass and Carbon fibers. Flax composites have been paired with thermoplastic, thermoset, as well as biodegradable matrices and have been shown to exhibit good mechanical properties [21]. Flax is locally produced in Canada, in fact, Canada has been the largest producer and exporter of Flax since 1994 [21]. While the utilization of the fibers for composites is relatively new, Flax seeds have been used for oil and dietary needs, while the bast has been extensively used in the textile and paper industries[70].

Flax is currently used in the European automotive industry as to reinforce the internal structure $[17 ; 71]$. Manufacturers blended Flax short fibers with polypropylene, as well as used a mixture of Flax and sisal fibers to reinforce doors in cars [20; 72] as well as crumple zones in the front bumper [73]. Combinations of Flax are also used as non-woven mats that are then compression molded as window pillars, interior trays, and rear trunk liners [74; 75].

Flax fibers are often compared and used as an alternative to Glass fibers. Hagstrand and Oksman [76] compared the tensile properties of Flax and Glass composites, concluding that the difference in mechanical performance was minor. Muralidhar et al. [77] also recommended Flax as a replacement for Glass fibers.

Flax composites exhibit non-linear behaviour under loading [22; 78] because of the elastovisco-plastic deformation of the fiber [21]. The behaviour then becomes linear to fracture as 


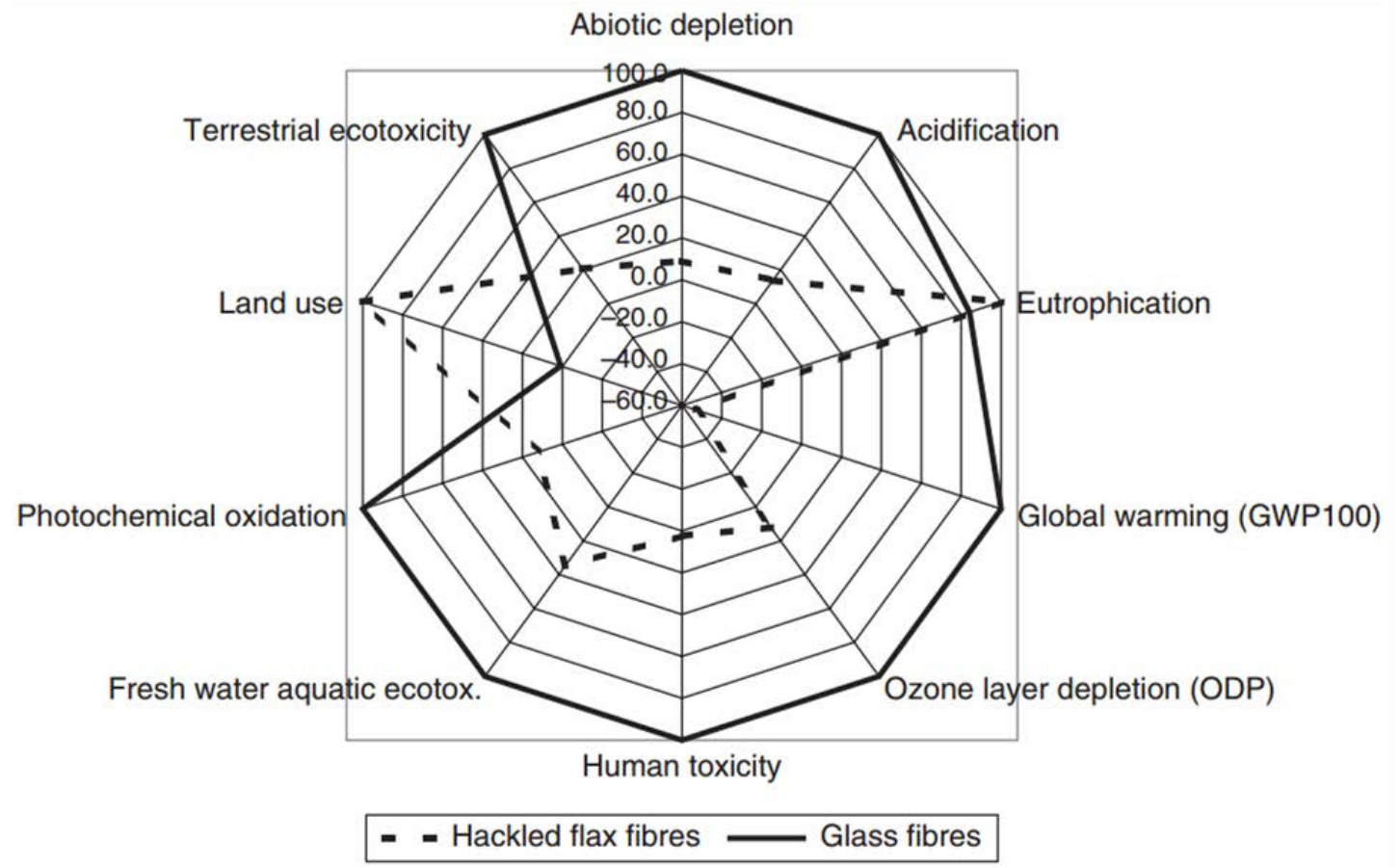

Figure 2.3: Environmental Impact of the productions of $1 \mathrm{~kg}$ of Flax and Glass Fibers [10]

the microfibrils are straightened [21]. Evidence of energy dissipation can be found during the loading and unloading, as a hysteresis loop emerges. Higher hysteresis amounts to higher energy dissipation, benefiting the vibration damping properties of the material [22]. Flax short fibers can also be injection molded, allowing its composites to enter many consumer products such as luggage bags, musical instruments, sports equipment and furniture[75]. Its use in bicycle frames over Carbon fiber has resulted in a stiff but vibrationally damped frame[79].

Flax also comes with some limitations. Flax fibers are hydrophilic, like many lignocellulosic fibers, which makes them incompatible with hydrophobic matrices, and degrades the tensile properties with increasing moisture absorption[13; 21$]$. The bast of a Flax plant has a multi-component structure consisting of nesting layers of fibers held together by pectin. The elementary Flax fiber consists of layers of concentric cell walls. A central opening called a lumen contributes to the water uptake and is responsible for the hydrophilic nature of Flax fibers $[21 ; 80]$.

Treating Flax fibers with chemical treatments does reduce the water retention $[13 ; 17 ; 21$; 78]. However, non-woven Flax mats subjected to alkali, silane, acetylation and enzymatic treatment, showed no significant improvements in strength[81].

An elementary Flax fiber breaks down to cellulose, hemicellulose, lignin, pectin and wax. The cellulose fibrils behave as reinforcements with the lignin and pectin being the matrix, 

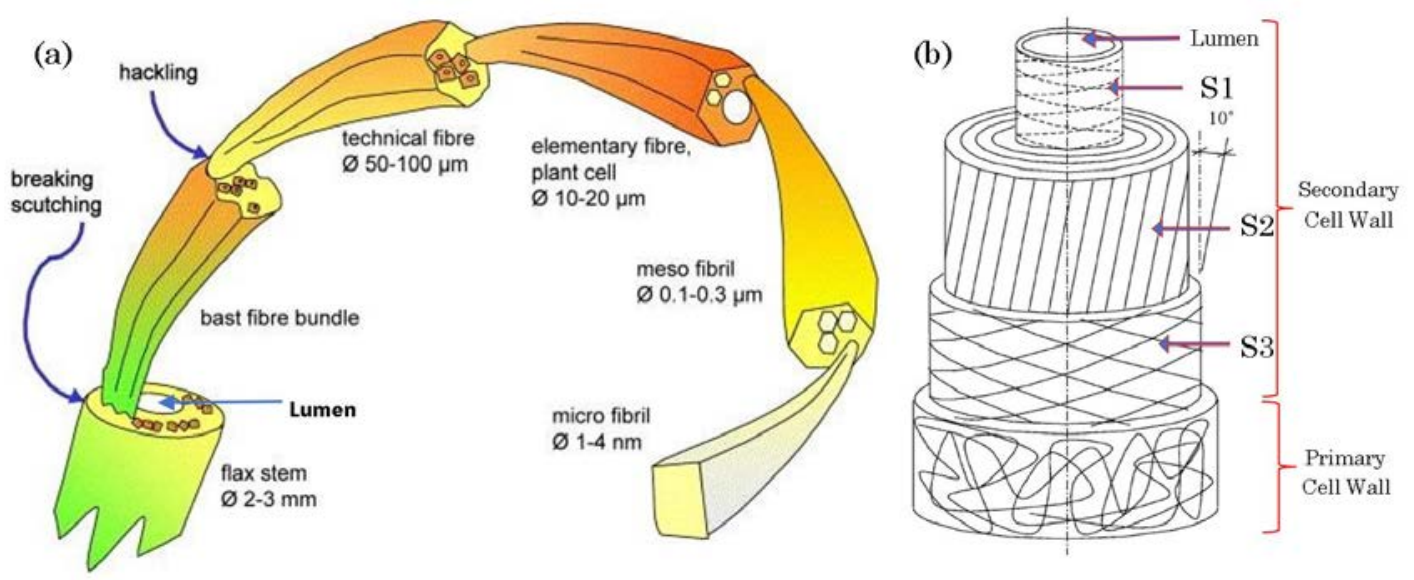

Figure 2.4: (a) Structure of Flax Stem, (b) Structure of elemenetary Flax fiber [82]

resulting in Flax fibers themselves, being a composite. The cell walls in the elementary fiber, consisting of cellulosic microfibrils, provide the strength and tend to form an angle with the fiber axis [21].

The properties of Flax fibers also depend on the time and location of harvest. In additions the properties are also dependent on gauge length and the diameter of the fiber. When loaded in tension, the microfibrils re-orient themselves parallel to the loading direction [78]. The initial angle of the microfibril determines the stiffness of the Flax fibers resulting in a high variability in the mechanical properties [78]. The resulting variation in the structure, can cause the longitudinal tensile modulus to fluctuate between 27-91 GPa and the strength between 300-1300 MPa [78]. It is also worth noting that these mechanical properties depend on gauge length and the diameter of the fiber tested.

Flax fibers are available as unidirectional Flax fibers, prepregs, woven fabrics, and yarns for commercial composite applications and can be combined with many manufacturing techniques such as filament winding, pultrusion, vacuum infusion, and compression molding[83].

\subsection{Aramid/Kevlar Fibers}

Apart from Glass and Carbon, some of the most commonly used synthetic fibers are part of the aramid family, whose fibers consist of Carbon, oxygen, nitrogen and hydrogen atoms bonded in chains [84]. The most famous of the aramid fibers is Kevlar, formed by reacting para-phenylenediamine and xerophthalmy chloride through polymerization. They are then extruded into hot cylinders at $392^{\circ} \mathrm{F}$, washed and dried on spools. The fibers are then stretched 
to increase tensile strength and stiffness [84]. The individual fiber properties vary depending on spinning conditions, heat treatments and/or solvents used [32].

\section{Hydrogen-Bonded Sheet}

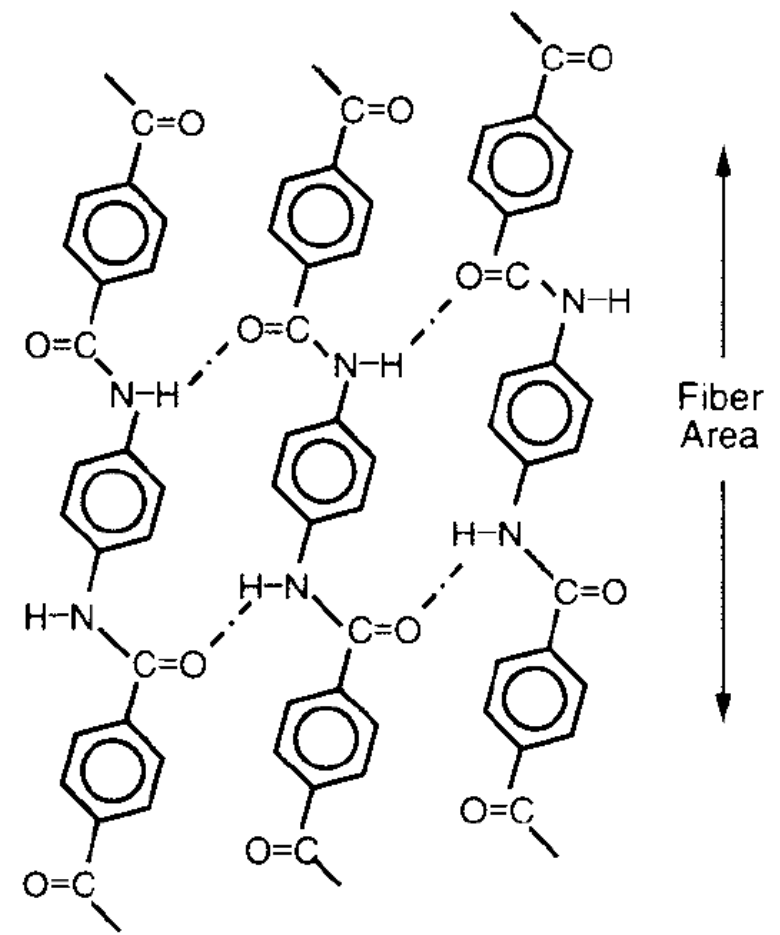

Sheets Stacked Together

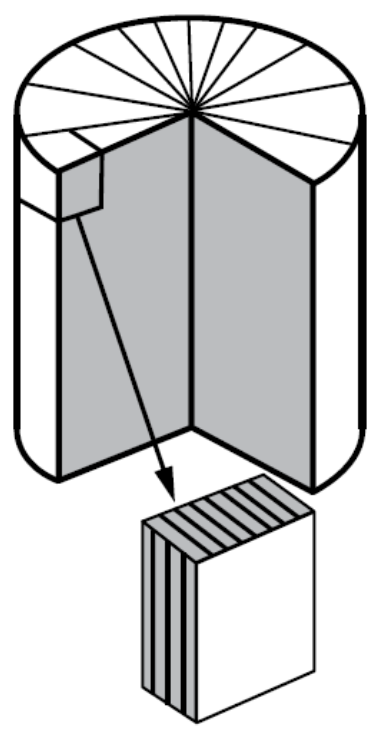

Figure 2.5: Structure (right) and Stacking(left) of Kevlar fibers (Dupont, 2017)

While there are many synthetic polymers with a variety of properties, Kevlar's superiority depends on the polymer chains as well as the aromatic stacking interactions between adjacent strands. Kevlar fibers exhibit high tensile strength and stiffness at a low density, are relatively cheap and offer some degree of resistance to high temperatures. Combing Kevlar fibers with a matrix creates and strong light weight, and high-performance material, which offers excellent impact resistance and damage tolerance [85]. Kevlar therefore, has been popular in impact applications such as bullet proof vests. While versatile, Kevlar is highly susceptible to UV damage and deteriorates rapidly, however, resins do act as barrier and can prevent loss of strength[86].

Kevlar comes in different types of fibers and filaments with their own individual properties and performance criteria. Kevlar 29 and Kevlar 49 are the most commonly used grades. Kevlar 49 has a higher tensile strength and stiffness than Kevlar 29, while both maintain the same density. Kevlar 29 comes in a tighter weave, and thus the fabrics made are built for ballistic 


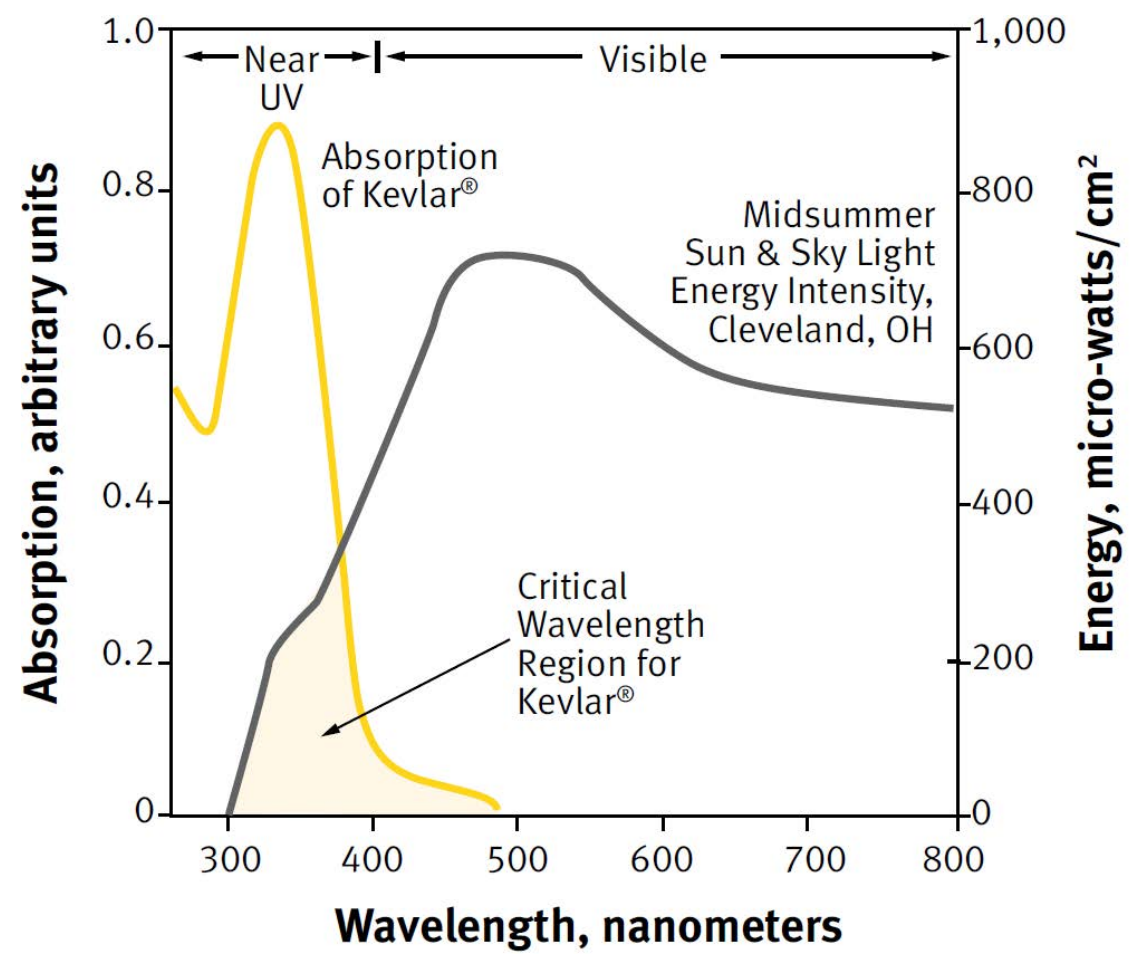

Figure 2.6: Solar Electromagnetic Absorption Spectrum of Kevlar fibers (Dupont, 2017)

protection. Kevlar 29 is predominantly used in protective body armor, armor helmets, ballistic panels, ropes and cables. Meanwhile, Kevlar 49 is suited for high-performance composite applications such as boats, aircrafts, and sporting equipment[84].

Kevlar 129 and Kevlar 149 offer an improvement over Kevlar 29 and Kevlar 49 fibers. Kevlar 129 is higher in strength and stiffness than Kevlar 29 [87] and Kevlar 149 is an aerospace grade fiber with the highest performance and tensile modulus of all Kevlar fibers [88].

While strong in tension, Kevlar 49 is flexible, and [89]needs to be reinforced with a rigid matrix A major disadvantage of aramid fibers is their compression strength [28], being only one-eighth of their tensile strength [32] Under compression, kink bands form in the fibers, due to their anisotropic nature, resulting in deformation occurring around $0.5 \%$ strain[32; 90]. Kevlar also exhibits poor inter-facial adhesion in resins, resulting in lower bonding between fibers [89]. Silane treatments are often performed to increase surface roughness and improve adhesion. Overall the strengths of Kevlar far outweigh the weaknesses, as they can be overcome with the proper methods and tools. The following table shows a comparison between different synthetic fibers and Kevlar. 

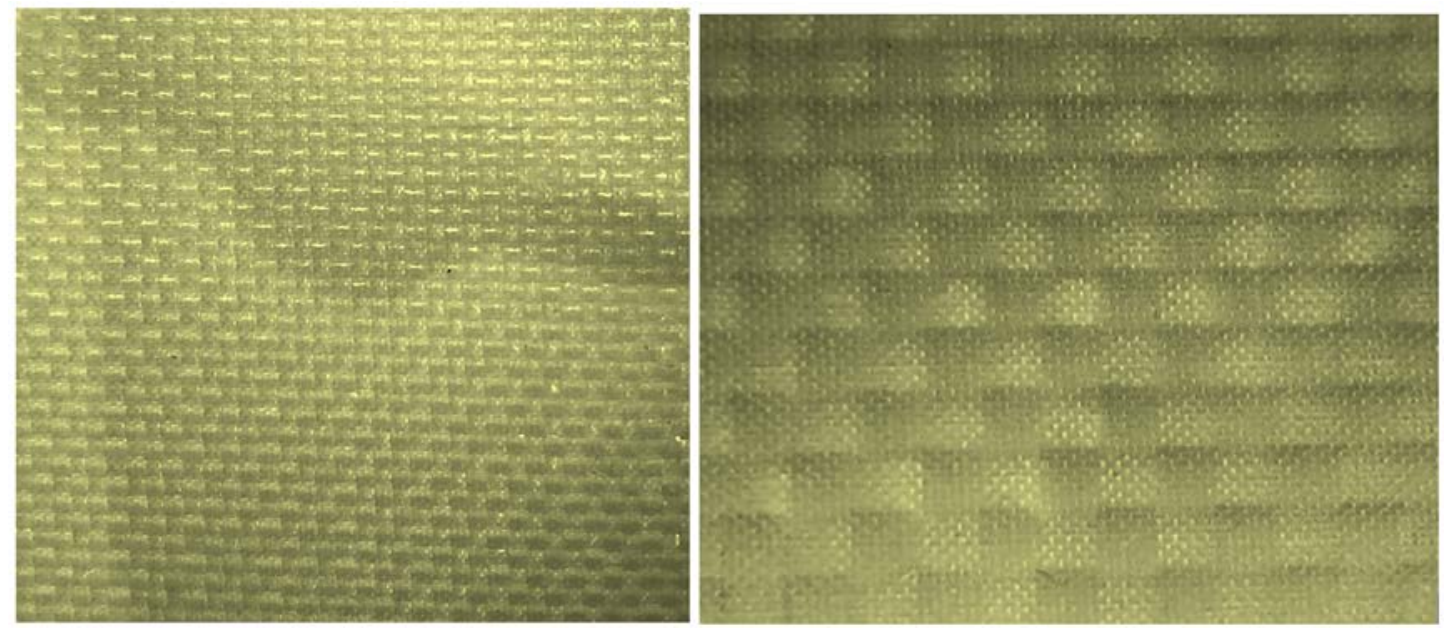

Figure 2.7: Kevlar 29 (left) and Kevlar 49 (right) both with Over Under bidirectional Weaving pattern

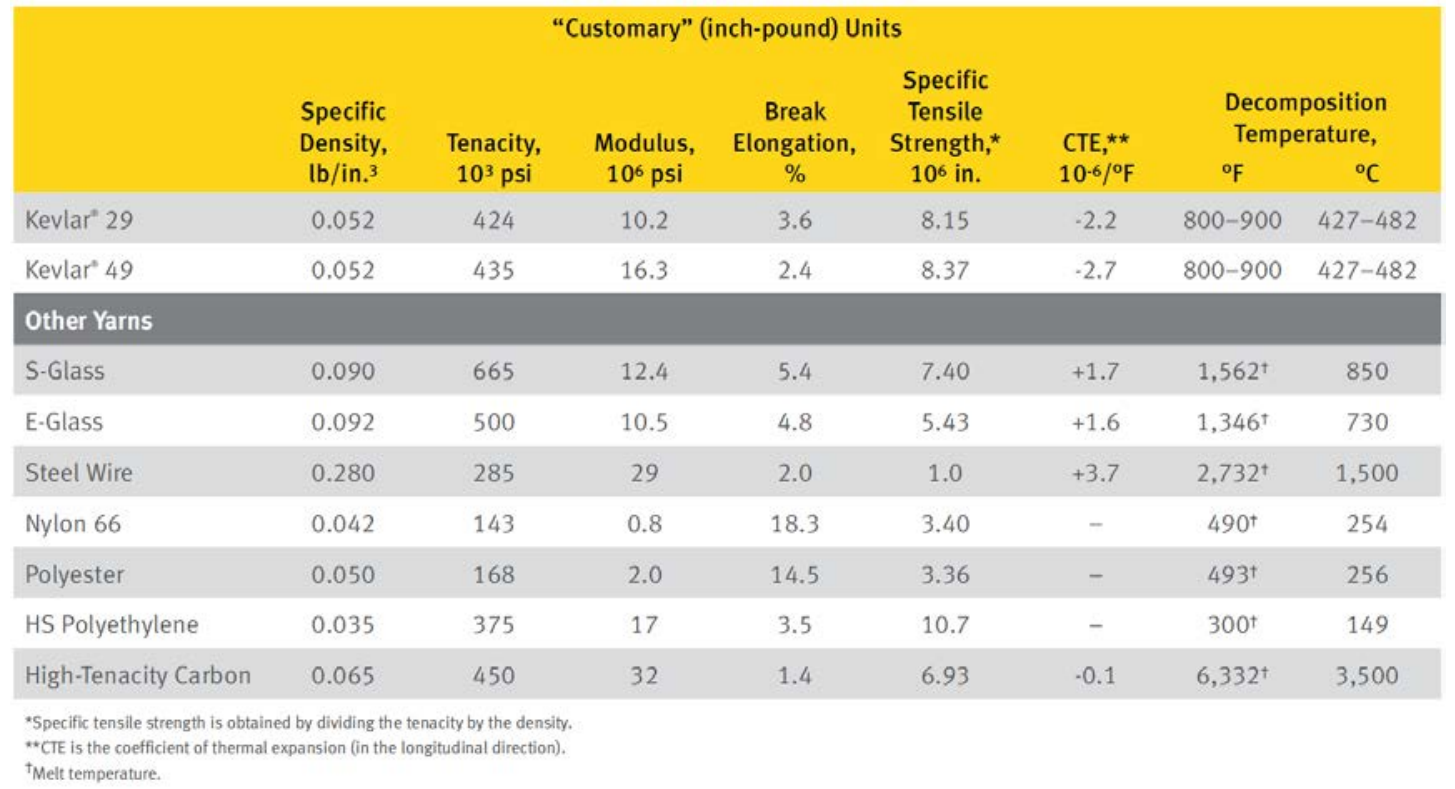

Figure 2.8: Comparion of properties between Kevlar and other synthetic polymer fibers (Dupont, 2017)

\subsection{Polymer Matrices}

Polymers consist of long chains of hydroCarbons, held together by covalent bonds. They offer low cost, are inert, low density, are easily mouldable, and are the most commonly used matrix substitute [32]. The properties of a polymer matrix are based in the intermolecular bonds and the molecular structure. Thus, they can have many different varieties but generally, can be classified into three categories i.e. thermoplastics, elastomers and thermosets. 
Elastomers lie between thermosets and thermoplastics. While they are not as permanent as thermosets, they are lightly joined polymer chains that exhibit partially rigid and plastic behaviour [91]. Natural and synthetic rubber are a prime example of elastomers, and while they are not regularly used as matrices, they do improve ductility in epoxies by co-polymerizing with the naturally the brittle matrices [92].

Thermoplastics and thermosets are defined by their reaction to heat. Thermoplastics can be reformed and remolded under heat and pressure, making them completely reversible and recyclable. Polyether-ether ketone (PEEK), polyethylene, acrylic plastics and nylon are all considered thermoplastics. Thermoplastics melt or become malleable when heated over their Glass temperature. These polymers have strong intramolecular bonds but are weaker intermolecularly [32]. Thus, they offer high ductility, fracture and impact resistance as well as relatively higher operating temperatures [93]. They are widely used in aircrafts to offer highimpact resistance to windows.

Thermosets cannot be remolded or re-melted. They are harder and become permanent if heated above their Glass transition temperature. Initially, thermosets are soft and flow like a liquid. However, when heated to the Glass transition temperature, the resin and hardener chemically react. The molecular structure of the polymer is changed, a consequence of the cross-linking of molecules, which creates strong covalent bonds, turning the material permanently into a solid. Because of this cross-linking, thermosets have a higher modulus and strength in comparison with thermoplastics [93]. However, due to this chemical permanency, they are more brittle and have a lower toughness. Thermosets include polyamides and epoxies, which are extensively used through all manufacturing industries due to their high strength, durability, low shrinkage and chemical volatility, as well as resistance to heat and humidity [93].

The matrix in a composite affects the mechanical properties of the composite laminate especially in the transverse loading direction. Interfacial bonding is of utmost importance in shear applications and the brittleness of the matrix affects the compression properties. Swolfs et al. [94] hypothesized fiber breakage to be the main cause of composite failures. They showed that a broken fiber can still contribute due to the transference of shear forces in the matrix. A thermally stable and resistant matrix is also required when dealing with high temperature applications [32]. Due to the flexible nature of Flax and Kevlar, a rigid matrix is required to hold the fibers together, ensure efficient transference of force, and offer protections from environmental factors. A hybridization of Flax and Kevlar with the appropriate epoxy matrix has the potential to display high specific strength, stiffness, toughness and 
damping ability, as well as reducing the impact of water and other environmental factors. A material with these properties would be highly suited to and sought after, for applications in the automotive and sports equipment industries. 



\section{Chapter 3}

\section{Manufacturing of Composites}

Composite materials, nowadays, are being used in all major industries around the world. Their outstanding mechanical and physical properties have made them an indispensable part in modern material applications. A composite is generally made by layering fiber reinforcements in a specific decided pattern, while saturating all layers with the matrix, to ensure maximum saturation. Composite materials offer an infinite versatility in their properties. By changing the material reinforcements and the matrix along with their placement and orientation in the composite structure, they can be tailored to any required need[95].There are many techniques that have been used to manufacture composites, such as: resin transfer moulding (RTM), hand layup methods, compression moulding, pultrusion, vacuum infusion etc[21]. Each of the different techniques have their advantages and disadvantages, however, due to the shallow learning curve and relatively low cost, the hand layup method followed by heat compression moulding was used to create the specimens.

\subsection{Materials}

\subsubsection{Flax fibers}

Flax fibers are available in many different forms ranging from yarns and rovings to short fibers and mats [59; 76; 96-98]. The Flax fiber bundles are also woven into fabrics, with multiple weave variations available $[61 ; 68 ; 99]$.

A dry fabric roll of FlaxPly ${ }^{\circledR}$ UD 150 from Lineo NV, Belgium [100], was used in this study as fiber reinforcements. Majority of the fiber bundles present in the fabric are unidirectional, with some fibers periodically weaved for support, resulting in a $0^{\circ}$ to $90^{\circ}$ ratio of $40: 3$ i.e. for 


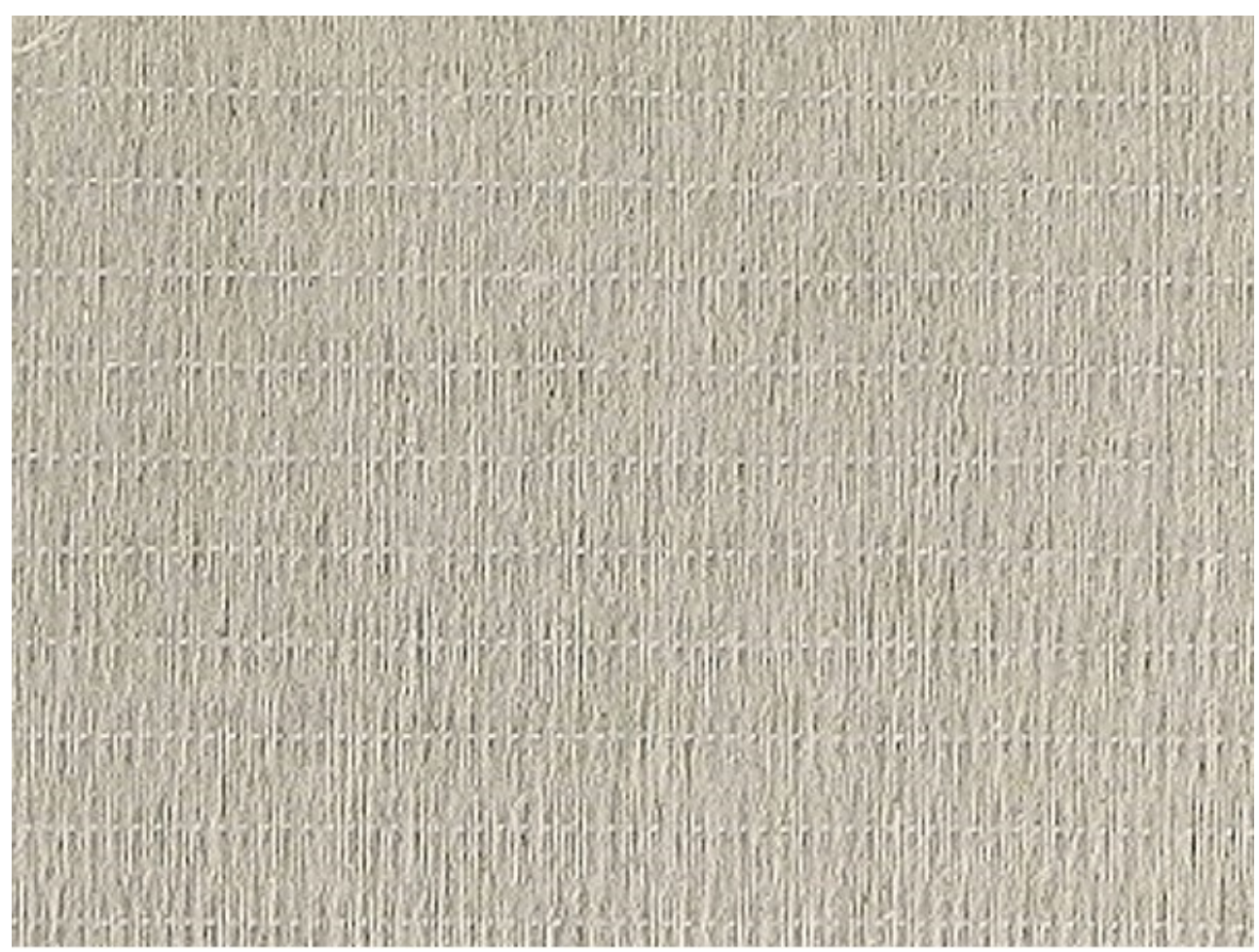

Figure 3.1: UD FlaxPly ${ }^{\circledR}$ fabric roll from Lineo NV, Belgium, shown prepared for cutting on a flat table.

every 40 fibers in the $0^{\circ}$ direction, there are 3 fibers woven in the $90^{\circ}$ direction, per unit area. While technically, this fabric is considered a weave, published studies [78], show that the cross fibers do not have a significant contribution in the composite performance, hence, the fabric may be considered as unidirectional As discussed earlier, Flax bast fibers come in bundles of elementary fibers, which in this case, have a twist rate of approximately 5 turns $/ \mathrm{cm}$. The table (Table 3.1)below lists the physical properties of the Flax fiber fabric, as taken from the supplier.

Table 3.1: Physical Properties of Lineo FlaxPly UD 150 [100]

\begin{tabular}{cccccc}
\hline Density & Grammage & SA:Vol & Yarns & Picks & Thickness \\
\hline $1.473 \mathrm{~g} / \mathrm{cm}^{3}$ & $150 \mathrm{~g} / \mathrm{m}^{2}$ & $0.106 \mathrm{~mm}^{-1}$ & 40 (warp) & 3 (weft) & $0.165 \mathrm{~mm}$ \\
\hline
\end{tabular}




\subsubsection{Kevlar fibers}

Kevlar® 49 fabric is used extensively in the composites industry. It offers high strength and stiffness, excellent impact performance and has a similar density to Flax. For this study, Kevlar 49, style-5500, 13 x 13 yarns/inch plain weave, made by BFG industries was chosen. While unidirectional fibers provide the highest performance, a cross weave was chosen to balance the overall performance of the composite. Many studies show that there is a benefit provided by woven fiber fabrics in enhancing the mechanical properties of composites [101-103].

Pothan et al.[104] and Yan etal [21] performed tensile and flexural tests on different weaving and layering patterns on the tensile and flexural behaviour, and determined that a weave pattern enhances the overall strength of the composites. Gujjala et al.[103] and Khan et al.[105], both, studied the effects of woven fibers and their structure on the mechanical properties of jute hybrid composites. They concluded that hybrid composites containing woven fabrics tend to perform better as a well-rounded material, than their unidirectional counterparts. Hence, for this study, a Kevlar weave was chosen, in order to provide the Flax with better multi-directional support.

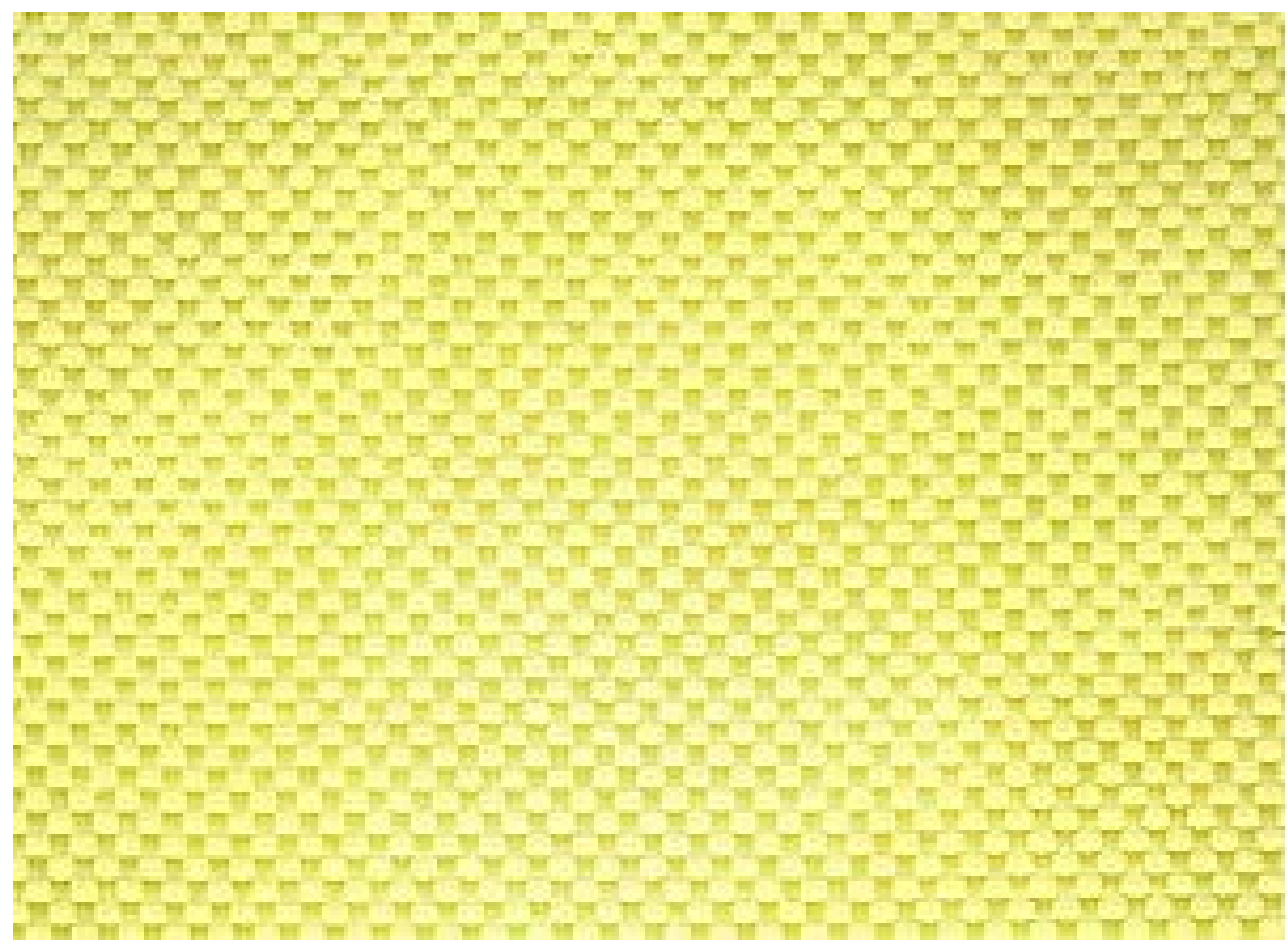

Figure 3.2: $\operatorname{Kevlar}^{\circledR} 49$, (BFG Industries)

The properties of Kevlar 49 are known, however, the data mostly consists of yarns and unidirectional fibers. BFG Industries does not list the mechanical properties for this style of 
fabric. Therefore, the mechanical performance data for this weave was derived from a study done by Zhu et al. [106]. who performed tests on a 17x17 yarns per inch weave pattern.

Using the tensile strength and strain of the $17 \mathrm{x} 17$ fabric, along with the ratio of the breaking strengths, the properties of the $13 \times 13$ plain weave were calculated(Table 3.2).

Table 3.2: Physical and Mechanical Properties of Kevlar 49(BFG Industries)

\begin{tabular}{lc}
\hline Density & $1.44 \mathrm{~g} / \mathrm{cm}^{3}$ \\
\hline Grammage & $169.5 \mathrm{~g} / \mathrm{m}^{2}$ \\
\hline Thickness & $0.254 \mathrm{~mm}$ \\
\hline Tensile Modulus & $117 \mathrm{GPa}$ \\
\hline Tensile Strength & $2.34 \mathrm{GPa}$ \\
\hline Failure Strain & $2.6 \%$ \\
\hline Poisson's Ratio & $0.35-0.63$ \\
\hline Breaking Strength(warp and fill) & $113.8 \mathrm{~N} / \mathrm{mm}$ \\
\hline
\end{tabular}

\subsubsection{Matrix}

Thermosets are known to best complement the performance of PMCs. Therefore, an epoxy resin system consisting of Araldite ${ }^{\circledR} \mathrm{LY} 1564$ and Aradur ${ }^{\circledR} 22962$ (Huntsman Advanced Materials, The Woodlands, TX, USA) was chosen due to its compatibility with Kevlar and Flax fibers. Araldite ${ }^{\circledR}$ LY 1564 is a low-viscosity resin while the Aradur ${ }^{\circledR} 22962$ is a cycloaliphatic polyamine hardener. This epoxy resin system cures at a maximum of $150^{\circ} \mathrm{C}$, which is below the degradation temperature of both the Flax and Kevlar fibers. The supplier recommended ratio of 4:1, resin to hardener, was used. The following table (Table 3.3) shows the properties of resin determined via tests performed by an independent study [78]: 
Table 3.3: Physical and Mechanical Properties of Araldite ${ }^{\circledR}$ LY 1564 and Aradur ${ }^{\circledR} 22962$ Resin System(Huntsman Advanced Materials, The Woodlands, TX, USA))

\begin{tabular}{lc}
\hline Density & $1.15 \pm 0.04 \mathrm{~g} / \mathrm{cm}^{3}$ \\
\hline Elastic Modulus (Tension) & $3.03 \pm 0.46 \mathrm{GPa}$ \\
\hline Elastic Modulus (Compression) & $3.57 \pm 0.38 \mathrm{GPa}$ \\
\hline Ultimate Tensile Strength & $67.17 \pm 2.45 \mathrm{MPa}$ \\
\hline Ultimate Compressive Strength & $73.99 \pm 4.64 \mathrm{MPa}$ \\
\hline Failure Strain (Tension) & $3.61 \pm 0.23 \%$ \\
\hline Failure Strain (Compression) & $3.72 \pm 0.95 \%$ \\
\hline Poisson's Ratio & $0.403 \pm 0.007$ \\
\hline
\end{tabular}




\subsection{Manufacturing}

\subsubsection{Stacking Sequence and Ply Orientations}

The number of plies and stacking sequence in a composite are very deterministic of its properties. At room temperature, higher number of plies tend to produce higher modulus values [99]. Thicker composites also perform better under compression loads and are shown to be resistant to buckling $[40 ; 41 ; 78]$. Laminae stacked in symmetry eliminate the coupling stiffness in the laminate. By having no coupling of in-plane and out of plane forces or displacements, there are zero deformations. Practically, symmetric laminates are thermally stable and do not warp/twist due to the temperature changes, while curing. In order to achieve mid-plane symmetry, stacked plies were required to be in multiples of two.

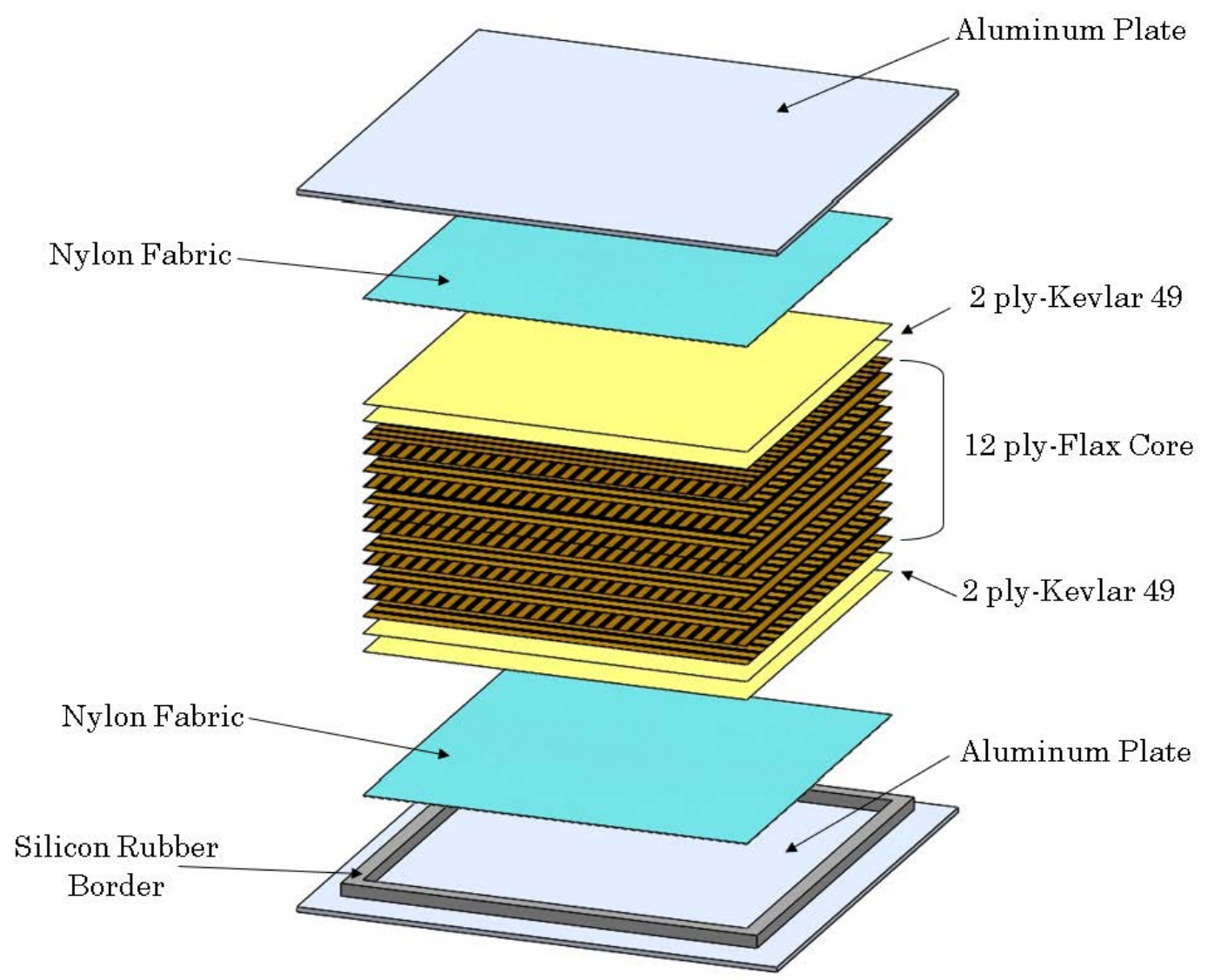

Figure 3.3: Manufacturing Assembly for KFE Composites

The plates were manufactured using 12 layers of Flax sandwiched between 2 layers of Kevlar weave, at each end (Figure 3.3). While adding more Kevlar layers would provide bet- 
ter mechanical properties, the aim of this study was not to produce a high-performance hybrid, rather, it was to use a minimal amount of Kevlar, that would improve the properties, while still remaining relatively green. Since the layup was decided to be a sandwich structure i.e. $\left[W_{K 2} /(0 / 90)_{F}\right]_{S}$, the number of plies, in order to maintain symmetry would have to be 8 or a multiple thereof. Thus, using this and the preference used in other published works $[40 ; 41 ; 78 ; 107 ; 108]$, a 16-layer configuration was chosen.

Three 12" x 12" hybrid laminate configurations were manufactured along with a pure Kevlar/epoxy laminate : with the following stacking sequences;

- Unidirectional $\left[W_{K 2} / 0_{F 6}\right]_{S}$

- Cross-Ply $\left[W_{K 2} / \pm 45_{F 6}\right]_{S}$

- Angle-Ply $\left[W_{K 2} /[0 / 90]_{F 6}\right]_{S}$

- Kevlar/Epoxy $\left[W_{K}\right]_{16}$

where the $K$ and $F$ represent the woven Kevlar and the Flax fibers respectively.
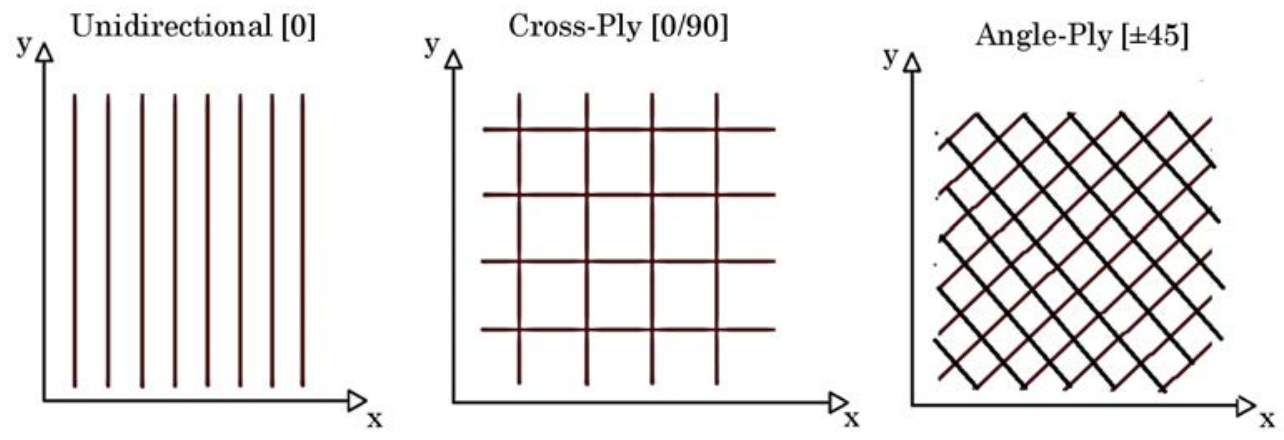

Figure 3.4: Three Flax ply orientations visualized

Figure 3.4 visualizes the different ply orientations utilized for the three stacking sequences. It should be noted though that the orientation displayed pertains only to the Flax fibers. The Kevlar weave was laid along the loading axis for all stacking sequences. This provided an excellent test bench for studying the interface between the Kevlar and Flax fibers in different orientations and understanding the impact ply orientation has on the performance and damage behaviour of the hybrid.

Unlike the unidirectional stacking sequence, the fiber relation in the cross-ply and the angle-ply is the same i.e. the fibers are oriented perpendicular to each other in consecutive laminae. Hence both stacking sequences behave symmetrically, and any differences in performance will be due to the loading axis and the inter-facial bonding with the Kevlar fibers. 


\subsubsection{Fiber Volume Fractions}

Gning et al. [99] showed that compression pressure directly correlates to higher fiber fractions, while reducing plate thickness. This decrease in thickness can be offset by introducing a higher ply count. When fibers are laid equally adjacent to each other in the loading direction, the load is distributed amongst them, reducing individual fiber stresses. aligning the fibers to the loading axis increases the amount of fiber clusters that can be packed together. The higher the fiber density with respect to the loading axis, the stronger the material Bodros et al. [109] also showed that the tensile strength and elastic modulus of the Flax composite increased with higher fiber content.

However, having too high of a fiber volume also decreases the composite strength. As the matrix does not have enough space to surround and fully bond with the fibers [110].

Realistically, there exists a volume ratio, that is optimal to bonding and load sharing between the fibers and the matrix. Gibson [111] showed that due to manufacturing restrictions, fiber volume tends to be in the range of $50 \%$ to $70 \%$. Considering the high ply count and the thickness requirement, a 50-50 fiber to matrix ratio was chosen. Mahboob et al.[78] used Gning etal's[99] findings to perform a study that determined that a pressure of 5 Bar resulted in a 50 percent fiber volume, with a plate thickness of approximately $4 \mathrm{~mm}$. Later in this chapter, numerical analysis along with SEM observations was performed to gauge accurate volume fractions of the configurations.

\subsubsection{Manufacturing Procedure}

The manufacturing process was customized based on the curing cycle of the resin. The process consists of a manually stacking the plies and then use compression molding to cure the resin. A Carver Auto Series Hydraulic Press (Figure 3.5) was used which uses two 15" x15" heated platters, top and bottom, to provide a maximum of 30 tons of compression. The pressure and temperature cycles can programmed, to perform the curing cycle automatically.

The composite was hand-laid between two aluminum plates, which are then sandwiched

and placed into the press. As mentioned earlier, the curing cycle for the resin was provided by the resin manufacturer and was followed as detailed in their data sheet The detailed steps of the manufacturing procedure are listed as follows

1. The Flax and Kevlar fibers were hand cut in to 12"x12" squares. According to the stack- 


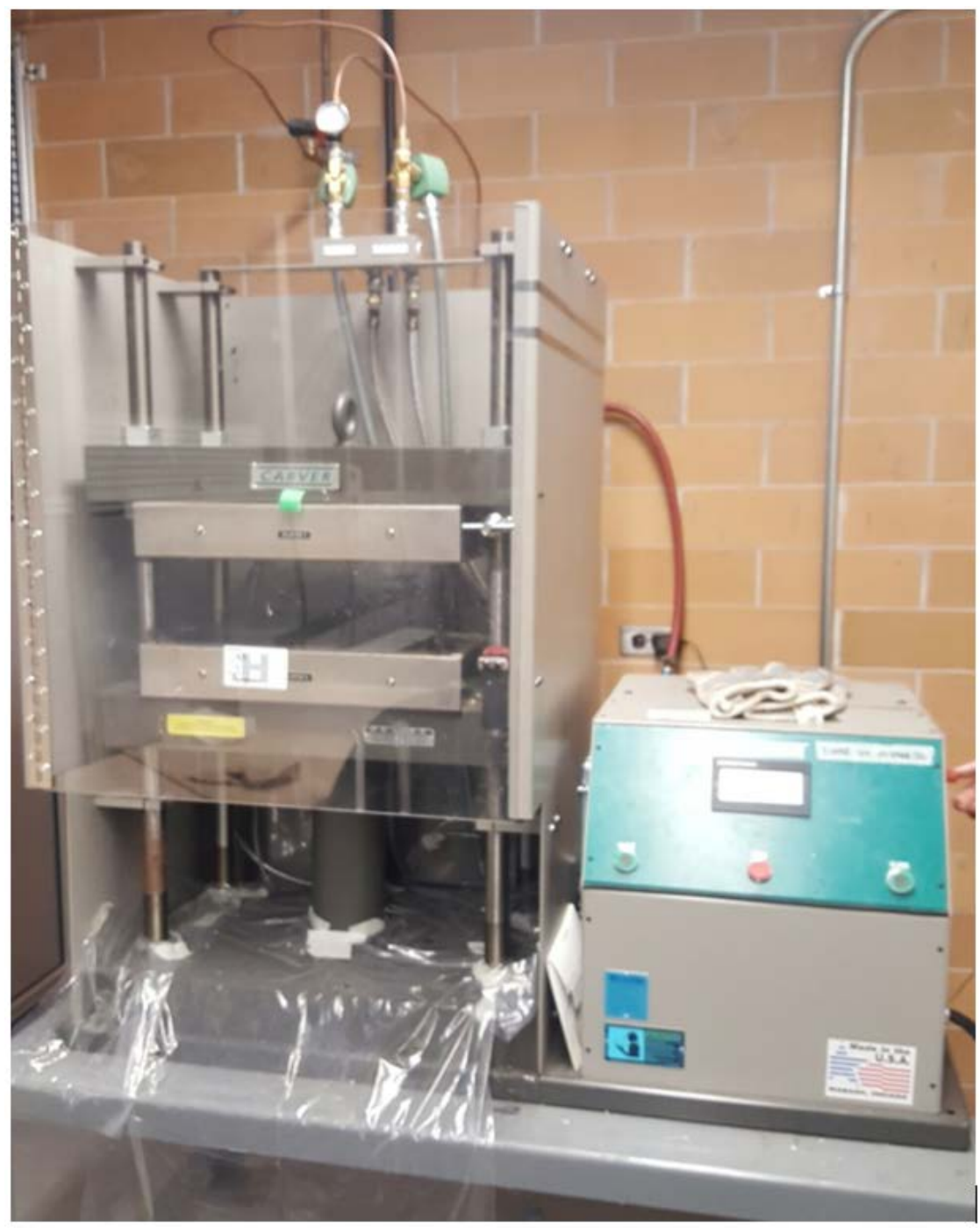

Figure 3.5: Carver Auto Series Hydraulic Press

ing sequence, each plate was made from twelve layers of Flax plies, sandwiched between four Kevlar laminae.

2. Two 15" x 15" plates were wrapped and vacuum sealed using a high temperature plastic membrane, in order to prevent the resin from sticking to the plates. Silicon rubber was used to create a 12 "x12" border in the center of one of the sealed plates. This border prevented the resin from leaking out during the lay-up process, while also preventing the fibers to deform and slip during compression moulding, due to the excess resin being squeezed out.

3. Before starting the lay-up process, the plies were inspected to remove outside contami- 


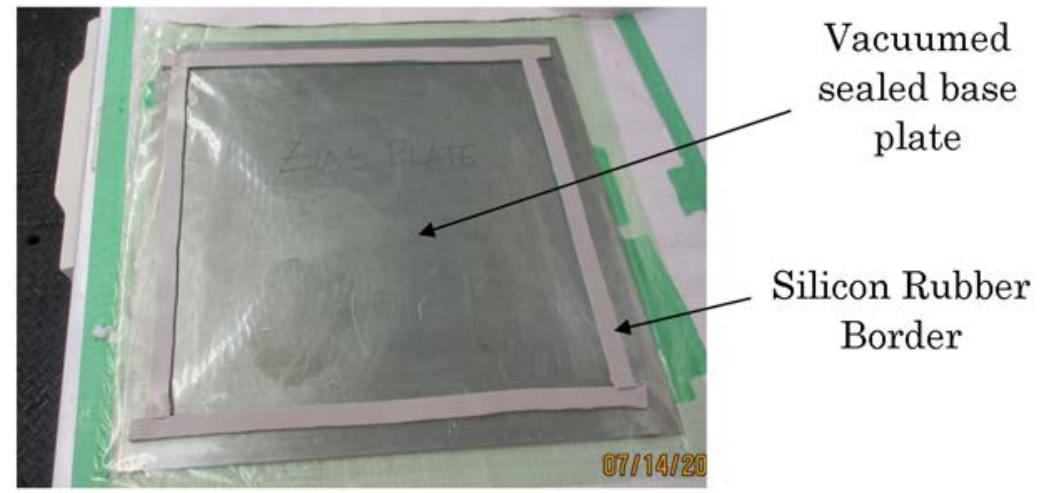

Figure 3.6: High temperature plastic membrane Vacuum sealed base aluminum plate with $12 " \mathrm{x} 12$ " silicon rubber border to prevent resin leakage

nants and stray fibers. The amount of epoxy was estimated by using twice the weight of the fibers used. A 4:1 mixture of the epoxy(Araldite ${ }^{\circledR}$ LY 1564) and hardener(Aradur ${ }^{\circledR} 22962$ )) was added to a cup and stirred to ensure a complete blend.
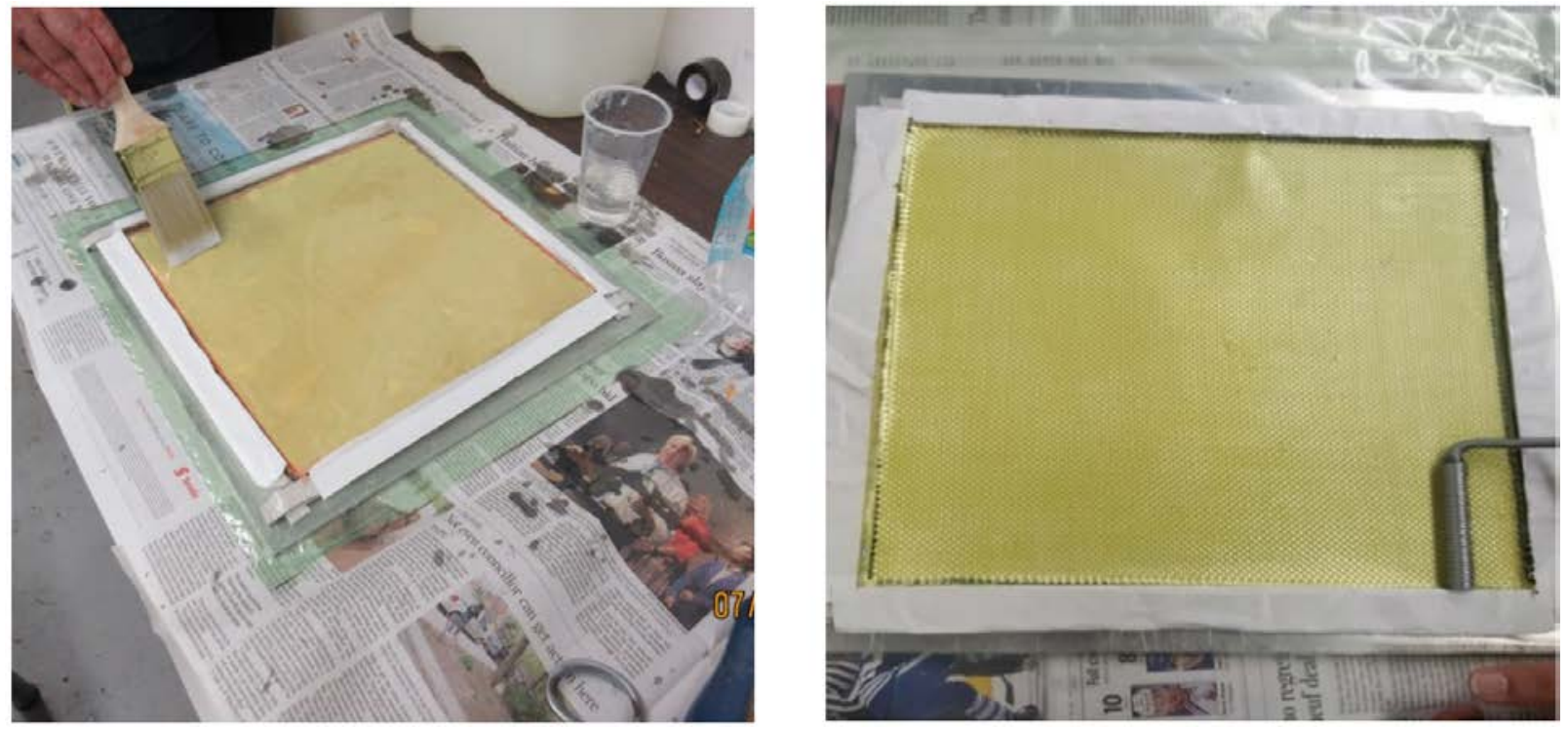

Figure 3.7: Using a laminate brush to spread resin (le ft ), Using a roller to compress plies and extract trapped air (right)

4. A layer of peel ply was placed at the bottom of the mold, to prevent the composite from adhering to the plastic. The nylon-base fabric is air and water permeable, allowing the resin and released air to exit the laminate. After a base coat of the epoxy, fiber laminae are placed according to the respective stacking sequence, with epoxy being applied and 
spread to saturation after each successive ply. A roller was used to gently compress each layer, to remove trapped air and adhere the plies together.

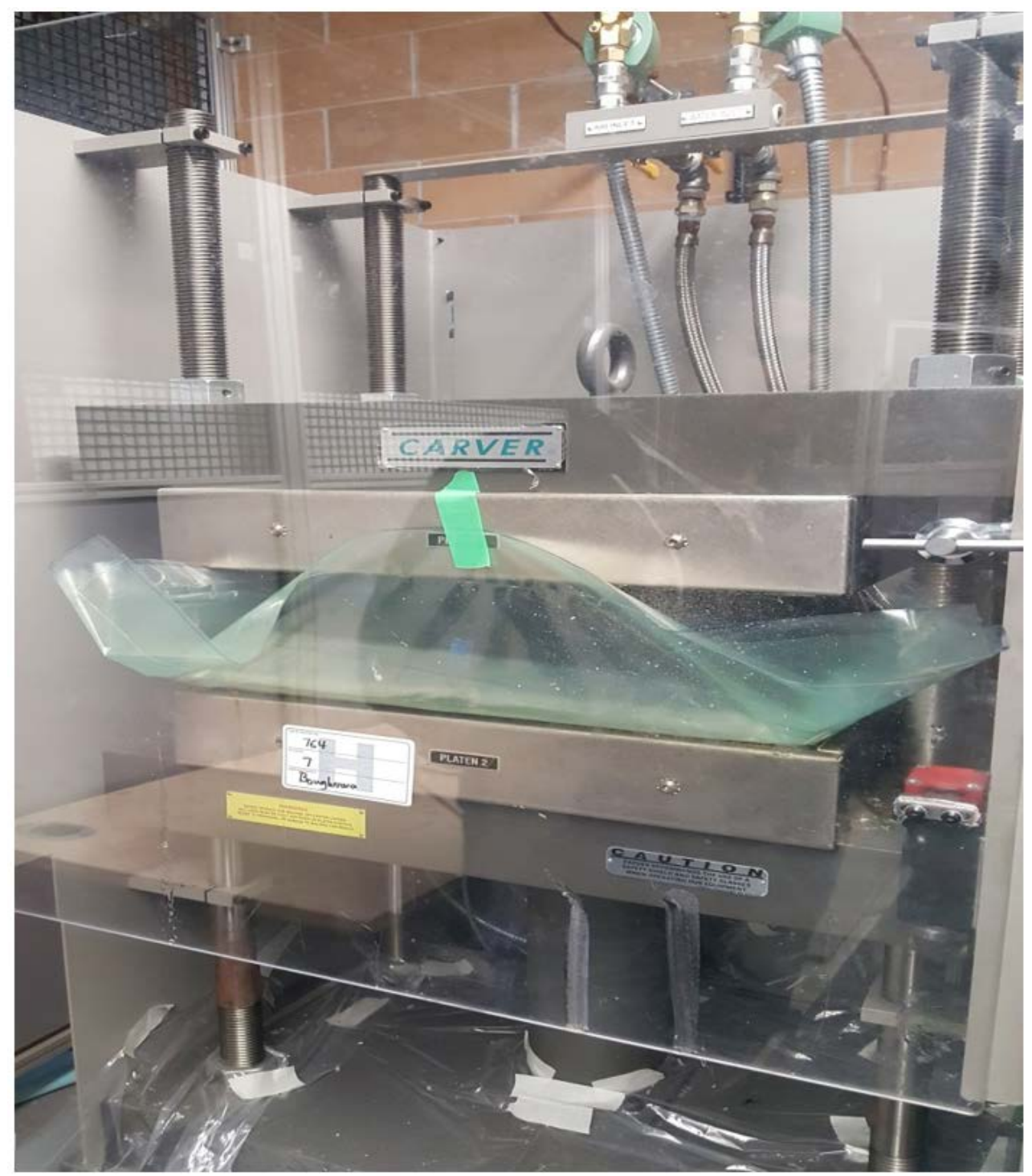

Figure 3.8: Plate assembly vacuum sealed in High temperature plastic membrane bag, and inserted in to Carver Press

5. To close the lay-up, another peel ply was stacked on the top. The molding plate was placed on top and the assembly was placed inside a high temperature plastic bag and vacuum sealed. This contained the leaked resin during compression, preventing spillage. The mold was placed into the center of the heated platters, to ensure equal distribution of force. The resin was gradually heated to its Glass temperature $\left(150^{\circ} \mathrm{C}\right)$ and held at 5 bars of pressure, for two hours. The temperature and pressure of the curing cycle is 
visualized in Figure 3.9.

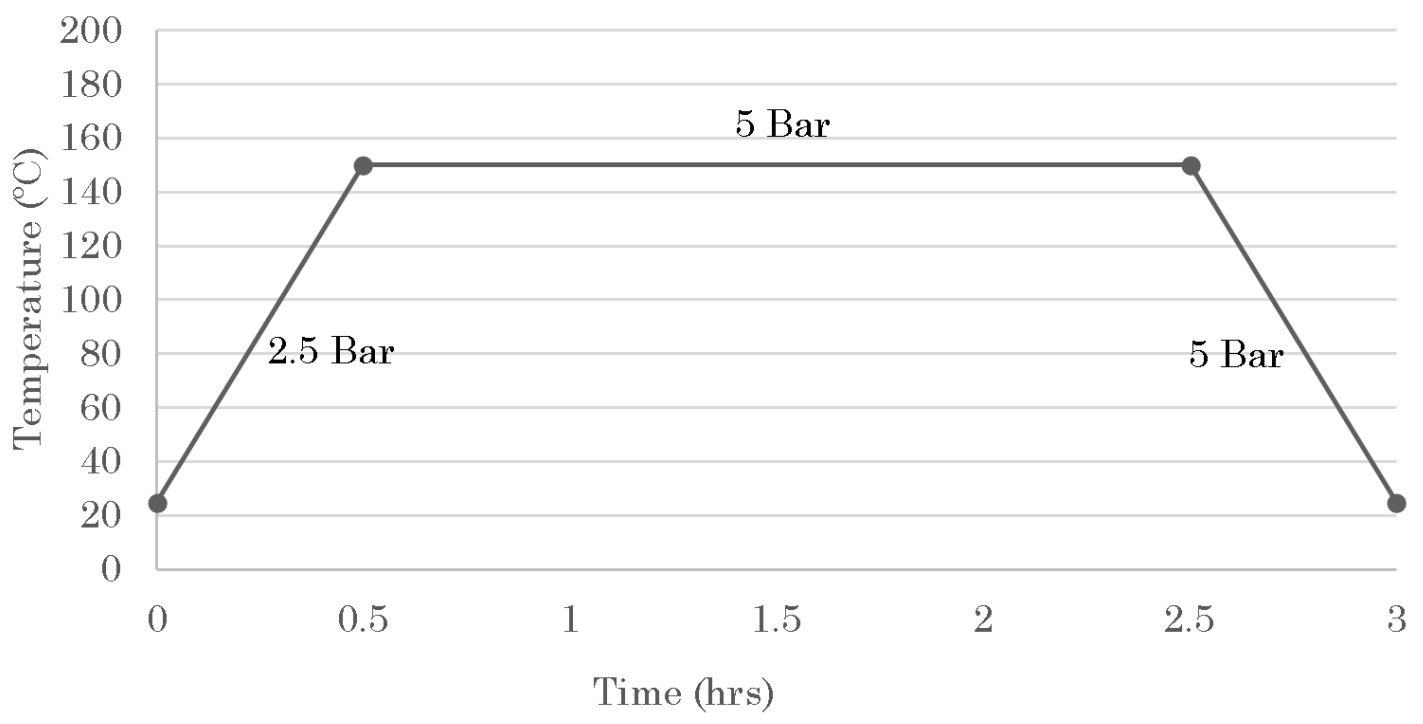

Figure 3.9: Temperature and Pressure curing Cycle used for Huntsman Resin System 


\subsubsection{Specimen Preparation}

The manufactured plates came out at 12" x 12" with an average thickness of 3-4 mm. For testing purposes, the plates were cut using a $0.35 \mathrm{~mm}$ diamond edged table saw and edge ground to finish. The specimen sizes were chosen based on the ASTM standards. Two different dimension sets were picked for the multitude of tests performed to determine the mechanical properties of the hybrid composite material under different loading conditions. Figure 3.10 shows the measurements of the specimens tested.
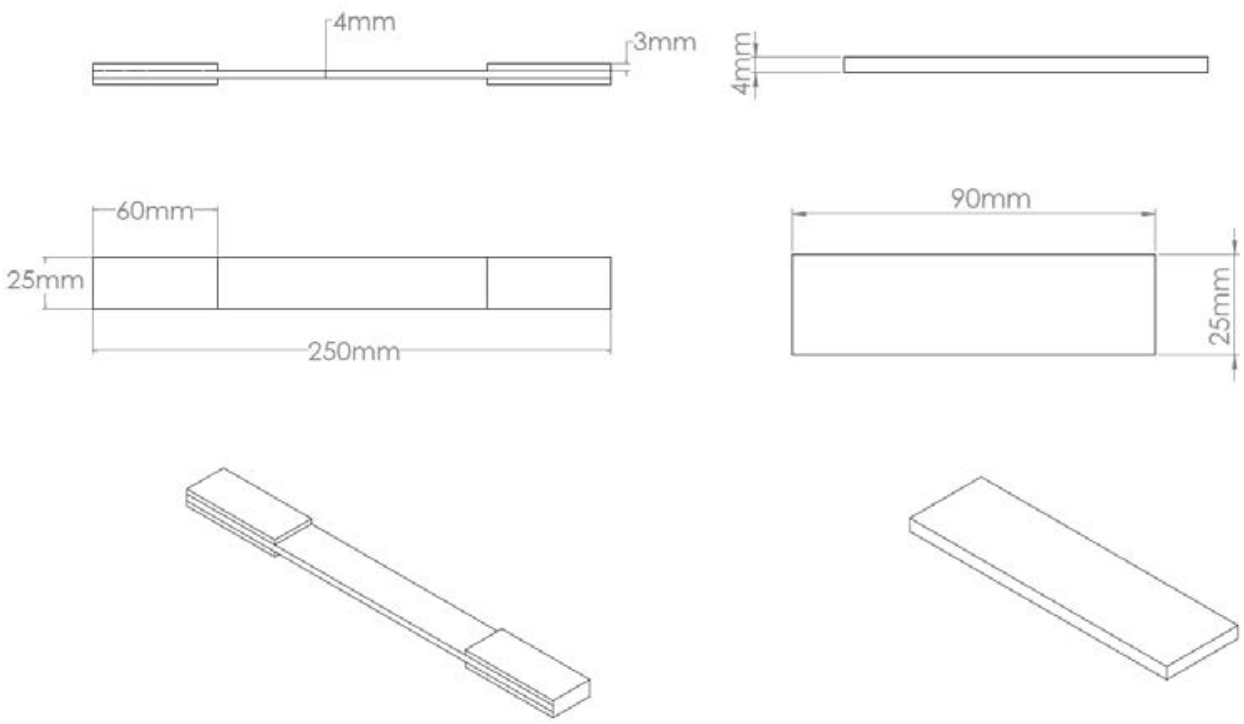

Figure 3.10: Dimensions for Torsion, Bending and Tension Specimens ( $l e f t$ ), all compression specimens $(r i g h t)$

\subsubsection{Volume Fraction Validation and Porosity}

ASTM D3171 [112] is the default standard for measuring constituent content in composite materials. However, the standardized methods list methods that are unsuitable for use with natural fibers. Dissolution in acids and burning out the matrix would both cause extensive degradation in the natural fibers themselves, rendering fiber weight fraction measurements moot. Therefore, an optical method used by Mahboob et al. [78], Phillips et al. [113] and El Sawi et al. [108] was used to estimate the volume fractions of the fibers. Sample crosssections were used to take microscopic images using a Scanning Electron Microscope (JEOL, JSM-6380, Tokyo, Japan). The pictures were then analyzed using an open-source image analysis software named ImageJ (Image Processing and Analysis in Java, developed by National In- 


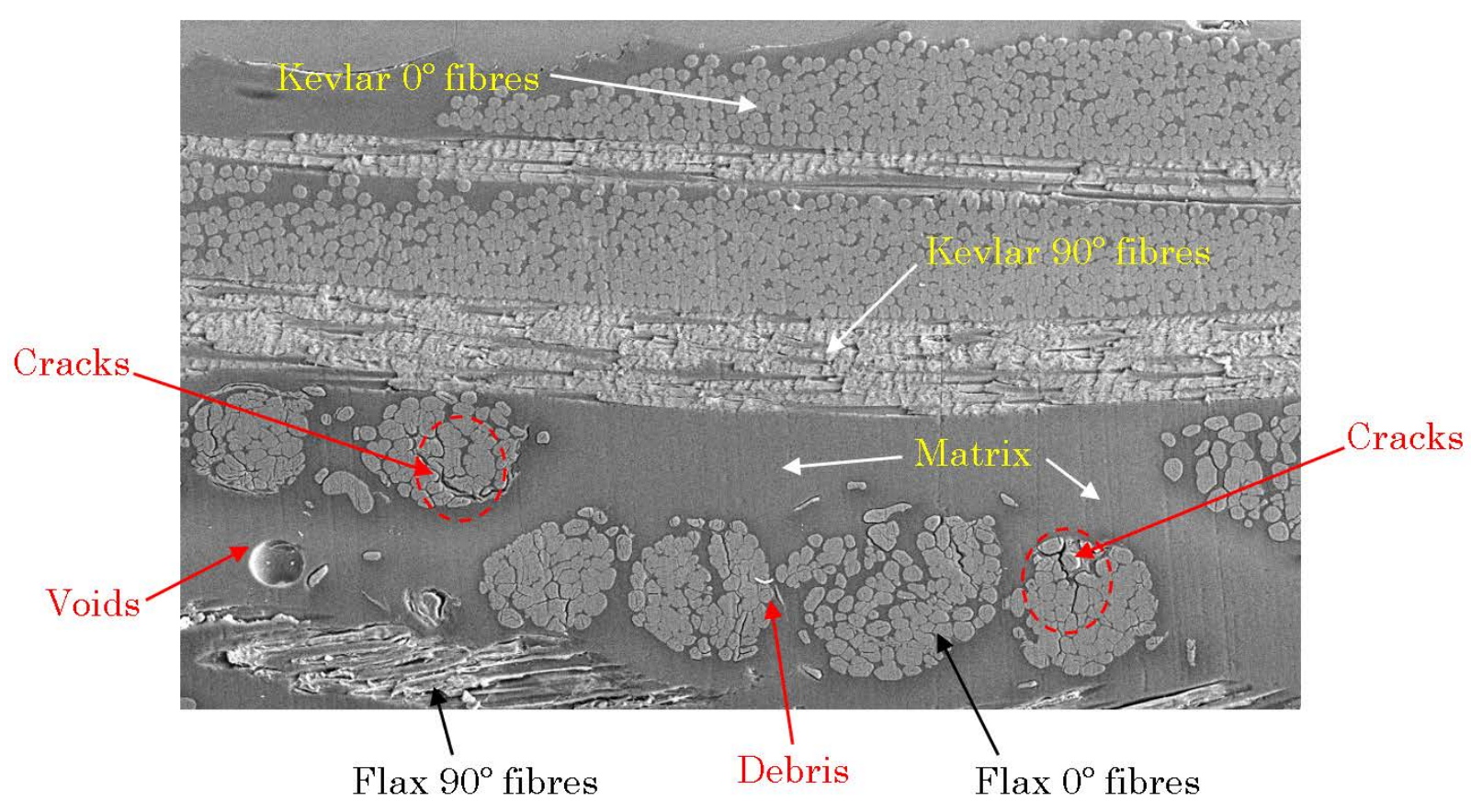

Figure 3.11: Sample SEM cross-section image taken at 100x magnification to show fibers, matrix and different flaws present

stitutes of Health, USA). Optical analysis requires there be adequate contrast between fibers and matrix for optimal accuracy. Specimens were prepared by setting cut cross-sections in
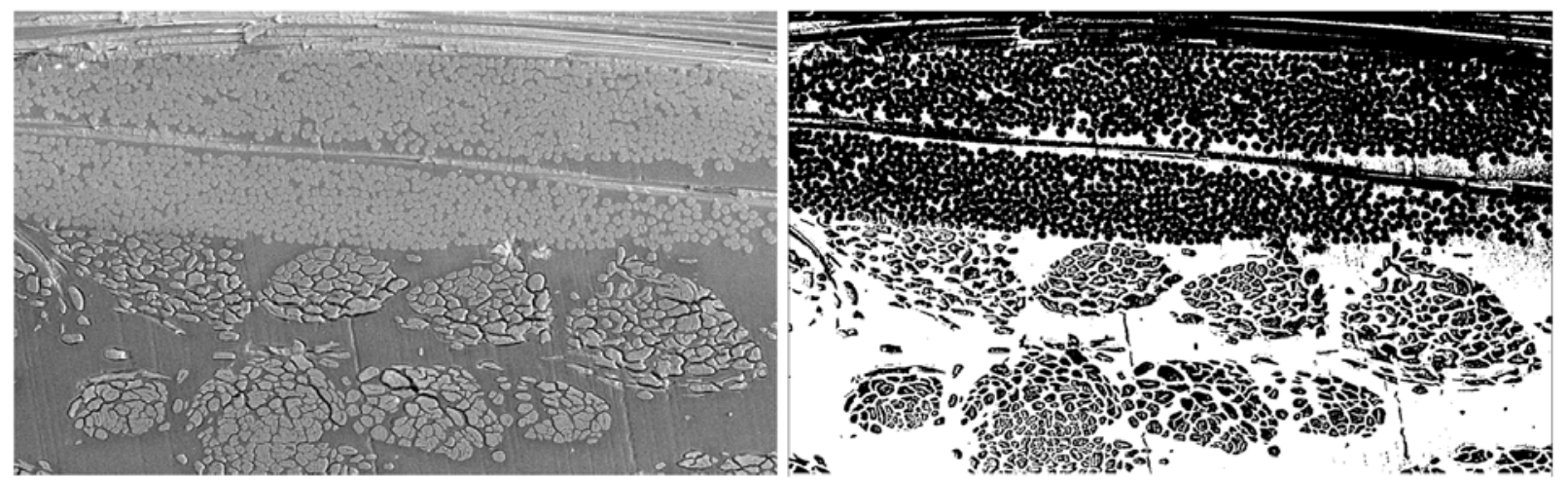

Figure 3.12: Example 100x SEM image of KFE UD hybrid cross-section in 8-bit greyscale (left), and the same image processed into black and white (right) to get a b/w ratio of the fiber vs. the matrix, which corresponds to the area fraction.

LECOSET 7007 cold curing resin, and sequentially polishing them until a final grit of $0.05 \mathrm{mi}-$ crons. At least 20 sample images were taken from multiple locations for each composite sequence. Due to the difference in the fiber sizes of Kevlar and Flax and their relative ply count, majority of the images taken were of the Flax core for the hybrids. 
Figure 3.12 a shows an example of the SEM image taken, which is then processed to make the fibers and matrix stand out. Area fractions were then calculated for the regions, to get an estimate of the volume fractions.

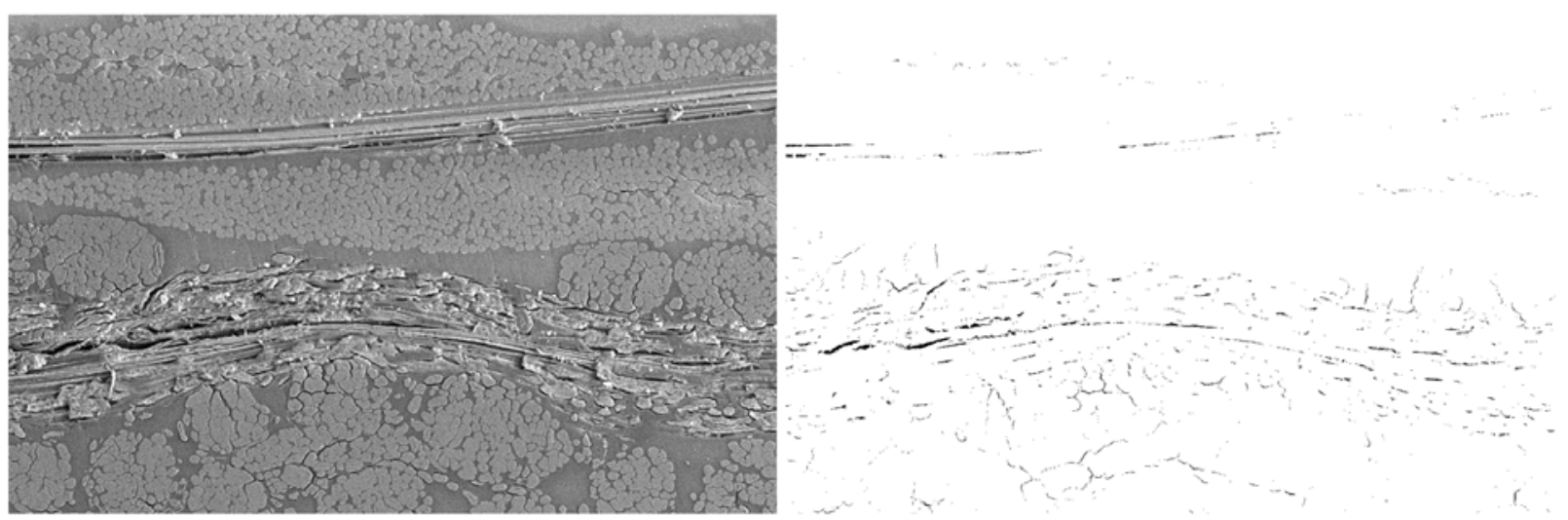

Figure 3.13: Example 100x SEM image of KFE Crossply hybrid cross-section in 8-bit greyscale $(l e f t$, and the same image reduced in brightness and contrast to make the cracks stand out (right)

By further analyzing the SEM images, the cracks and voids were isolated. Due to the darker nature of the cracks, they easily stood out of the composite images as shown in Figure 3.13. Using area fractions, the void content was also measured. Table 3.4 shows the fiber content and porosity of the three stacking sequences.

Table 3.4: Fiber Volume Fractions and Porosities of UD, Cross-Ply, Angle-Ply and Pure Kevlar

\begin{tabular}{lcc}
\hline & Fiber Volume Fraction (\%) & Porosity (\%) \\
\hline UD & $48.25 \pm 3.29$ & $1.96 \pm 0.54$ \\
Cross-Ply & $51.64 \pm 1.69$ & $2.38 \pm 1.72$ \\
Angle-Ply & $50.36 \pm 3.105$ & $2.91 \pm 1.84$ \\
Kevlar/Epoxy & $65.57 \pm 5.76$ & $0.53 \pm 0.04$ \\
\hline
\end{tabular}

\subsubsection{Density Measurements}

The classical relation for density assumes that the ideal composite is devoid of any imperfections. Using the rule of mixtures, the theoretical density can be calculated as:

$$
\rho_{c t}=\rho_{f} v_{f}+\rho_{k} v_{k}+\rho_{m} v_{m}
$$


where $\rho_{c t}$ is the theoretical density of the composite, $\rho_{f}$ and $\rho_{k}, \rho_{m}$ are densities of the Flax, Kevlar and matrix respectively, and the $v$ are the volumes of the respective constituents. Due to the ideal nature of the theoretical composites, density was also measured using the displacement method. When the two densities are compared, an estimation of the void content can be extracted, using the following equation [114]:

$$
v_{v}=\frac{\rho_{c t}-\rho_{c x}}{\rho_{c t}}
$$

where $\rho_{c c}$ is the calculated density from Equation (3.1), and $\rho_{c x}$ is the measured density of the composite.

Using the experimental and theoretical data for the density and porosity, a comparison can be seen in Table 3.5. The measured densities and porosities agree with in the error range, with the classical relation, further justifying the viability of the optical method.

Table 3.5: Comparison between measured and calculated densities and porosities

\begin{tabular}{lccccc}
\hline & $\begin{array}{c}\text { Density(Theo.) } \\
\left(\mathrm{g} / \mathrm{cm}^{3}\right)\end{array}$ & $\begin{array}{c}\text { Density(Exp.) } \\
\left(\mathrm{g} / \mathrm{cm}^{3}\right)\end{array}$ & & $\begin{array}{c}\text { Porosity from Eq.(3.2) } \\
(\%)\end{array}$ & $\begin{array}{c}\text { Porosity(optical) } \\
\text { Kevlar/Flax }\end{array}$ \\
\cline { 2 - 4 } \cline { 5 - 6 } Kevlar/Epoxy & 1.32 & $1.30 \pm 0.03$ & & 1.52 & $2.42 \pm 1.37$ \\
\hline
\end{tabular}


Chapter 4

Static Behaviour of Kevlar/Flax/Epoxy Composites 


\subsection{Introduction}

Natural fiber Hybrid composites have been gaining traction in the last decade or so, due their versatility and environmental benefits. However, very little has been done in terms of fully characterizing and cataloguing a designed hybrid. Most research publications cater to one area of application, and their composite design is tailored to provide optimal results. Due to the numerous combinations present in hybrid composites, this leaves very little room for the studying their general behaviour. This section aims to provide a comprehensive mechanical profile of the Kevlar/Flax Hybrid composite and explain its underlying fracture mechanics.

Basic mechanical tests such as: tension, compression, three-point bending and torsion; were performed on the three KFE hybrid sequences. The strength of the inter-facial bonding between the Flax and Kevlar fibers and their failure mechanisms were also evaluated under different loading conditions. Furthermore, Rockwell hardness tests, along with a water absorption profile was assessed, to further gauge the behaviour of the material. At least 3 specimens of each hybrid composite were tested for all mentioned assessments.

\subsubsection{Digital Image Correlation (DIC)}

Extremely accurate strain measurement (to the micro scale) is required to completely understand a material's mechanical response. Strain for tensile and compression loading is usually measured via a strain gauge and/or an extensometer. Extensometers can only be applied to specimens under tensile loading due to their larger size. Compression loading requires the specimen span to be minimal, as a larger span encourages buckling. Therefore, only strain gauges can be considered ideal for compression loads. However, their time-consuming application and non-reusability makes them very inefficient when considered for a high number of specimens.

Thus, a different method was utilized to increase measurement efficiency. A Digital Image Correlation (DIC) setup provided by Correlated Solutions (Irmo, SC, USA) was used. DIC provides a non-contact measurement tool, where a speckled contrasted pattern is created on the face of the specimen, which is then imaged at consistent intervals while performing the test. The images are analyzed using the provided image correlation software $\left(\mathrm{VIC}-2 \mathrm{D}^{\mathrm{TM}}\right)$, uses the planar displacements between the speckled pattern to calculate axial and transverse strain. DIC provides strain measurements for any loading axis, eliminating the need for multi-axial strain gauges. Due to its full-field measuring capability, it can also extend the measurement range where traditional strain transducers are physically limited. 


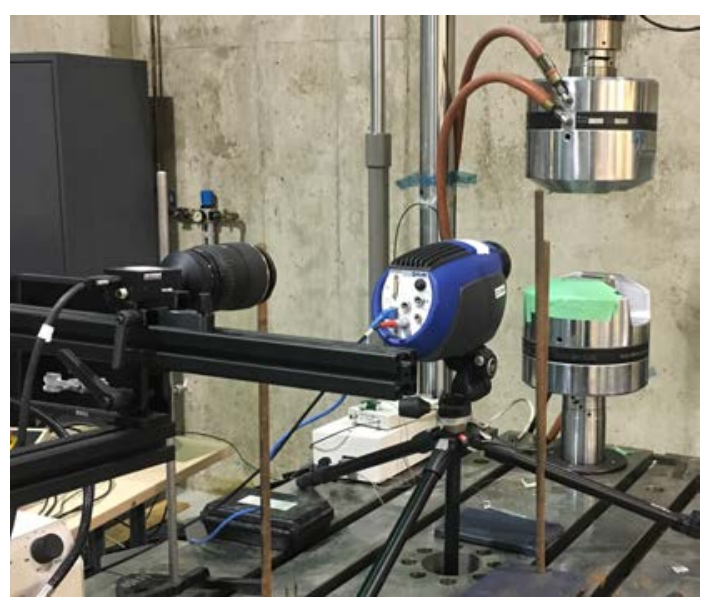

(a)

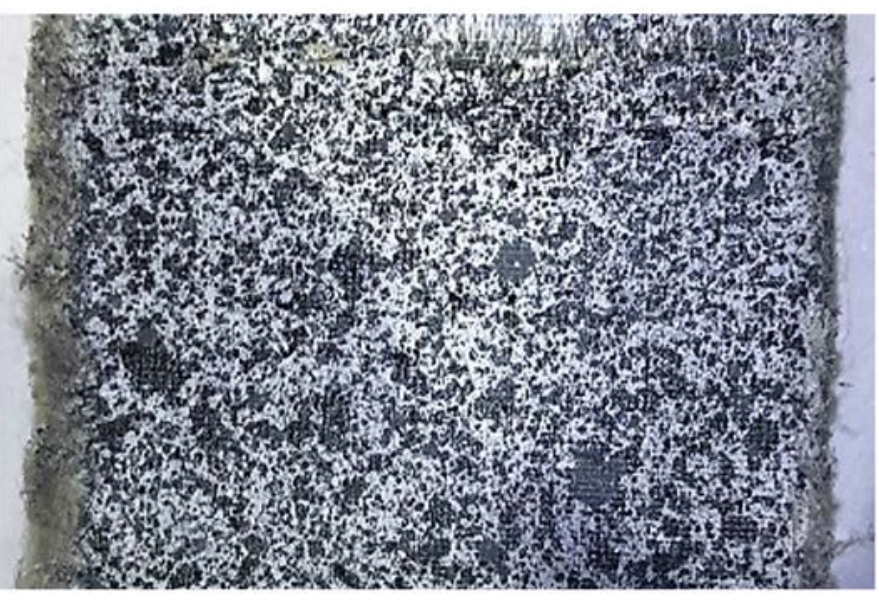

(b)

Figure 4.1: (a) Digital Image Correlation Imaging setup alongside the Testing Frame, (b) Speckled pattern sprayed on the surface of the sample

For accurate strain measurements, the DIC must be calibrated using traditional methods. Therefore, to validate the strain readings, the measurements were compared with a uniaxial extensometer (gauge length 0.5 in) (United Calibration Corp., Huntington Beach, CA, USA) and a $350 \Omega$ strain gauge, for both tension and compression. The results were authenticated with an excellent correlation $\left(R^{2}\right.$ value of $\left.0.96-0.98\right)$.

\subsubsection{Fracture Mechanisms}

Fracture mechanics are used to quantify damage mechanisms that occur under certain loading conditions. Traditionally, in polymers and metals, a few major cracks tend to propagate in clusters throughout the material [115], however for natural fiber composites, several different damage mechanisms come into play. These modes may propagate independently or accumulate influenced by each other $[114 ; 116 ; 117]$. Due to the natural growth and postprocessing of natural fibers, there are many variations present in the elementary structure that can affect the fracture mode accumulation. Fracture mechanics in composites can be generally categorized into the following:

Fiber Debonding Depending on the fiber's outer surface smoothness and the compatibility with the matrix, fibers can separate from the matrix. Due to this weak interfacial bond, cracks can form parallel to the fibers when there is a difference in the stiffness [32]. As fibers 
are usually stronger than the matrix in tension, debonding does not adversely affect the material's axial tensile performance, however, transverse and compression stiffness is reduced significantly.

Delamination As individual fibers debond along the fiber axis, they can accumulate cracks which propagate throughout the fiber surface, separating the fiber and matrix. When formed interlaminarly, these cracks develop high shear stresses, which in turn causes stresses between laminae. The cracks are then able to spread between the interlaminar fiber-matrix regions, causing separation alongside the adjacent plies. The accumulation of the debonding behaviour causes laminar delamination [32]. In composites with different orientations and fibers, delamination may occur in tension due to a difference in the interlaminar Poisson ratios and, due to buckling of different laminae in compression.

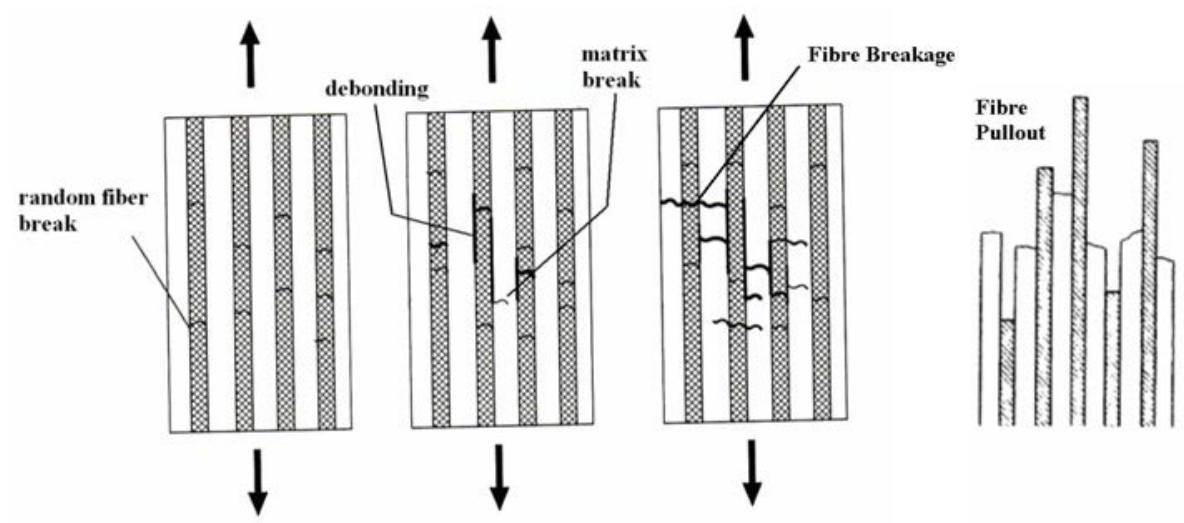

Figure 4.2: Different microdamage modes that lead to fracture in long fiber tension loading [Eitzenberger, 2007]

Fiber Breakage In all fibers, there exist many intrafiber imperfections. Under loading, these deficiencies act as initiation sites. Cracks form normal to the loading axis, and exceeding the strain limit of the fibers, cause breakage. [32]

Matrix Cracking Under loading, the matrix also undergoes deformation. Thermosets are usually more brittle than thermoplastics, hence do not exhibit high deformation. Matrix cracking initiates from inherent voids and inadequacies, which build stress concentrations within the matrix and encourage crack formation. These stress concentrations cause cracks to occur below the ultimate strength of the matrix, reducing mechanical performance, and cause failure [118]. 
Fiber Pullout When fibers fracture, they create stress concentrations inside the matrix. If a relatively stronger matrix is used, these stress concentrations may not occur in the fracture plane of the fiber. As fiber-matrix bonds are weaker then the matrix itself, an initiated matrix crack at failure causes the debonded fibers to get pulled out [32].

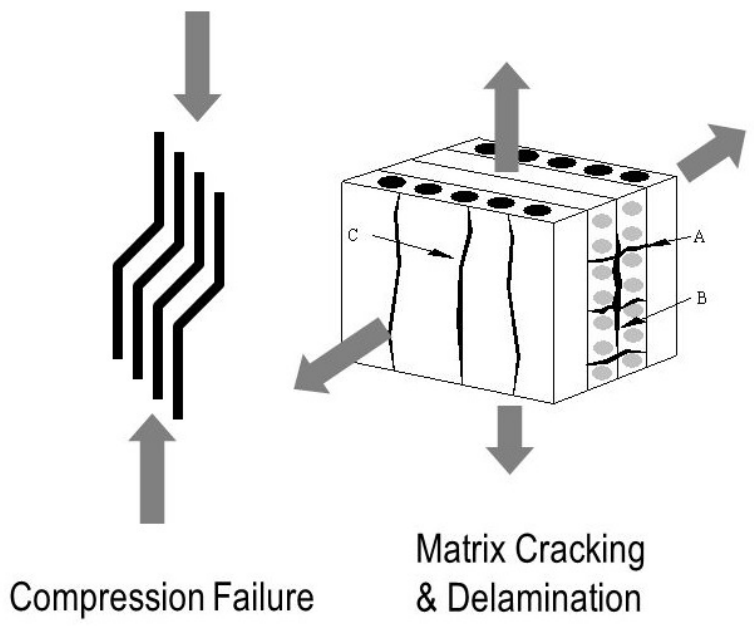

Figure 4.3: Compressive failure (buckling) (left) and Matrix cracking and Delamination (right) [Lesko, 2004]

For hybrid composites, the above-mentioned mechanisms can influence each other in complicated ways resulting in unexpected fracture behaviour. In composites, the fibers tend to describe the mechanical behaviour of the composite, and due to the different fiber types in a hybrid, these mechanical properties may interact differently. As a composite, carbon fiber and Kevlar are brittle and behave elastically, while Flax and other natural fibers, exhibit ductility and non-linear behaviour [119].

Different mechanisms like fiber-matrix debonding, matrix cracking etc.; can adversely affect the fiber directional performance of the composite. Romh'any et al. [120] found that in Flax composites, dominant damage mechanisms can change depending on the tensile stress levels. Fiber-matrix debonding is rampant at lower tensile loading, whereas, fiber pullout and breakage dominate at high stresses. Compression in composites, while affected by fiber strength, mostly depends on the matrix. The matrix surrounds the fiber, acting as physical support, to keep the fiber straight and discourage buckling [115]. Bos et al. [59] noted that in compression, kinks appear in the cell walls of Flax fibers, which encourage buckling, similar to synthetic fibers like Kevlar [66]. 


\subsection{Water Absorption}

Good engineering design requires materials to perform admirably under any condition. Composites are being used for a widespread of applications in many industries. While synthetic fibers tend to be relatively hydrophobic, natural fibers are hydrophilic. Their poor performance in moist environments contributes to their slow adaptability in many fields. It is imperative then to use the freedom provided by hybridization to improve the moisture absorption of natural fiber composites. Therefore, water absorption tests were conducted, submerging the specimen in water, to evaluate the moisture uptake rate over time.

\section{Moisture Absorption over Time}

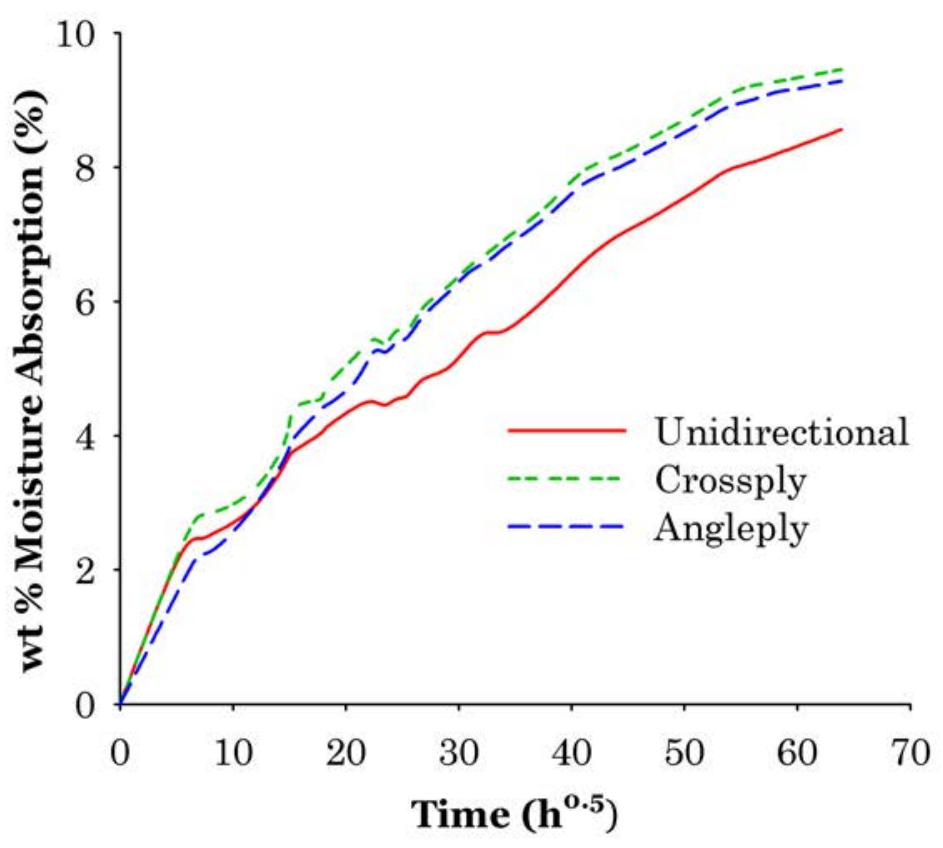

Figure 4.4: Water Absorption rate of UD, Crossply and Angleply KFE Hybrid

The tests were conducted in agreement with the ASTM standards (ASTM D5229/D5229M) [121]. The specimens were cut to specification and then placed in an oven to remove any pre-existing moisture. The samples were weighed after to the nearest 0.1 micro-gram using a Sartorius Lab 2000 Series (Sartorius Inc., NY, USA) weight balance, and submerged thereafter into distilled water. Measurements were taken every 24 hours until the samples reached saturation. The moisture uptake can be described by the following function Eq. (4.1),

$$
\Delta M(t) \%=\frac{M_{t}-M_{0}}{M_{0}} \times 100
$$


Table 4.1: Moisture Uptake of UD, Crossply and Angleply Hybrid, along with Flax and Kevlar results reported in the literature

\begin{tabular}{lc}
\hline & Moisture Uptake(\%) \\
\hline UD - $\left[W_{K 2} / 0_{F 6}\right]_{S}$ & $8.41 \pm 0.03$ \\
Crossply - $\left[W_{K 2} /(0 / 90)_{F 6}\right]_{S}$ & $9.19 \pm 0.06$ \\
Angle Ply - $\left[W_{K 2} /( \pm 45)_{F 6}\right]_{S}$ & $9.40 \pm 0.03$ \\
Flax [40] & 17.2 \\
Kevlar (DuPont 2017) & 3.5 \\
\hline
\end{tabular}

where, $\Delta M(t)$ is the percent water uptake, $M_{0}$ is the initial weight, before submersion, and $M_{t}$ is the sample weight at time $t$.

The results for all three stacking sequences are shown in Table 4.1. There are different models that can be used to understand the moisture absorption behaviour [122; 123]. The most commonly used models follow Fick's Laws. Fickian diffusion requires the surface concentration of materials to reach equilibrium immediately and remain constant throughout the absorption process. According to the model, the moisture content $(c(t))$ can be expressed as a function of time $(t)$, the diffusion coefficient $(D)$, the saturated moisture weight $\left(c_{s}\right)$ and the thickness $(d)$ using the following relation (Eq. 4.2),

$$
c(t)=c_{s}-c_{s} \frac{8}{\pi^{2}} \sum_{k=1}^{20} \frac{1}{(2 k-1)^{2}} \exp \left[-\frac{(2 k-1)^{2} D \pi^{2}}{d^{2}} t\right]
$$

Simplifying Eq. 4.2, it can be said that the moisture absorption following Fickian patterns can be described as, $[39 ; 122 ; 124]$

$$
M(t)=4 M_{\infty} \sqrt{\frac{D t}{\pi h^{2}}}
$$

where, $M_{\infty}$ is the maximum water weight gain. This shows that Fickian materials follow a linear pattern in the initial stages with respect to $\sqrt{t}$, until a saturation point $M_{\infty}$ is reached.

It can be seen from Figure ?? that the samples absorb water at a higher rate due to the hydrophilic cellulose fibers, and over the submersion period, eventually approach saturation. Therefore, it can be stated that the hybrid KFE composites exhibit Fickian behaviour.

The samples show different absorption rates, depending on the ply orientation. This is caused due to the difference in the fiber cross-sectional area exposed to water. Natural fibers 
absorb more moisture at the fiber tips, which results in swelling, further encouraging microcracks in the matrix, which are then filled with liquid via capillary action [125]. Therefore, fiber-cross sections absorb moisture at higher concentrations, as evident in the UD moisture uptake rate being lower than the cross and Angle ply. It can be seen that Kevlar fibers also contribute to the moisture concentration, which adds to the overall moisture uptake, however, they still provide an excellent over all benefit to pure Flax due to the hybridization.

\subsection{Rockwell Hardness}

The hardness of a composite material determines its resistance to wear and tear. While mostly dependent on the matrix, the fiber bonding also contributes to the hardness, as stronger fiber-matrix bonds transfer forces efficiently. There is no standard currently used for polymermatrix composites, therefore, the ASTM standard for plastics (ASTM D785-08) [126] was used as a substitute. The tests were performed on LR300TD Rockwell Hardness tester (LECO Corporation, St. Joseph, MI, USA) using a 1/8in diameter steel sphere at a load of $100 \mathrm{~kg}$ (HRE standard). The larger diameter of the ball allowed equal load distribution, as the fibers cause variations in data depending on the surface area[120]. Three $1 i^{2}$ samples from each stacking sequence were used with 10 readings taken from randomly chosen locations. The hardness calibration and reading were automatically controlled by the machine. Before testing, all samples were examined to ensure flatness in order to maintain optimal contact between the surface and the probe. The results can be seen compared to other materials in table.

Table 4.2: Surface Hardness results for Hybrid UD, Crossply and Angleply

\begin{tabular}{lc}
\hline & Surface Hardness(HRE) \\
\hline UD - $\left[W_{K 2} / 0_{F 6}\right]_{S}$ & $49.61 \pm 1.24$ \\
Crossply - $\left[W_{K 2} /(0 / 90)_{F 6}\right]_{S}$ & $44.06 \pm 1.38$ \\
Angle Ply - $\left[W_{K 2} /( \pm 45)_{F 6}\right]_{S}$ & $48.84 \pm 2.45$ \\
\hline
\end{tabular}

The hardness is dependent on the fiber concentration and the ply orientation. The UD reports the highest reading, as the fibers are aligned, and any force exerted onto them get easily dispersed. The Angle ply also shows a high surface hardness, especially compared to the crossply. While both are exactly the same in terms of ply interaction, they display different results. This is attributed to the Kevlar skin, as the fibers in the crossply are in the same direction as the Kevlar weave, increasing fiber concentration, whereas, the fibers are bonded at an angle of $45^{\circ}$, with respect to each other. 


\subsection{Tension}

The tensile tests were performed on a MTS 322 (Eden Prairie, MN, USA) hydraulic test frame at standard room temperature and pressure. In accordance with the ASTM standard (ASTM D3039/D3039M-14) [127] at least three specimens measuring 250mm x 25mm were tested for each stacking sequence. The strain rate was kept constant at $2 \mathrm{~mm} / \mathrm{min}$, on a $150 \mathrm{kN}$ load cell. The sample was held $60 \mathrm{~mm}$ on either side in grips (Deluxe-Action Wedge Grips, United Calibration Corp., Huntington Beach, CA, USA) at a consistent pressure of 2000 psi, with the extensometer placed along the loading axis onto the sample. The DIC setup was used to gauge transverse properties during testing. The samples were loaded under tension till failure. The results were tabulated and the extracted mechanical properties in tension are shown in Table 4.3. Overall mechanical properties are greatly improved in all aspects, indicating a boost to mechanical performance.

Table 4.3: Mechanical properties of UD, Crossply and Angleply laminates in Tension, compared to their constituents

\begin{tabular}{lcccc}
\hline & $\begin{array}{c}\text { Modulus, Tensile } E_{t} \\
(\mathrm{GPa})\end{array}$ & Strength $\sigma^{t u}(\mathrm{MPa})$ & Fail strain $\epsilon^{t u}(\%)$ & Poisson's ratio \\
\hline $\mathrm{UD}(11)^{1}$ & $30.45 \pm 0.69$ & $335.66 \pm 13.73$ & $1.60 \pm 0.07$ & $0.134 \pm 0.034$ \\
$\mathrm{UD}(22)^{2}$ & $11.72 \pm 0.81$ & $147.03 \pm 0.62$ & $1.69 \pm 0.03$ & $0.056 \pm 0.010$ \\
Crossply & $21.36 \pm 0.38$ & $244.52 \pm 9.16$ & $1.56 \pm 0.02$ & $0.060 \pm 0.026$ \\
Angle Ply & $15.27 \pm 0.21$ & $201.46 \pm 1.87$ & $1.88 \pm 0.04$ & $0.458 \pm 0.034$ \\
Flax $(11)^{1}[78]$ & $31.42 \pm 1.47$ & $286.70 \pm 13.30$ & $1.53 \pm 0.07$ & $0.353 \pm 0.011$ \\
Flax $(22)^{2}[78]$ & $5.58 \pm 0.5$ & $33.86 \pm 1.35$ & $1.36 \pm 0.18$ & $0.067 \pm 0.003$ \\
$\operatorname{Kevlar}$ & $38.52 \pm 0.47$ & $532.08 \pm 5.73$ & $1.59 \pm 0.08$ & $0.045 \pm 0.003$ \\
\hline
\end{tabular}

1 (11) - Fiber Direction

2 (22) - Transverse

Studying the stress-strain curves generated for the stacking sequences, certain inferences can be made. All hybrid orientations exhibited relatively linear behaviour until fracture [Figures (4.5, 4.6)]. Mahboob et al. [78] reported significant bi-linear behaviour in transverse loading for Flax/ epoxy composites. However, such pronounced behaviour was not observed in the hybrid composites (Figure 4.5(b)), which can be due to the Kevlar plies assisting and improving the performance of the Flax core. In polymer-matrix composites, the ply orientation significantly affects the failure strain. The hybrid displays variations in the failure strain ranging from 1.5-1.8\%. Though, the range is narrower when compared to pure fiber composites, 


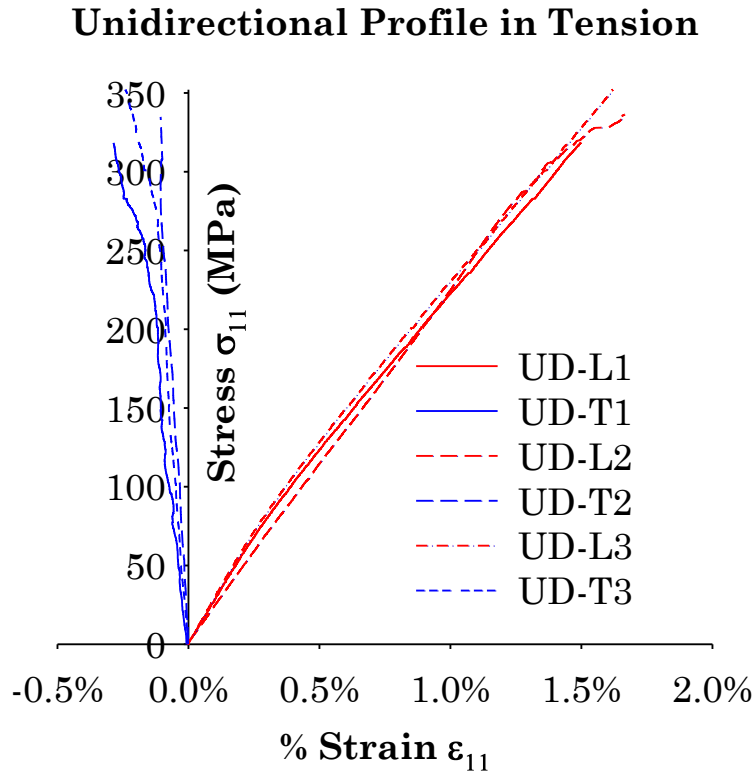

(a)
UD Transverse Profile in Tension

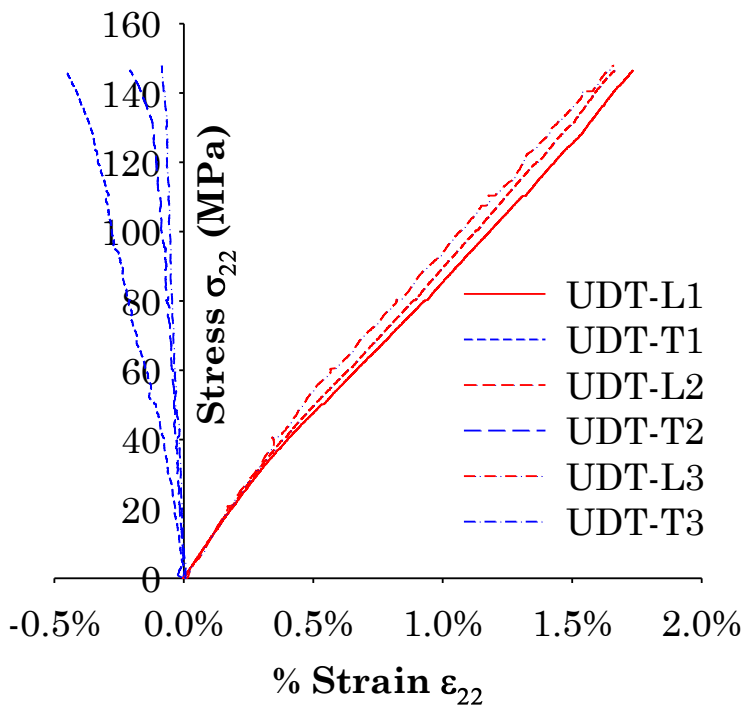

(b)

Figure 4.5: (a) fiber-direction and (b) Transverse Profile in Tension for UD - $\left[W_{K 2} / 0_{F 6}\right]_{S}$ Hybrid Composite

Crossply Profile in Tension

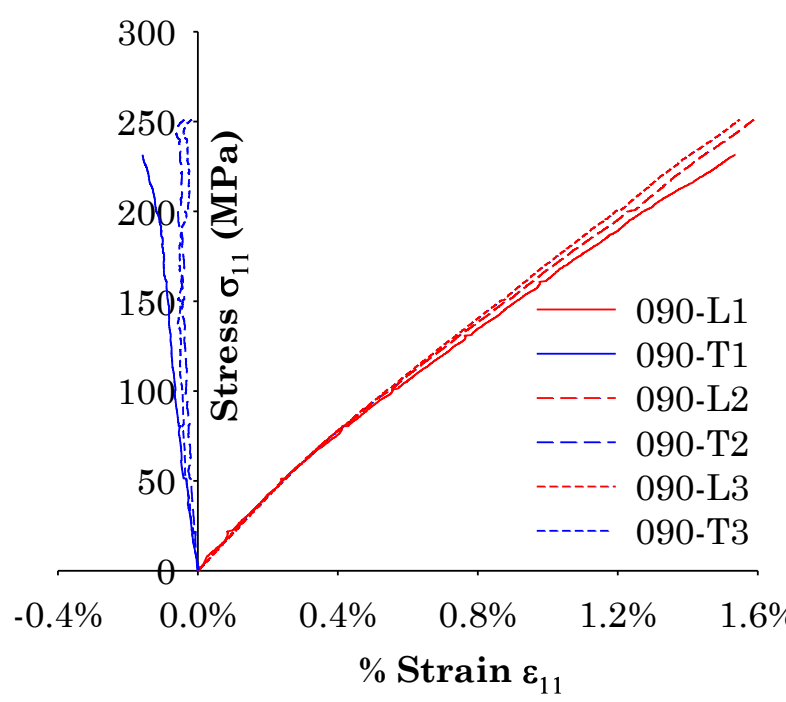

(a)

\section{Angled Ply Profile in Tension}

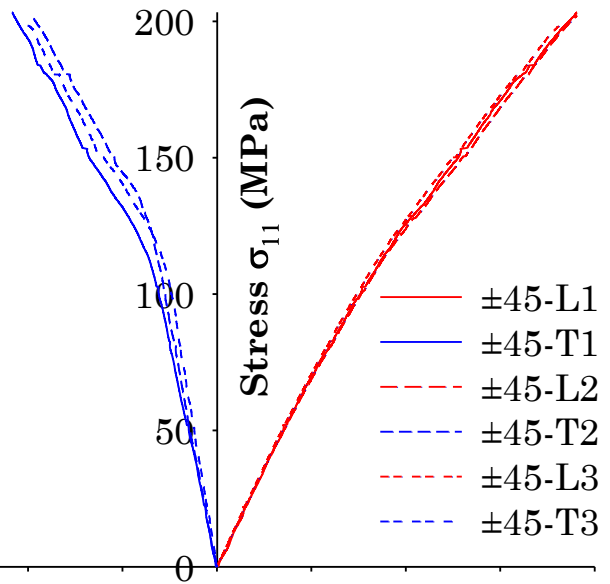

$\%$ Strain $\varepsilon_{11}$

(b)

Figure 4.6: (a) Crossply $\left[W_{K 2} /(0 / 90)_{F 6}\right]_{S}$ and (b) Angleply $\left[W_{K 2} /( \pm 45)_{F 6}\right]_{S}$ Profile in Tension for KFE Hybrid Composites 
as the Kevlar plies remained consistent through all stacking sequences reducing the failure strain threshold. Tests performed on the epoxy resin by Mahboob et al. [78] determined the failure strain for the epoxy to be near $4 \%$. This confirms that the fibers are causing the dominant loading response. For the KFE hybrid specimens, there was a variation observed in the tensile modulus in the 0.3 to $0.5 \%$ strain range, where the slope becomes shallower. Many publications report this behaviour in Flax composites $[65 ; 78 ; 128 ; 129]$. As the hybrids are $80 \%$ Flax, this behaviour can be caused the reorientation occurring within the Flax microfibrils themselves. The walls of the elementary fibers are helically structured, and under tensile loading, these structures realign themselves with the loading axis. This realignment when completed, changes the loading behaviour and lowers the elastic modulus. This behaviour can be further corroborated, as after the realignment, the behaviour remained linear until failure. Traditionally, in composites, the crossply laminates display half of the initial modulus and ultimate failure stress of their unidirectional counterparts [78]. However, the presence of the Kevlar layers affected this behaviour in the hybrid and improved the properties from $50 \%$ to a $30 \%$ reduction. It should also be noted that the Poisson's ratio (Table 4.3 ) in the UD laminate was significantly lower when compared to Flax. The transverse strain was reduced due to the presence of the $90^{\circ}$ Kevlar fibers present in the weave, which provided resistance to contraction in the transverse direction. 

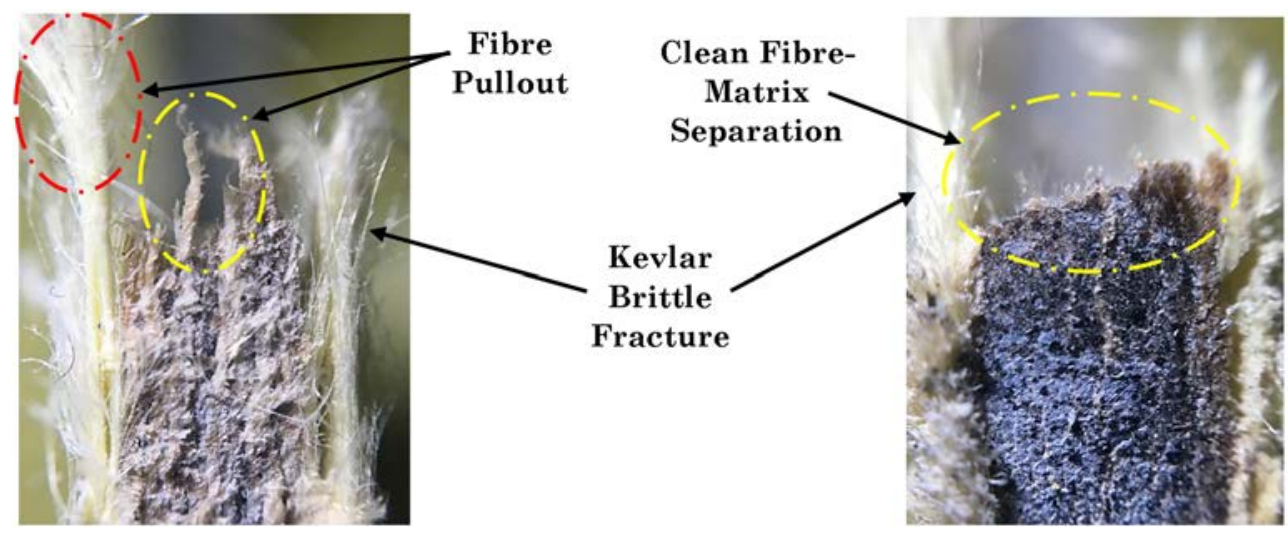

Figure 4.7: fiber-direction (left) and Transverse (right) Fracture Side Profile in Tension for UD Hybrid Composite
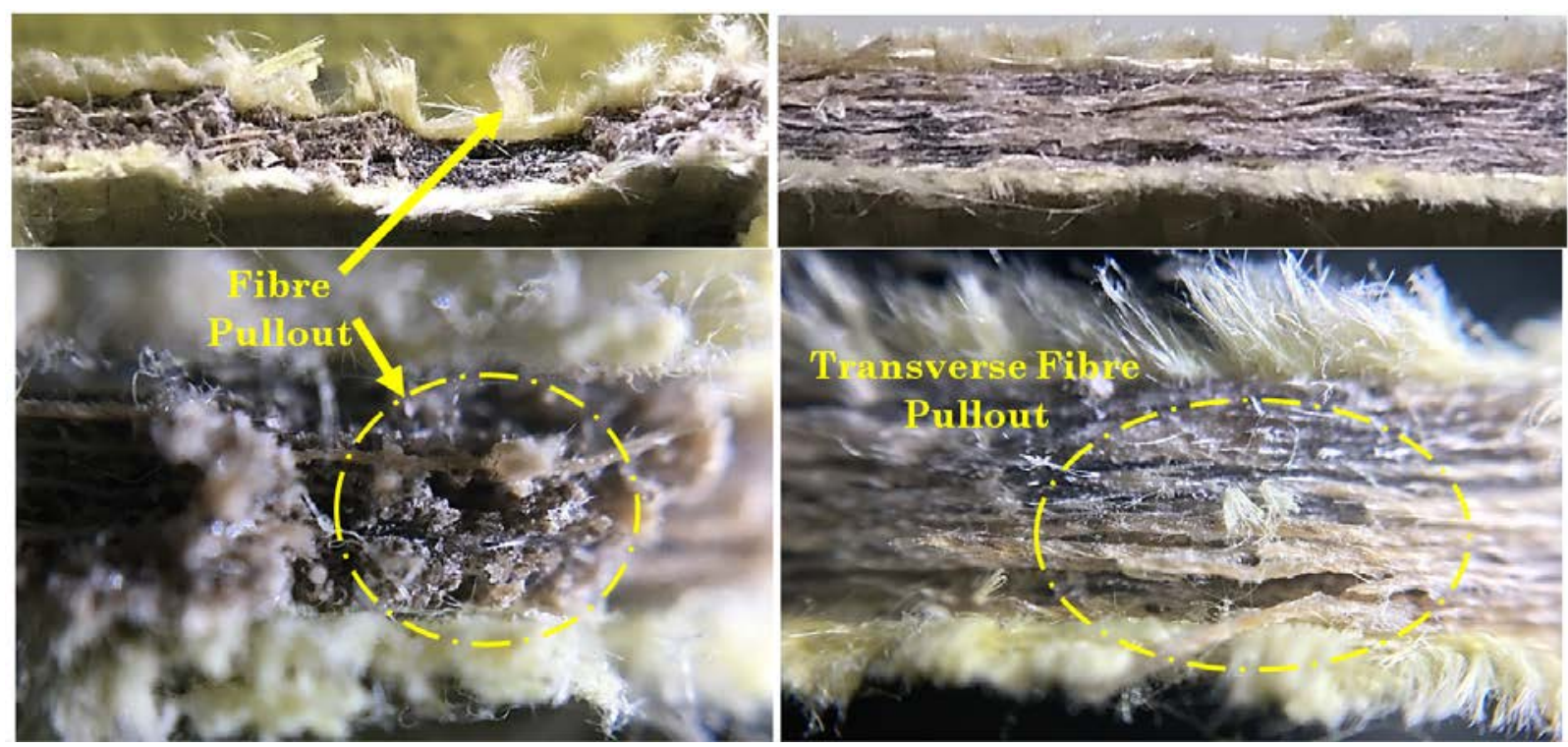

Figure 4.8: fiber-direction (left) and Transverse (right) Fracture Face in Tension for UD Hybrid Composite

Analyzing the fracture sites of the different hybrid laminates, showed multiple failure modes occurring. Figures 4.7 and 4.8 show the fractured UD and transverse samples. The UD configuration displays no delamination occurring at or near the fracture, indicating excellent interfacial bonding. Fiber pullout is evident and expected as per previous studies [40; 41; 78]. Kevlar and Flax are shown to undergo clean fiber breakage under tensile loading. Due to the perpendicular fiber alignment of the transverse specimens, the Flax fibers in the core separate from the matrix. Figure 4.8 shows the fiber debonding occurring on the fracture surface, with minor occurrences of the fibers being pulled out, displaying excellent fiber-matrix adhesion. 
The crossply specimen fractures in Figures 4.9 and 4.10 present both fiber pullout and fiber-matrix debonding occurring, as both the UD and transverse orientations are present. The Angle ply configuration is the first to show delamination occurring between the Kevlar and the Flax at the fracture site. Angle Flax fibers tend to orient themselves along the loading axis under tensile loads [78]. Therefore, the $45^{\circ}$ angle decays as load increases, causing the fibers to shift create stress concentrations, which if high enough, can cause delamination to occur along the fiber. As the interfacial bond between Kevlar and Flax is not as strong as the intralaminar Flax bonding, this delamination behaviour is observed at the interface of the two fibers.

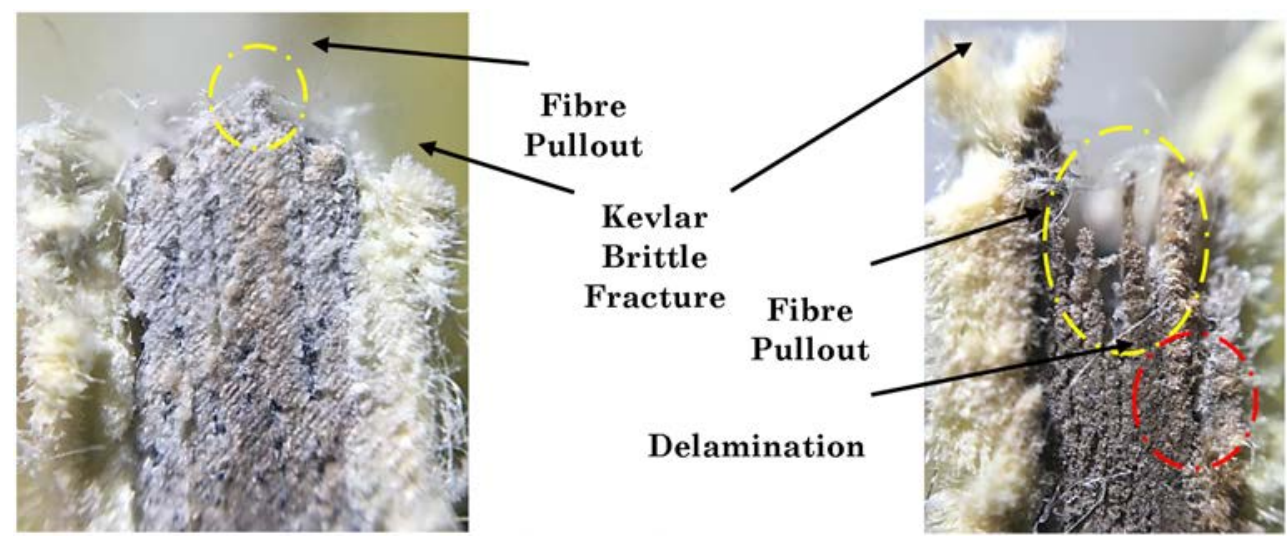

Figure 4.9: Crossply (left) and Angleply (right) Fracture Side Profile in Tension
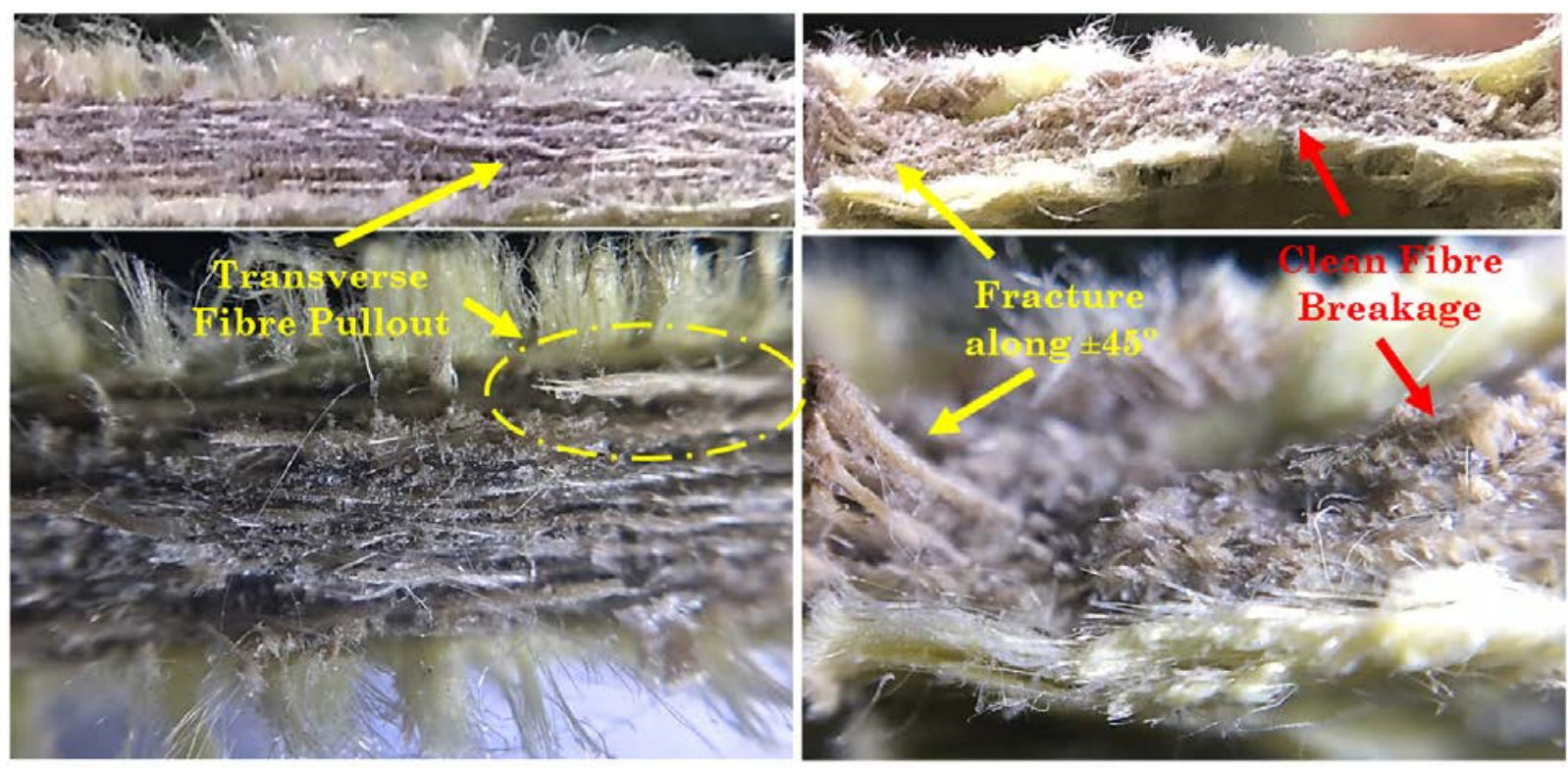

Figure 4.10: Crossply (left) and Angleply (right) Fracture Face Profile in Tension 


\subsection{Compression}

Compression tests were performed as per ASTM standard (ASTM D695-15) [130] on the MTS 322 Test Frame, with a strain rate of $2 \mathrm{~mm} / \mathrm{min}$ on the $150 \mathrm{kN}$ load cell. At least three $100 \mathrm{~mm}$ $\mathrm{x} 25 \mathrm{~mm}$ specimens were tested for each stacking sequence. Due to the use of DIC for strain measurement purposes, an anti-buckling system was not utilized as it would obstruct the view. The specimens were gripped at with 1500psi of pressure, and the gauge length of the specimens was kept at $2 \mathrm{~mm}$ to reduce out of plane buckling. The samples were loaded until failure and/or till buckling was detected. Table 4.4 displays the mechanical properties in compression, extracted from the test data.

Table 4.4: Mechanical properties of UD, Crossply and Angleply laminates in Compression, compared to their constituents

\begin{tabular}{lcccc}
\hline & $\begin{array}{c}\text { Modulus, Compressive } E_{c} \\
(\mathrm{GPa})\end{array}$ & Strength $\sigma^{c u}(\mathrm{MPa})$ & $\begin{array}{c}\text { Fail strain } \epsilon^{c u} \\
(\%)\end{array}$ & Poisson's ratio \\
\hline $\mathrm{UD}(11)^{1}$ & $34.08 \pm 1.58$ & $116.03 \pm 2.30$ & $0.55 \pm 0.07$ & $0.203 \pm 0.046$ \\
$\mathrm{UD}(22)^{2}$ & $12.19 \pm 0.97$ & $75.33 \pm 3.59$ & $1.73 \pm 0.18$ & $0.059 \pm 0.004$ \\
Crossply & $17.082 \pm 0.08$ & $86.62 \pm 0.27$ & $2.48 \pm 0.12$ & $0.056 \pm 0.002$ \\
Angle Ply & $13.69 \pm 0.12$ & $83.22 \pm 3.32$ & $1.69 \pm 0.07$ & $0.301 \pm 0.014$ \\
Flax $(11)^{1}[78]$ & $30.32 \pm 3.04$ & $127.11 \pm 5.08$ & $1.60 \pm 0.29$ & $0.396 \pm 0.046$ \\
Flax $(22)^{2}[78]$ & $5.70 \pm 0.71$ & $79.94 \pm 9.95$ & $2.61 \pm 0.53$ & $0.066 \pm 0.010$ \\
Kevlar & $37.87 \pm 1.10$ & $104.39 \pm 1.85$ & $0.46 \pm 0.03$ & $0.049 \pm 0.032$ \\
\hline
\end{tabular}

1 (11) - Fiber Direction

2 (22) - Transverse

Kevlar's poor performance in compression, negatively affects the hybrid laminates. While the elastic modulus sees an improvement, the ultimate stress suffers in comparison to Flax. The bidirectional weave further reduces performance, as the fibers already contain bends, which facilitate buckling. Figures display the stress strain curves for the different stacking sequences.

All specimens display non-linear behaviour overall, with the modulus degrading significantly around 0.3 to $0.5 \%$ [Figures $(4.11,4.12)$ ]. This indicates an initiation of compressive failure modes, decreasing laminate performance. Fibers in composites can develop kinks under compression. These kinks introduce weak points in the fibers and amplify any out of plane forces, causing buckling. The non-linear compressive behaviour can be attributed to the onset of buckling, which limits the laminate's compressive strength. Similar to tensile, a 
Unidirectional Profile in Compression

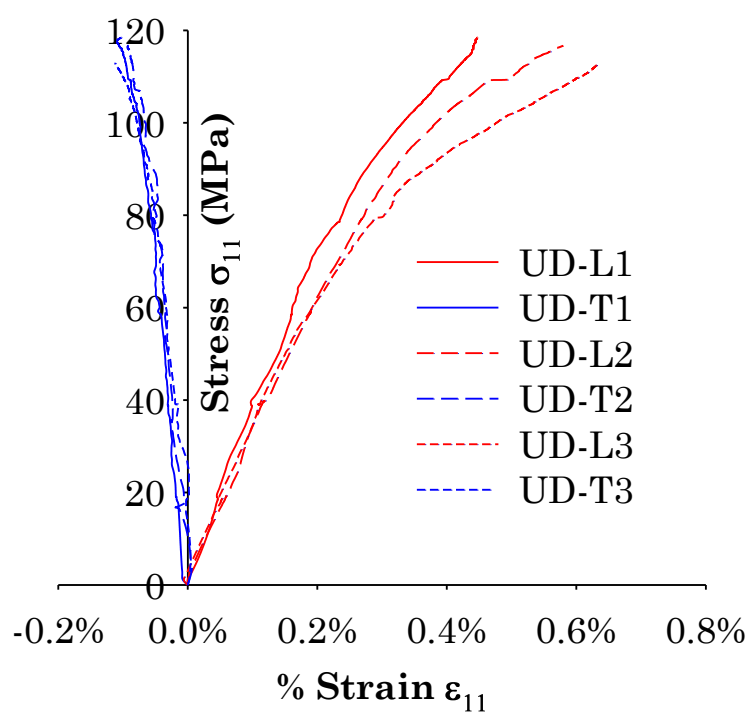

(a)
UD Transverse Profile in Compression

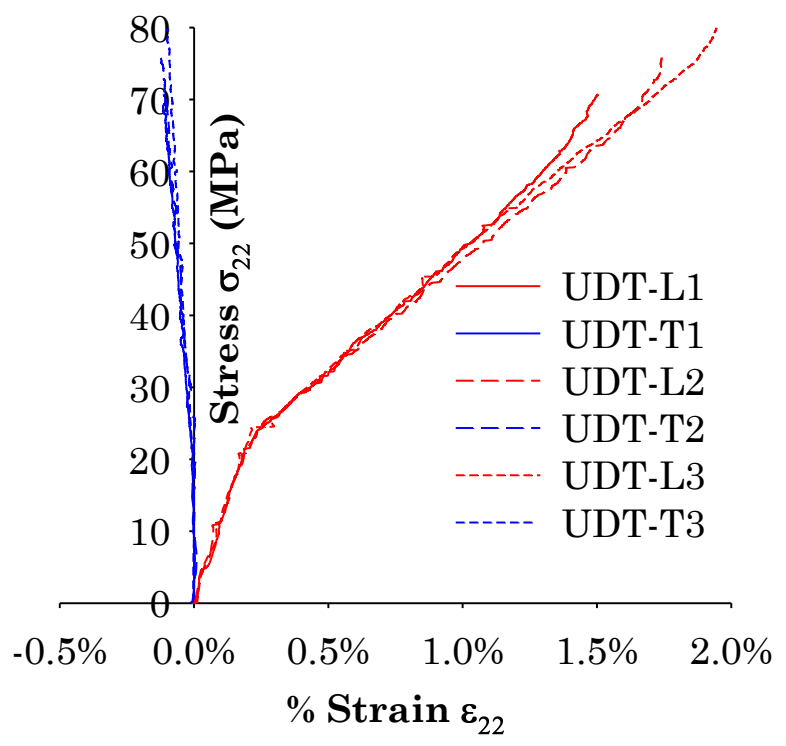

(b)

Figure 4.11: (a) fiber-direction and (b) Transverse Profile in Compression for UD - $\left[W_{K 2} / 0_{F 6}\right]_{S}$ Hybrid Composite

Crossply Profile in Compression

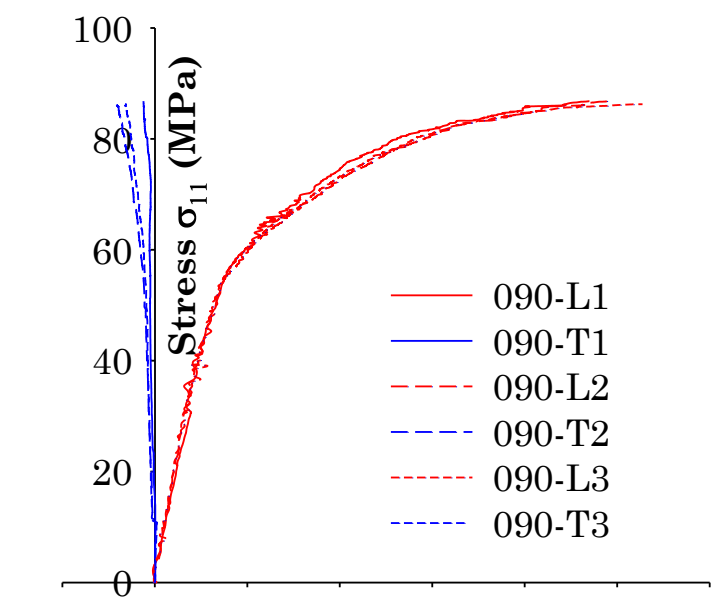

$-0.5 \% 0.0 \% \quad 0.5 \% 1.0 \% 1.5 \% 2.0 \% 2.5 \% 3.0 \%$

$\%$ Strain $\varepsilon_{11}$

(a)

\section{Angled Ply Profile in Compression}

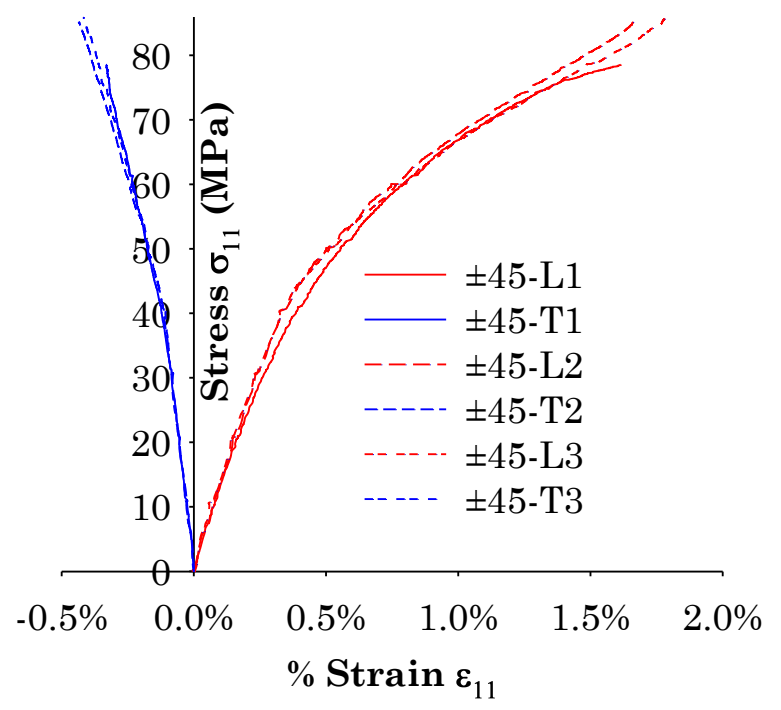

(b)

Figure 4.12: (a) Crossply $\left[W_{K 2} /(0 / 90)_{F 6}\right]_{S}$ and (b) Angleply $\left[W_{K 2} /( \pm 45)_{F 6}\right]_{S}$ Profile in Compression for KFE Hybrid Composites 
significant improvement was observed in the transverse strain behaviour for all orientations, due to the bi-directional Kevlar weave.

The matrix strength is a major contributor to overall laminate performance. Figure 4.11(b) shows the transverse loading profile of the UD hybrid. The ultimate stresses are shown to be a lot closer, than the tensile counterparts. The buckling of the Kevlar fibers can also easily be evidenced around $0.3 \%$ strain mark.
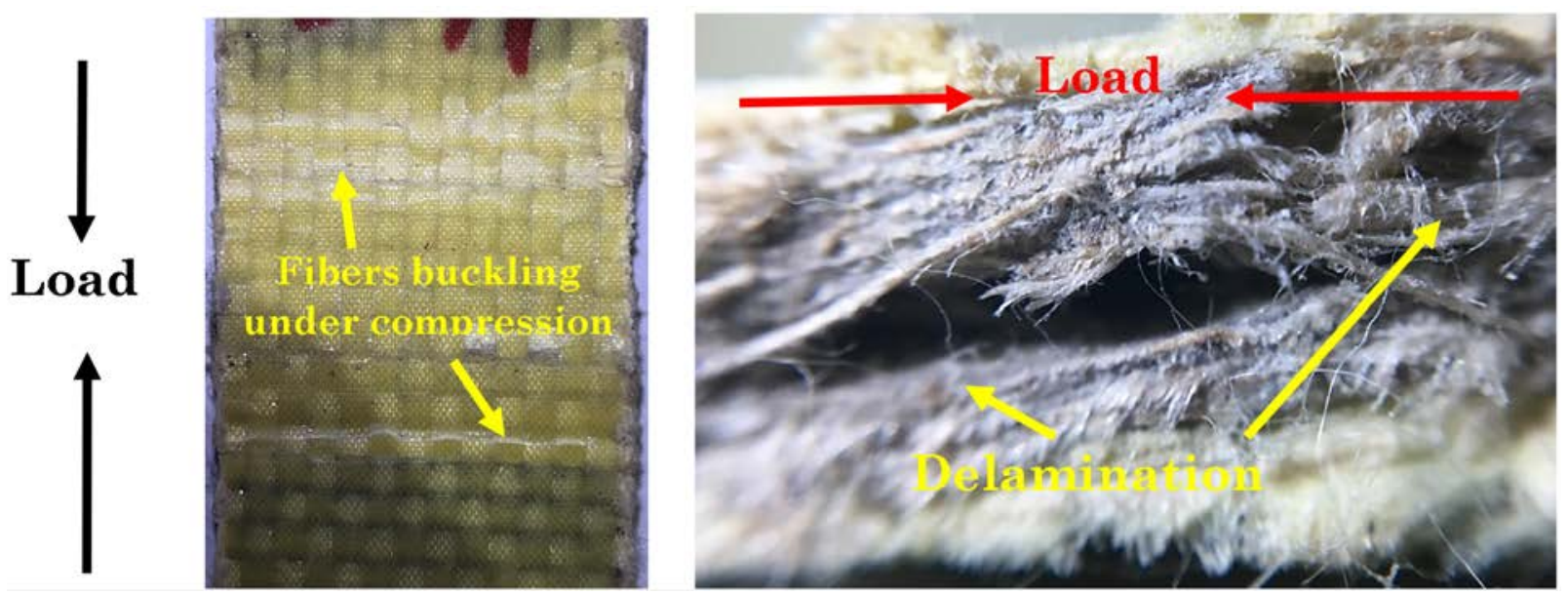

Figure 4.13: fibers buckling occurring in Kevlar skin for UD KFE Hybrid (left) and Fracture Side Profile in Compression (right)
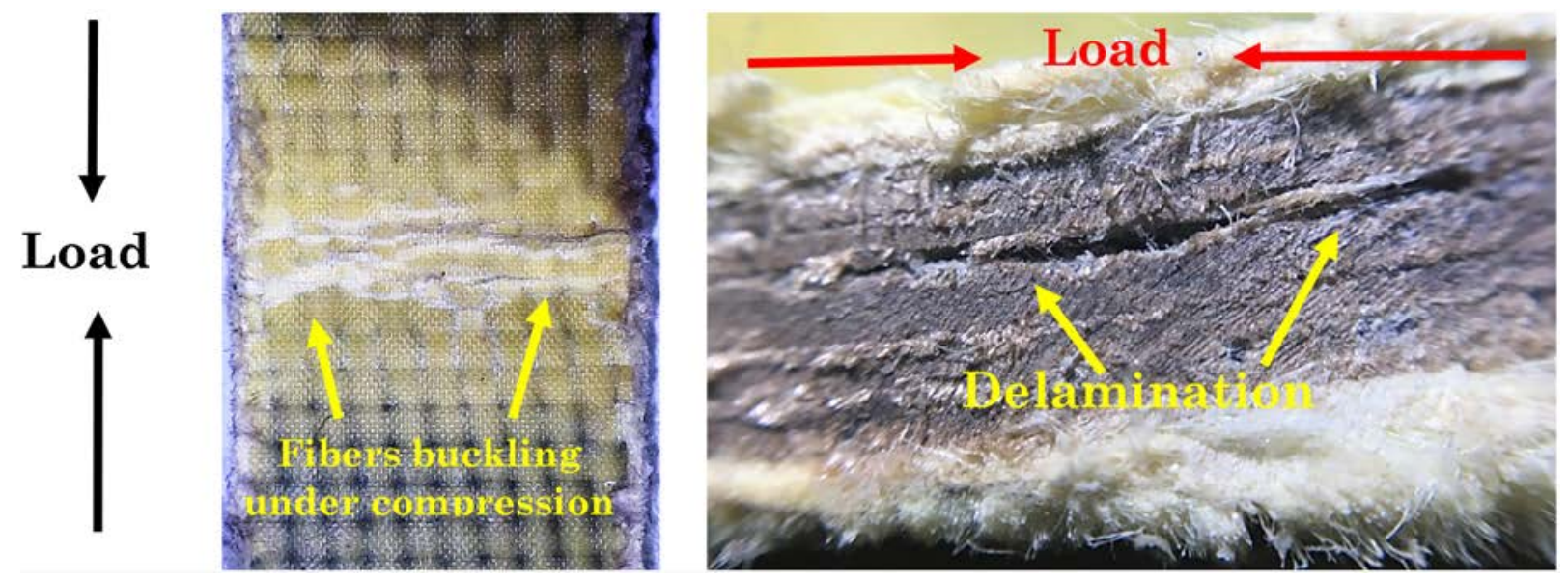

Figure 4.14: fibers buckling occurring in Kevlar skin for Crossply KFE Hybrid (left) and Fracture Side Profile in Compression (right)

As stated, buckling is the dominant failure mode for fiber-based PMC's. Out of plane buckling, encourages delamination, as displayed in Figures $(4.13,4.14,4.15)$. The weaker intralaminar bonds are broken perpendicular to the loading axis, causing laminae to separate. The 

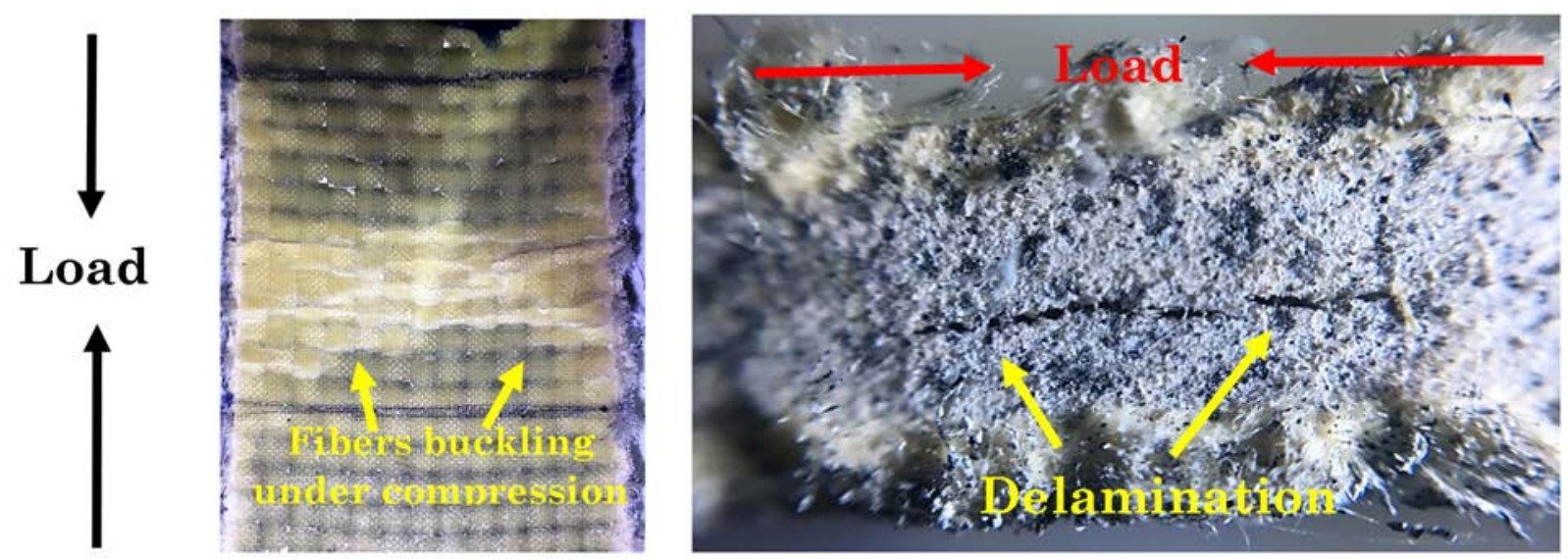

Figure 4.15: fibers buckling occurring in Kevlar skin for Angleply KFE Hybrid (left) and Fracture Side Profile in Compression (right)

intensity of delamination is highly dependent on the amount of fibers aligned with the loading axis. The Angle ply hybrid(Figure 4.15, displayed the lowest out of plane delamination, as the fibers can more easily buckle along the fiber axis.

\subsection{Bending}

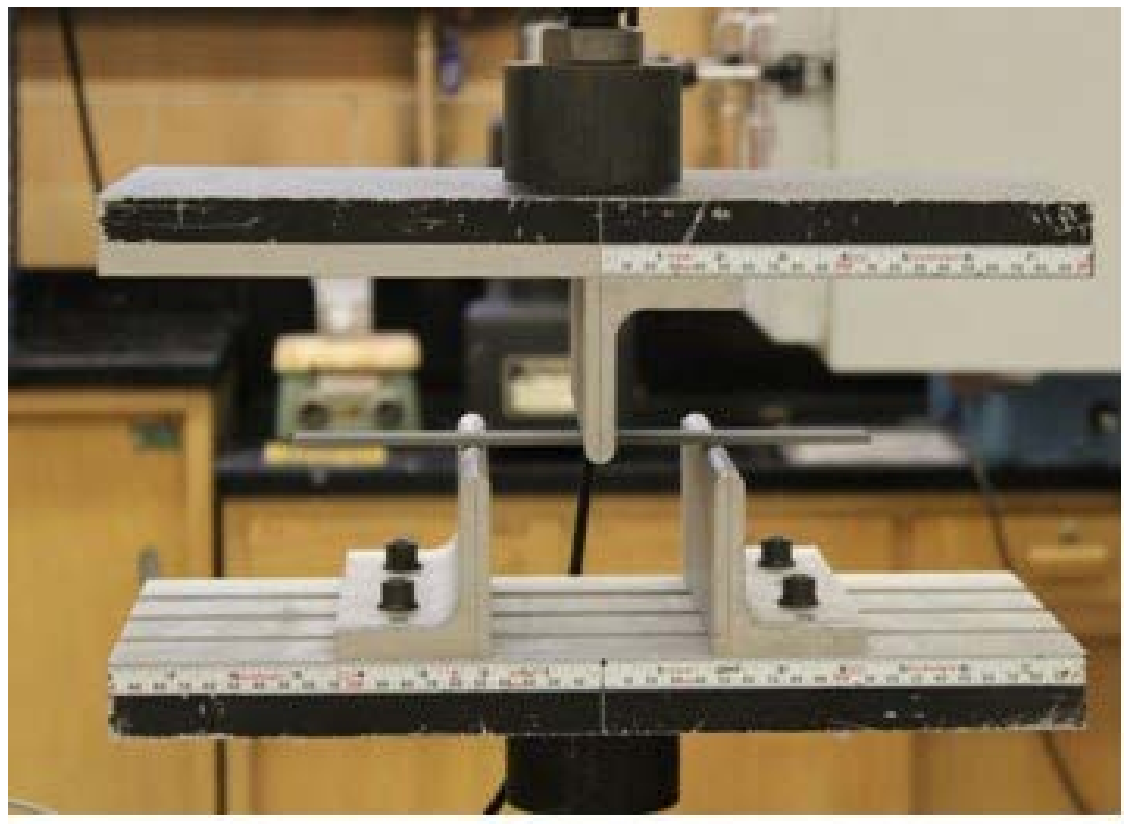

Figure 4.16: Three point Bending test Setup

Based on the ASTM standard (ASTM D7264/D7264M) [131], 250mm x 25mm specimens 
were used to perform three-point bending tests. The samples were loaded onto a STM series test machine (United Calibration Corp., Huntington Beach, CA) on a fixture with a span length of $100 \mathrm{~mm}$ in order to reduce out of plane shear effects. Load was applied using a $50 \mathrm{kN}$ cell with a circular nose with a $3 \mathrm{~mm}$ radius, at a rate of $10 \mathrm{~mm} / \mathrm{min}$.

According to the ASTM standard, the flexural modulus $\left(E_{f}\right)$ and the maximum flexural stress $\left(\sigma^{f u}\right)$ can be calculated from the force and displacement curve, using the following relations (Eq. 4.4, 4.5):

$$
\begin{gathered}
E_{f}=\frac{M L^{3}}{4 b h^{3}} \\
\sigma^{f u}=\frac{3 P_{f} L}{2 b h^{2}}
\end{gathered}
$$

Where $M$ is the slope of the force vs. displacement curve, $L$ is the support span, $b$ is the width of the specimen, $P_{f}$ is the maximum load applied before failure, and $h$ is the thickness of specimen.

The load was applied until fracture, and the tabulated results are shown in Table 4.5.

Table 4.5: Mechanical properties of UD, Crossply and Angleply laminates in Bending, compared to their constituents

\begin{tabular}{lcc}
\hline & Modulus, Flexural $E_{f}(\mathrm{GPa})$ & Strength $\sigma^{f u}(\mathrm{MPa})$ \\
\hline Unidirectional & $23.42 \pm 0.49$ & $283.08 \pm 9.18$ \\
Crossply & $19.15 \pm 0.47$ & $247.98 \pm 3.82$ \\
Angle Ply & $14.95 \pm 0.13$ & $220.64 \pm 3.14$ \\
Flax/Epoxy & $17.504 \pm 0.801$ & $236.35 \pm 14.75$ \\
Kevlar/Epoxy[132] & 47.96 & 395.18 \\
\hline
\end{tabular}

The results show improvements in the modulus and ultimate stress, from the addition of the Kevlar weave. The ultimate stress values for the three stacking sequences are quite close, indicating that most of the work is done by the Kevlar skin due to the sandwich structure. Looking at Figure 4.17, the bending profile of the three hybrids follow similar behaviour until fracture. The specimens all behave linearly until around $1 \%$ strain, after which the behaviour becomes non-linear until fracture. This change in the modulus can be caused by the buckling of the inner layers under compression. As the failure strain for Kevlar and Flax is lower in compression compared to tension, the laminae in contact with the nose buckle early on, reducing the modulus of the composite. 
Bending Profile for UD

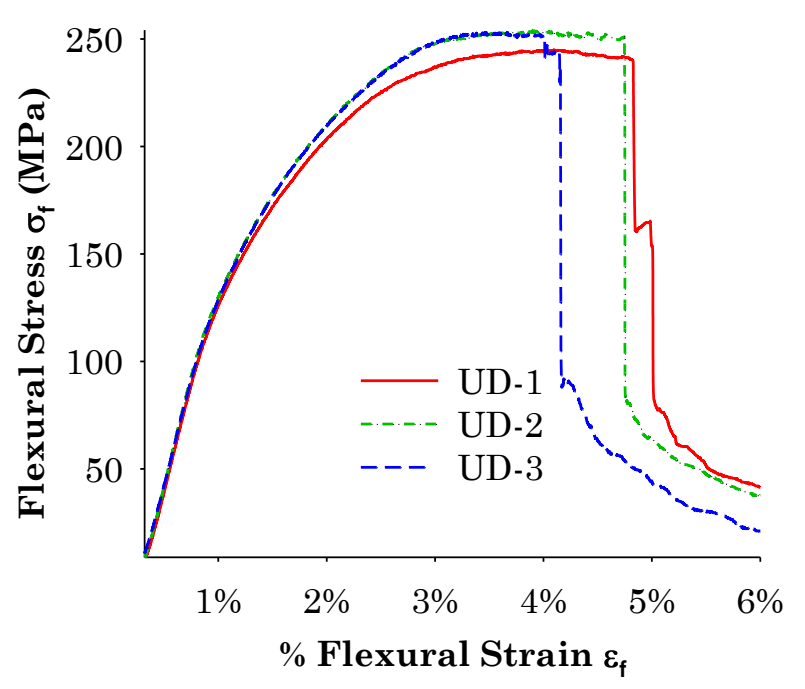

(a)
Bending Profile for Crossply

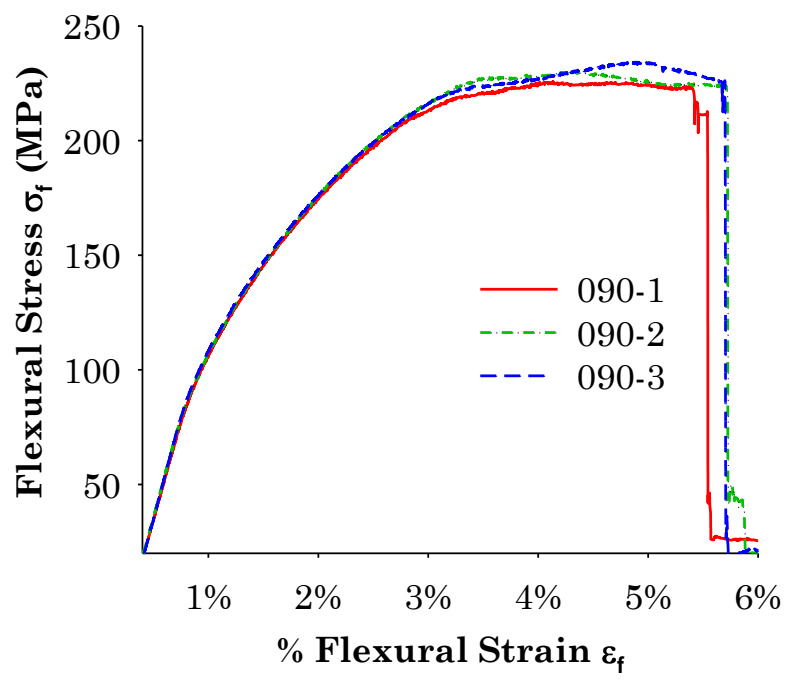

(b)

Bending Profile for Angleply

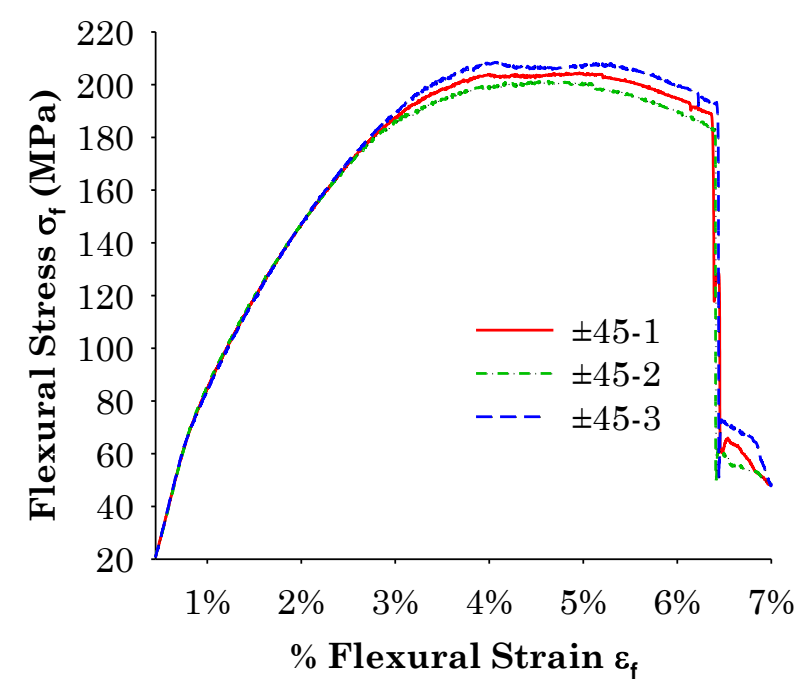

(c)

Figure 4.17: (a) UD - $\left[W_{K 2} / 0_{F 6}\right]_{S}$, (b) Crossply $\left[W_{K 2} /(0 / 90)_{F 6}\right]_{S}$ and (c) Angleply $\left[W_{K 2} /( \pm 45)_{F 6}\right]_{S}$ Profile in Bending

The stress strain curves also exhibit a minor deterioration occurring in the stress after the highest point. As the outer skin of the composite is Kevlar, its can withstand a much higher load before fracturing. The inner Flax laminae, however, are not as strong. Once the load reaches the peak, the inner Flax layers start to break, lowering the stress threshold, until total failure occurs when the Kevlar fractures. This phenomenon is more evident in the Angle ply 
as the $45^{\circ}$ aligned fibers have a much lower tensile strength than the Kevlar. It should also be noted that not all layers fracture, as evidenced by the continual decrease in stress in the graphs.

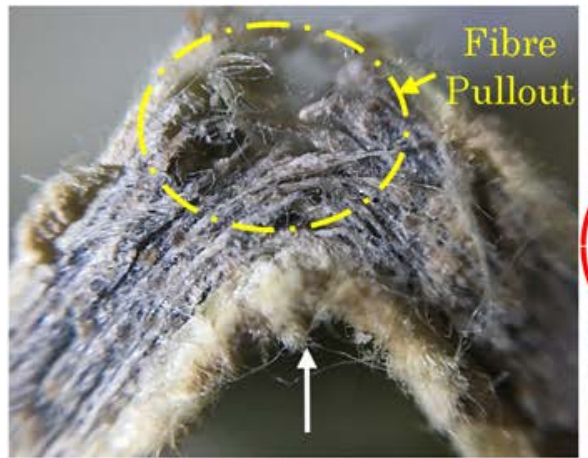

Load

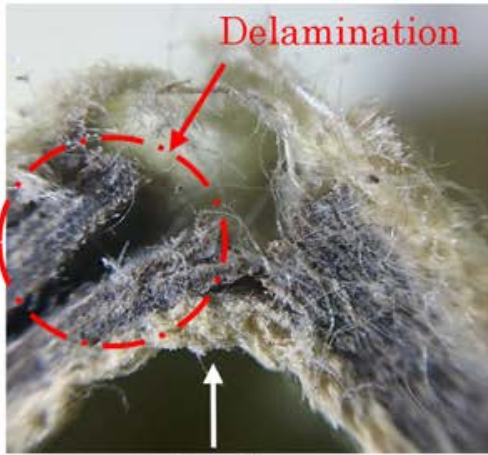

Load

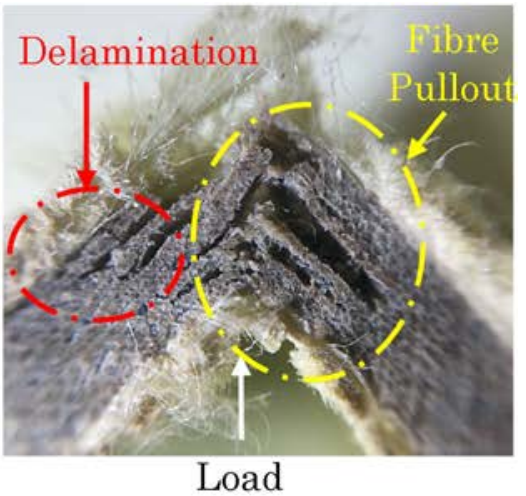

Load

Figure 4.18: Side Fracture for UD(left), Crossply(middle) and Angleply(right) Hybrid in Bending

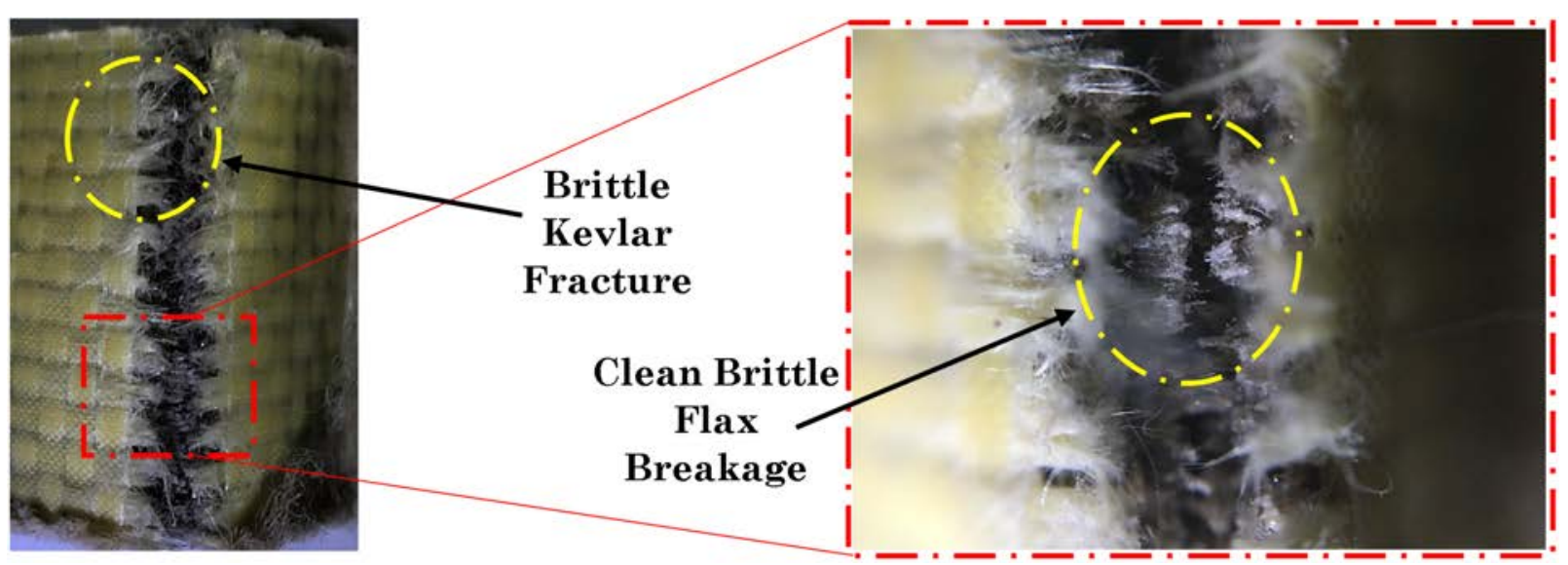

Figure 4.19: Fracture face for UD Hybrid in Bending (left) and fibers displaying clean breakage (right)

Analyzing the bending fractures in Figures 4.18-4.21, modes similar to the tensile and compression tests, are observed. The Kevlar fractures exhibits a clean brittle fracture, in all the samples. Due to its poor compression properties, it can be seen that the Kevlar layers under compression buckle easily and remain intact. The UD hybrid (Figure 4.19) shows clean fiber breakage and pullout in bending. The cross ply however, shows significant delamination occurring in the Flax laminae. As the cross ply is a combination of $0^{\circ}$ and $90^{\circ}$ plies, the interfacial bonds between the adjacent plies is not very strong, resulting in energy release occurring through delamination, rather than fiber breakage. The Angle ply (Figure 4.18) displays both 
damage modes. The $\pm 45^{\circ}$ plies are also perpendicular to each other and cannot withstand the full load, as the fibers are not oriented along the loading axis.

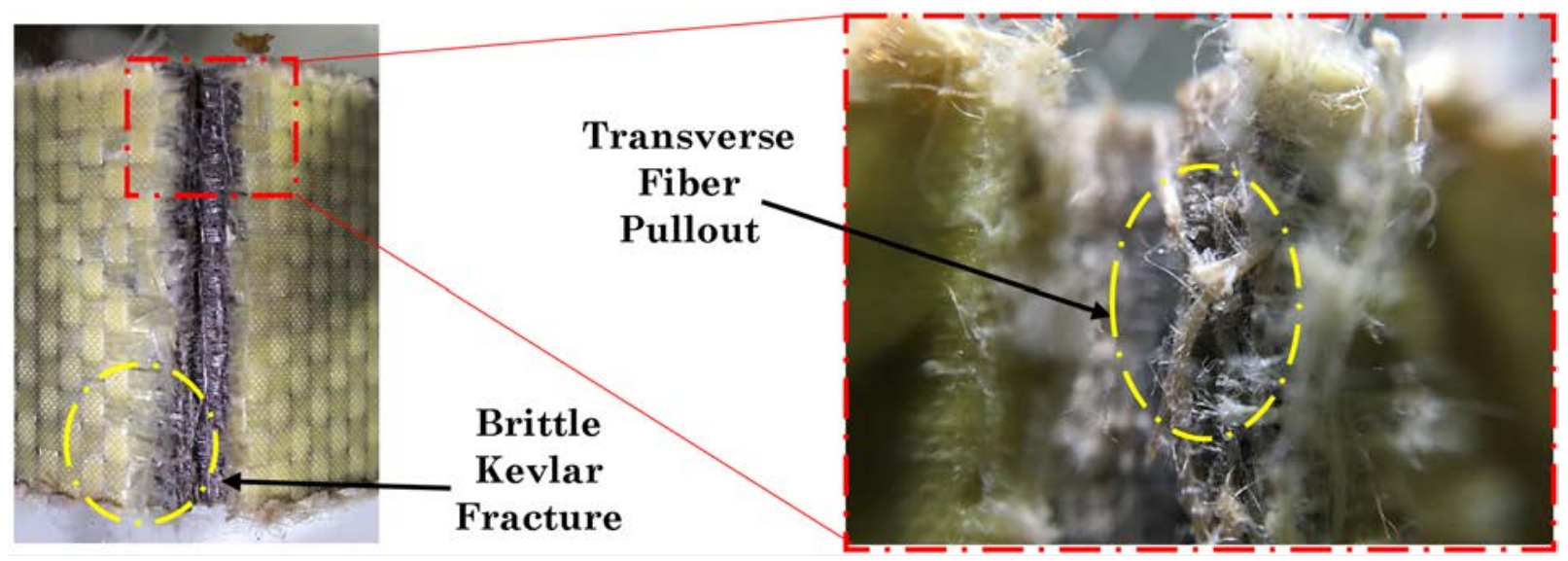

Figure 4.20: Fracture face for Crossply Hybrid in Bending (left) and fibers displaying clean breakage and pullout (right)

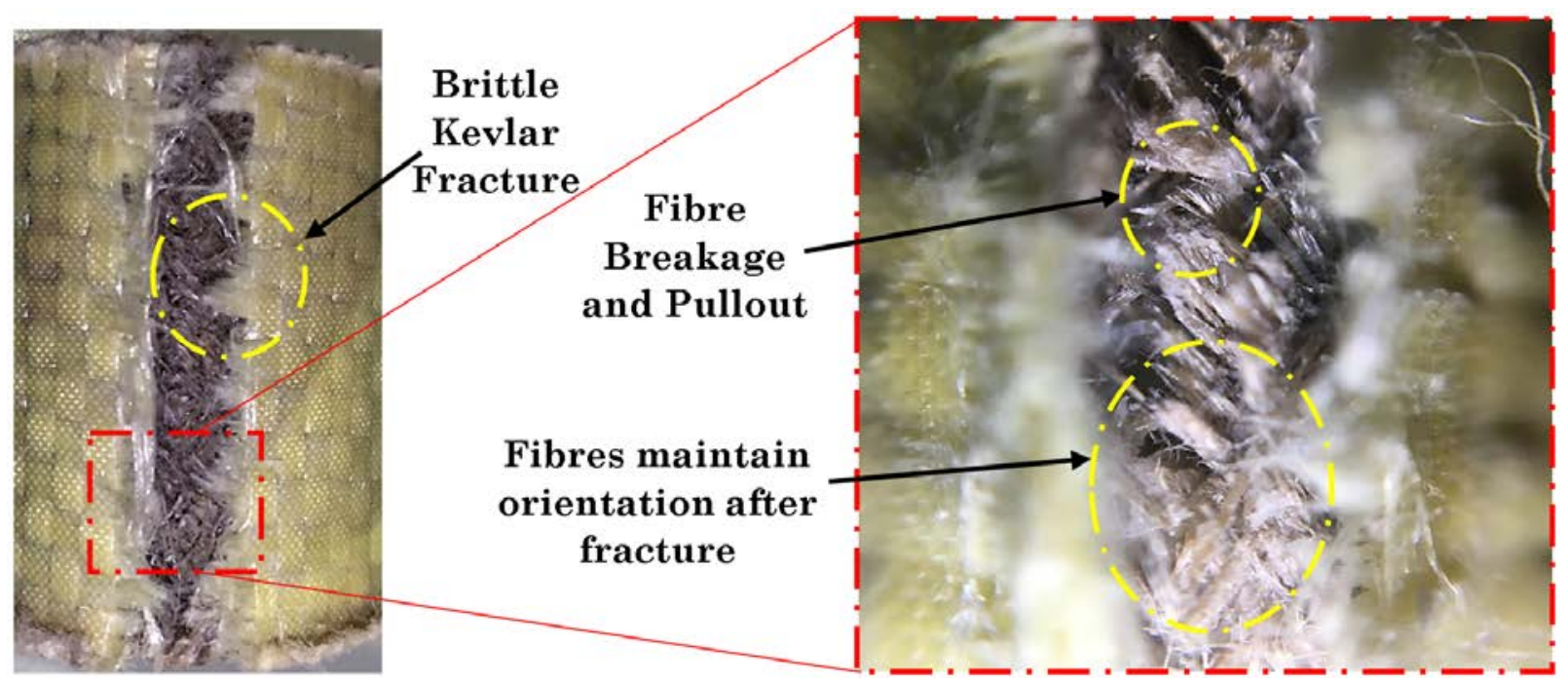

Figure 4.21: Fracture face for Angleply Hybrid in Bending (left) and fibers showing fracture along fiber axis (right)

\subsection{Torsion}

A set standard is not yet present for determining the shear properties of hybrid composite materials. Therefore, the torsion tests were performed based on the ASTM standard (ASTM E143-13) [133], which states the general testing method for the shear modulus. ASTM E143-13 
specifies the conditions for circular cross sections. However, due to manufacturing limitations, producing circular test specimens was impractical. Therefore, similar analysis done on extracting shear properties of rectangular specimens by Huston and Josephs [134] was used.

Accordingly, the shear modulus $G$ and maximum shear strength $\tau^{u}$ can be calculated using the following equations(Eq. 4.6 and 4.7:

$$
\begin{gathered}
\theta=\frac{T L}{G K} \\
\tau^{u}=\frac{T}{K_{s}}
\end{gathered}
$$

Where $T$ is the maximum torque, $L$ is the span length, $\theta$ is the maximum twist angle and $K, K_{s}$ are torsional factors known as the "section moduli".

Three $250 \mathrm{~mm} \times 25 \mathrm{~mm}$ specimens were tested from each hybrid composite on a CTT series torque testing machine (Shenzhen Sans Testing Machine Co. Ltd., Shenzhen, China) at a torsion rate of $15 \mathrm{deg} / \mathrm{min}$. The samples were clamped along the midplane with flat grips on each side. The calculated shear modulus and strength are given in Table 4.6.

Table 4.6: Mechanical properties of UD, Crossply and Angleply laminates in Torsion, compared to their

\begin{tabular}{|c|c|c|}
\hline & Modulus, Shear $G$ (GPa) & Strength $\tau^{u}(\mathrm{MPa})$ \\
\hline $\mathrm{UD}(11)^{1}$ & $1.96 \pm 0.04$ & $185.19 \pm 2.44$ \\
\hline $\mathrm{UD}(22)^{2}$ & $1.99 \pm 0.02$ & $105.86 \pm 2.95$ \\
\hline Crossply & $1.68 \pm 0.02$ & $131.81 \pm 3.06$ \\
\hline Angle Ply & $3.035 \pm 0.07$ & $122.24 \pm 1.61$ \\
\hline $\operatorname{Flax}(11)^{1}[78]$ & $2.07 \pm 0.13$ & $37.35 \pm 1.78$ \\
\hline Kevlar/Epoxy & $3.23 \pm 0.05$ & $250.04 \pm 3.09$ \\
\hline
\end{tabular}
constituents

${ }^{1}$ (11) - Fiber Direction

2 (22) - Transverse

For further analysis, plots for the torque vs. twist angle are shown in Figures (4.22 and 4.23). All specimens exhibit a fairly linear behaviour until fracture. All hybrids also experience a minor change in modulus in the initial stages. In the UD(Figure 4.22(a)) and crossply(Figure 4.23(a)), the composite stiffens as it moves closer to fracture. For a rectangular specimen under torsion, the stress increases with the proximity to the perimeter. The fibers near the midplane experience less stress than the fibers at the edges. However, as the twist angle increases 
Shear Profile for UD

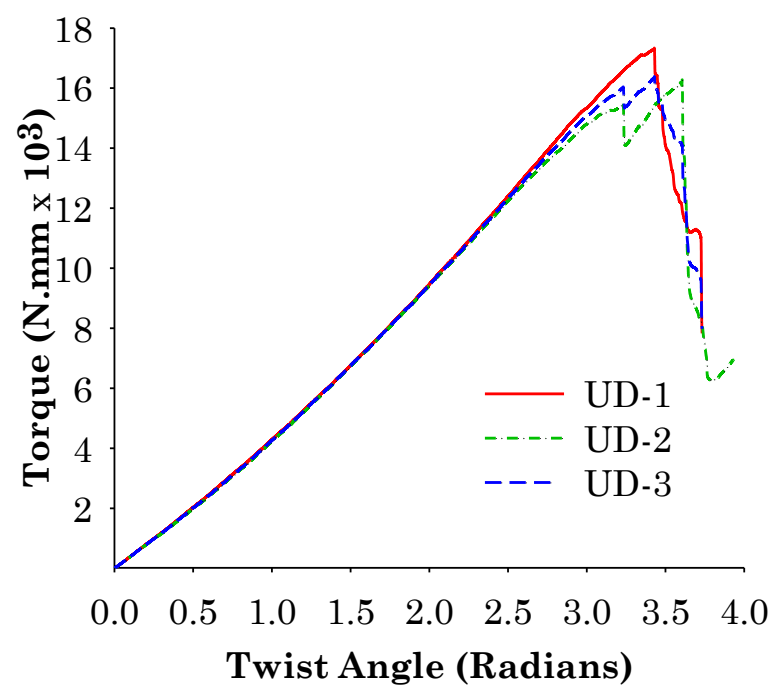

(a)
Shear Profile in Transverse

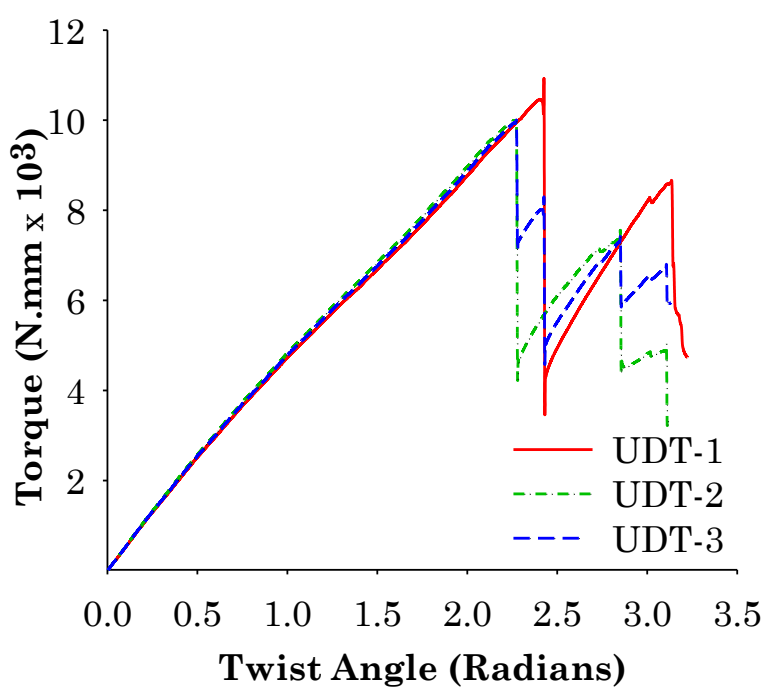

(b)

Figure 4.22: (a) fiber-direction and (b) Transverse Profile in Shear for UD - $\left[W_{K 2} / 0_{F 6}\right]_{S}$ Hybrid Composite

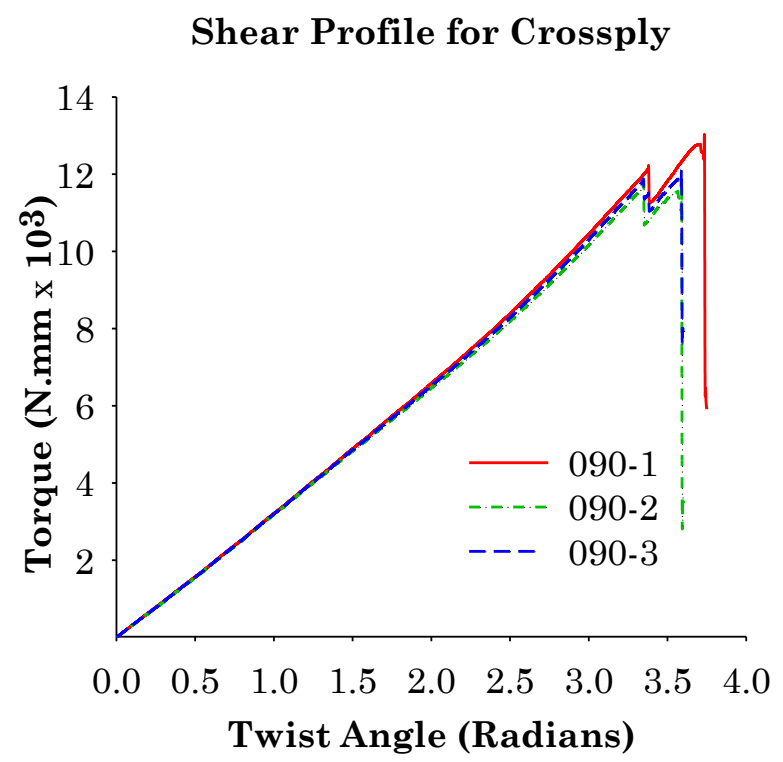

(a)

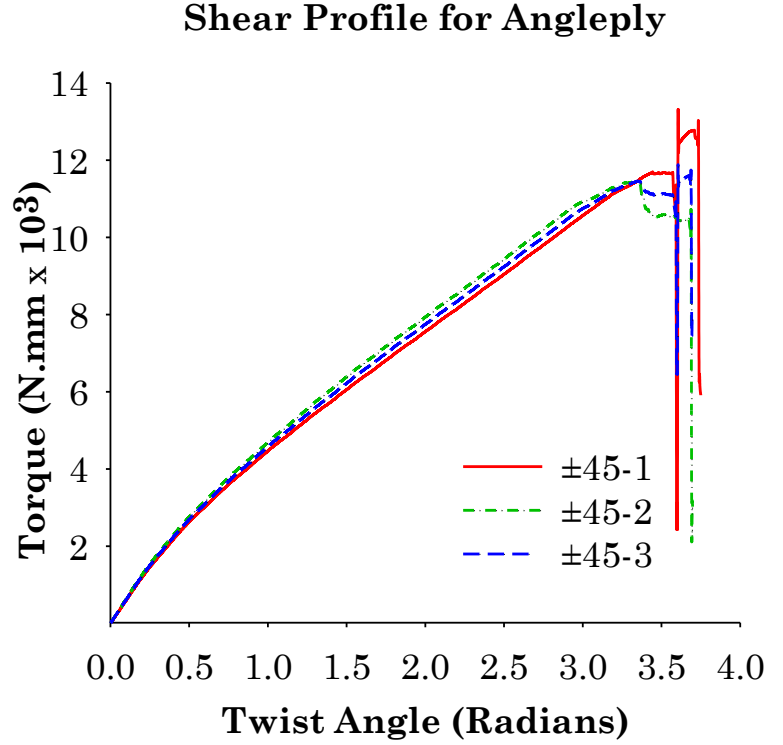

(b)

Figure 4.23: (a) Crossply $\left[W_{K 2} /(0 / 90)_{F 6}\right]_{S}$ and (b) Angleply $\left[W_{K 2} /( \pm 45)_{F 6}\right]_{S}$ Profile in Shear for KFE Hybrid Composites

after $1 \mathrm{rad}$, the numbers of fibers resisting increases, thus, increasing the stress threshold of the composite. The Transverse (Figure 4.22(b)) and Angle ply (Figure 4.23(b)) display the op- 
posite phenomenon. As the fibers are not parallel to the mid-plane axis, a bending loading is applied rather than tension. Increasing the twist angle, encourages the development of kinks due to compression, reducing the shear modulus. This behaviour cannot be seen in the 0/90 crossply as the fibers perform better in tension, overshadowing the bending load. However, the stiffening of the modulus is delayed to after an twist angle of 2 rads, indicating the influence of the $90^{\circ}$ fibers.
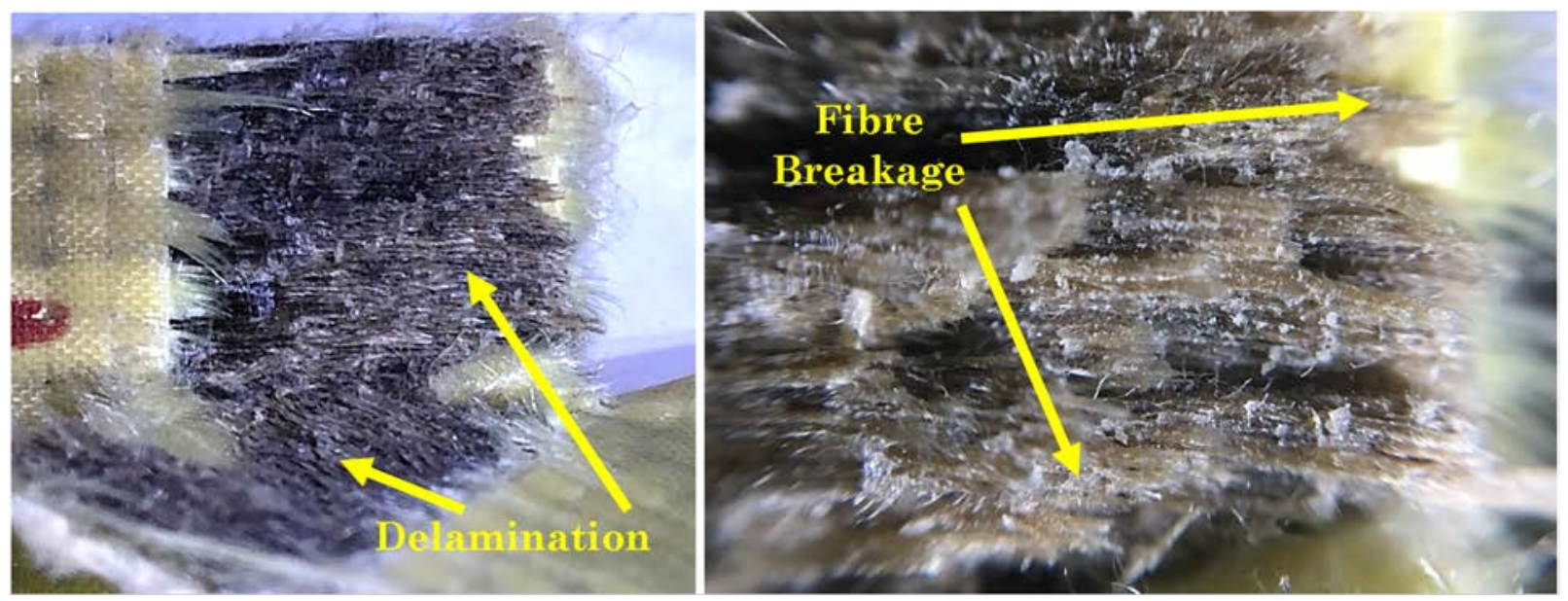

Figure 4.24: Fracture face for UD Hybrid in Torsion (left) and fibers showing delamination and fiber breakage (right)
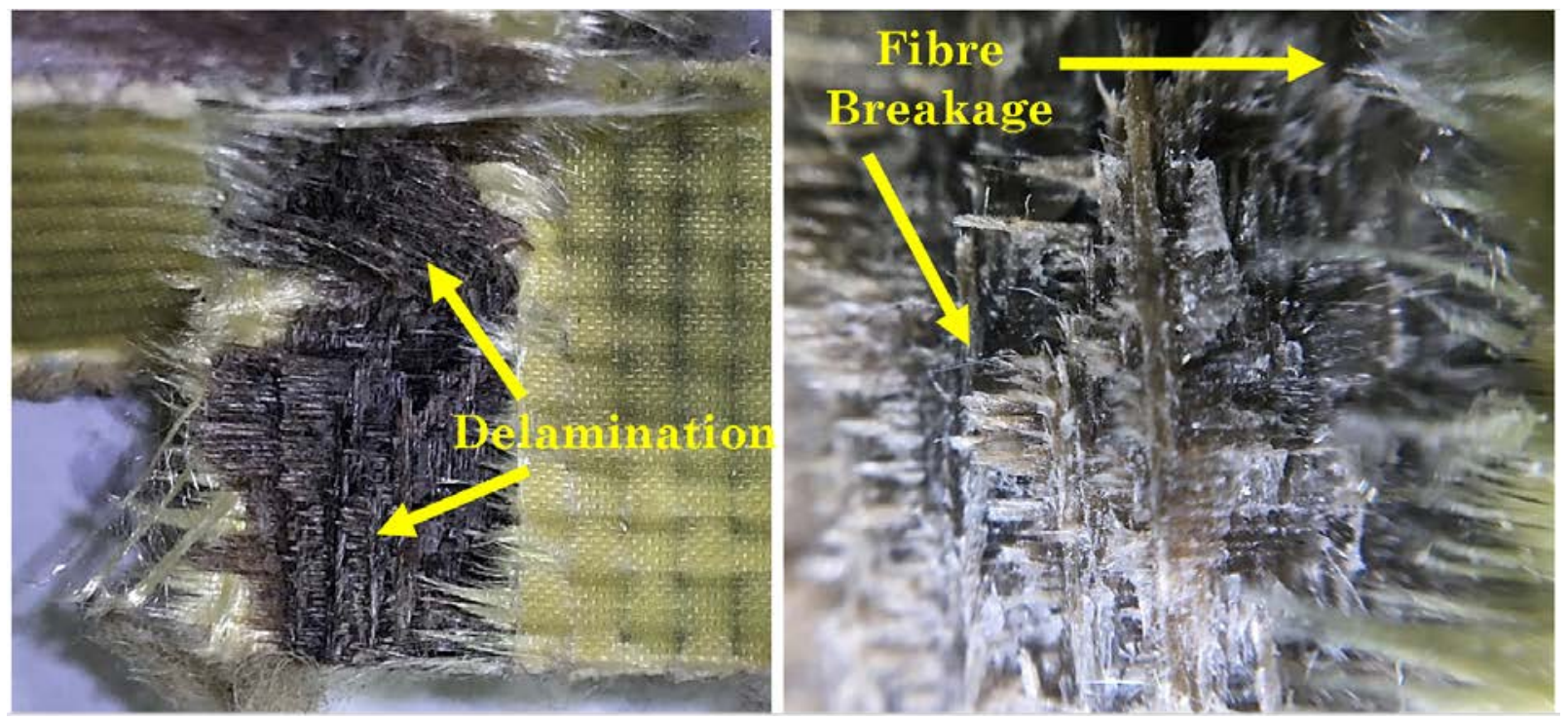

Figure 4.25: Fracture face for Crossply Hybrid in Torsion (left) and fibers showing delamination and fiber breakage (right)

The presence of Kevlar in the outer skins compliments all the hybrids, improving the performance in torsional loading as seen in Table 4.6. Due to its higher tensile strength, it can un- 
dertake higher stresses, while protecting the Flax core inside. The dominant damage modes in shear are delamination and fiber breakage. Both mechanisms are clearly observed in Figures $(4.24,4.25,4.26)$

It should also be noted that the composites do not fracture as a whole, as shown in both the curves and optical images. The layers fracture in accordance with proximity to the midplane. Ideally, the fracture should be as one, however, the energy is released via delamination rather than fiber breakage, as it is the weaker mode.
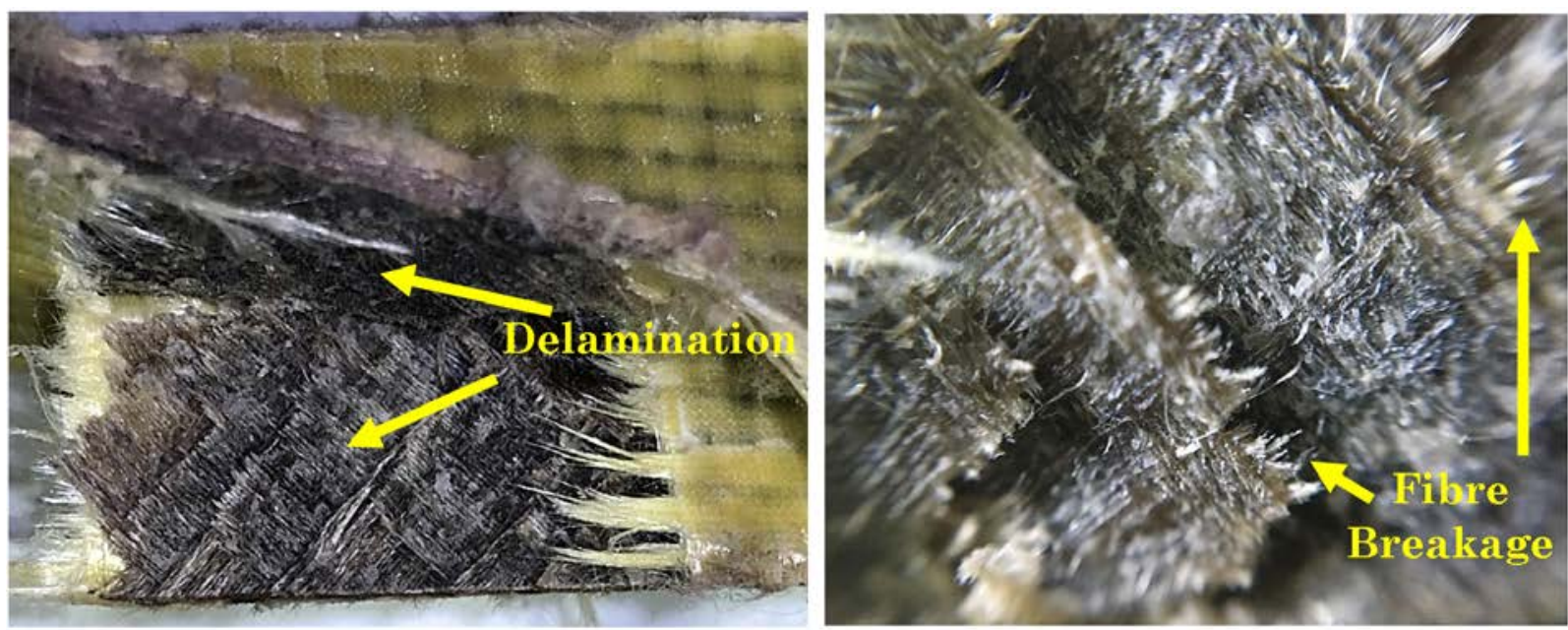

Figure 4.26: Fracture face for Angleply Hybrid in Torsion (left) and fibers showing delamination and fiber breakage along fiber axis (right) 


\subsection{Kevlar/Epoxy Tests}

Due to the literature gap present for the basic mechanical properties of Kevlar 49 weave, some tests were performed for a 16 layers Kevlar/Epoxy composite, for comparison purposes. All tests were performed in accordance with the ASTM standards detailed in the sections before. The properties of Kevlar 49 derived from the tests, as well as the literature, are given in the table below.

Table 4.7: Mechanical properties of Kevlar/Epoxy laminates tested and extracted from literature

\begin{tabular}{lc}
\hline & Kevlar/Epoxy \\
\hline Tensile Modulus & $38.52 \pm 0.47$ \\
Tensile Strength & $532.08 \pm 5.73$ \\
Compressive Modulus & $37.87 \pm 1.10$ \\
Compressive Strength & $104.39 \pm 1.85$ \\
Flexural Modulus [132] & 47.96 \\
Flexural Strength [132] & 395.18 \\
Shear Modulus & $3.23 \pm 0.05$ \\
Shear Strength & $250.04 \pm 3.09$ \\
\hline
\end{tabular}

Analyzing the curves for tension (Figure 4.27(a)) and compression(Figure 4.27(b)), it can be seen that Kevlar exhibits similar linear behaviour as other synthetic fibers composites. The effects of the weave deter any transverse strain, reducing the Poisson's ratio. Like the hybrid, the compression profile showed evidence of buckling at higher stresses, as Kevlar performs poorly in compression compared to Flax. All sample buckled around $100 \mathrm{MPa}$ at a failure strain of around $0.5 \%$, close to the hybrid, as well as the reported Flax data [78].

Kevlar outperformed the hybrid in torsion(Figure 4.27(c)), fracturing at a higher stress, as well as a higher twist angle. It can be inferred then that fracture in the hybrid composites is actually initiated at the outermost Flax plies, rather than the Kevlar skin. The high fracture toughness of Kevlar allows it to twist twice as much as the hybrid. Irregularities in the shear profile also indicate that Kevlar fiber breakage started occurring after 3.0\% strain and continuing until failure. This phenomenon was not observed in the hybrid, verifying the inference previously made. 


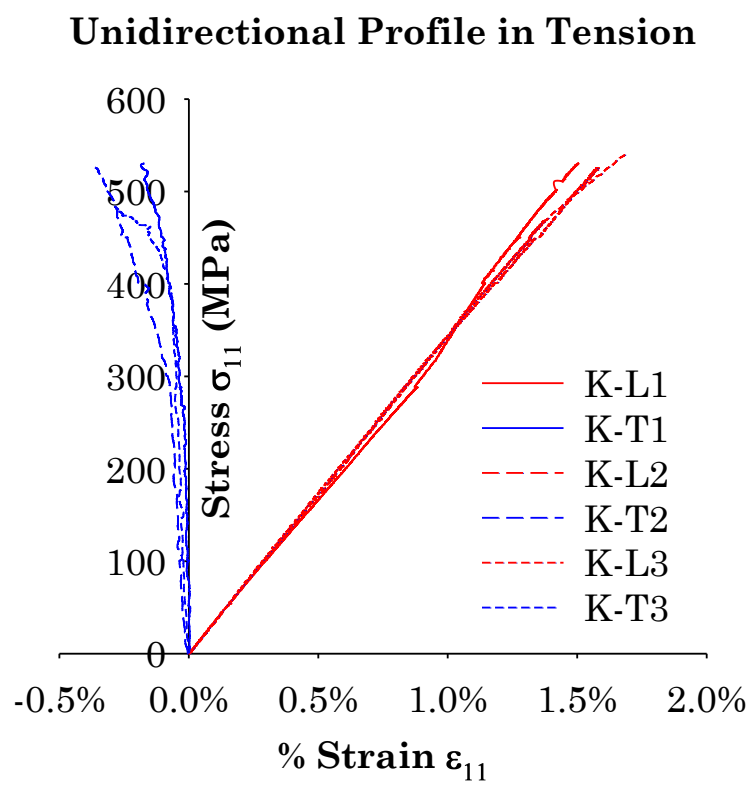

(a)

\section{Unidirectional Profile in Compression}

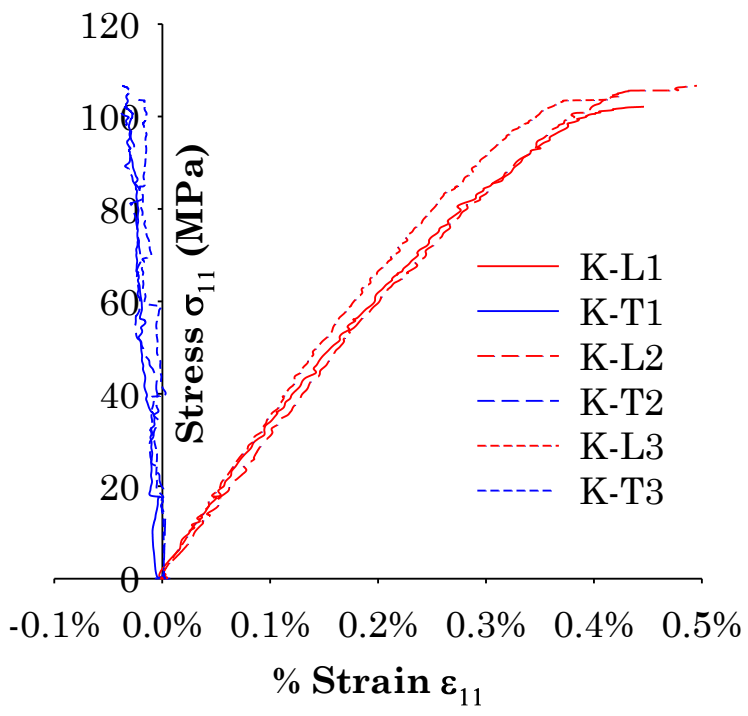

(b)

Shear Profile for Kevlar

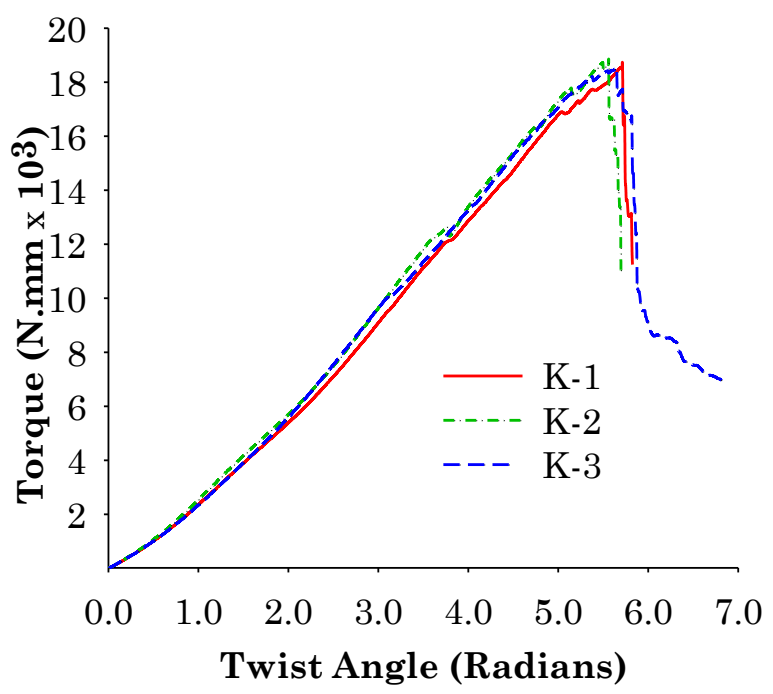

(c)

Figure 4.27: (a) Tension, (b) Compression and (c) Torsion Profile for 16-layer Kevlar/Epoxy Composite 


\subsection{Summary}

The tests conducted on the three hybrid configurations display improvements in the laminate properties over the constituent components. The composites were able to outperform pure Flax in tension, bending and torsion. The benefit of the sandwich structure is clearly evident, as the flexural and torsional properties are enhanced. The outer Kevlar skin compliments the inner Flax core remarkably well, due to their similar physical properties. Compression loading, however, suffers due to Kevlar's low resistance in compression. Many different fracture mechanisms were also identified to be dependent on loading conditions and fiber orientation. Fracture in hybrid composites is caused by multiple failure modes, which act independently and/or supplement each other to cause failure. Optical macroscopic observations highlighted fibre pullout and delaminations as the dominant failure modes in the KFE hybrid stacking sequences for all loading conditions. In summary, a complete in-depth characterization of the UD, Crossply and Angle ply stacking sequences of Kevlar/Flax/Epoxy hybrid laminates was performed. 


\section{Chapter 5}

\section{Quasi-static behaviour of Kevlar/Flax/epoxy composites}

\subsection{Continuum Damage Mechanics}

When developing a new material, it is important to predict the damage initiation and progression. While it is imperative to study mechanical behaviour of materials under multiple loading conditions, quantifying the damage accumulation and progression provides the means to better predict failure mechanisms and give useful insight into improving mechanical response.

Different damage mechanics are used to predict damage initiation and evolution in materials. They provide an alternative to mainstream destructive failure testing methods, and are statistically relevant even till fracture [135]. Damage mechanics can be used to characterize the material response over the loading life, as well as understand the underlying mechanisms responsible for failure [136].

Due to the numerical nature of prediction models, damage needs to be defined quantitatively. Therefore, the techniques used, quantify the distribution of defects and their densities as a means to describe damage behaviour [115; 136]. These techniques, named Continuum Damage Mechanics (CDM), use thermodynamic relations derived from macroscale behaviour to determine microscale damage [136]. Energy release caused by the formation of microcracks, can be related to the degradation of mechanical properties (such as the elastic modulus). The numerical models are able to simulate a complete damage profile of the fiber composites, without requiring the interference of external factors (cracks induced for fracture mechanics). They can also track intraply damage, unlike the traditional failure criteria, to better characterize damage evolution. 
Due to the constantly increasing adaption of fiber composites, many CDM models for composite damage have been introduced and integrated to compliment the experimental data. While these models do offer a comprehensive behaviour profile of fiber composites, their innovation in hybrids is still lacking [115; 137]. This chapter aims to understand the damage behaviour and help provide a precursor to developing damage models for multifiber hybrid composites.

\subsubsection{Mesoscale Damage Theory(MDT)}

One of the most widely used CDM model, is the Mesoscale Damage Theory (MDT) developed by Ladeveze et al. [138]. It is a versatile model that can predict the damage response of composites under various loading conditions[129; 139-145]. It focuses on the individual plies, rather than the complete laminate or the fiber and matrix constituents, as implied by the Meso.

MDT assumes that the damage profile for any fiber composites can be numerically modelled, based on the interply interactions. The interface between the plies is also idealized, ensuring perfect bonding and transfer of forces. However, the model may be adjusted if any out of plane deformation (such as delamination) is to be included [141-143]. These assumptions allow MDT to fully capture damage behaviour from initiation till fracture, and can also be adapted for hybrid composites, as the plies are not required to be of the same material.

At its most basic, MDT characterizes damage behaviour in fiber composites, based on the stiffness degradation and inelasticity accumulation. This classical theory of damage, developed by Lemaitre [146], is utilized to model the damage response in the Kevlar/Flax hybrid composite.

\subsubsection{Damage}

Consider a volume element in a body, at a scale small enough to be considered elemental, though, large enough to contain defects. The Damage variable in that element for direction $\mathrm{n}$ can then be defined as the ratio between the total surface sectional area $(S)$ and the surface area excluding the surrounding cracks and discontinuities $\left(S_{D}\right)$

$$
D_{n}=\frac{S-S_{D}}{S}
$$




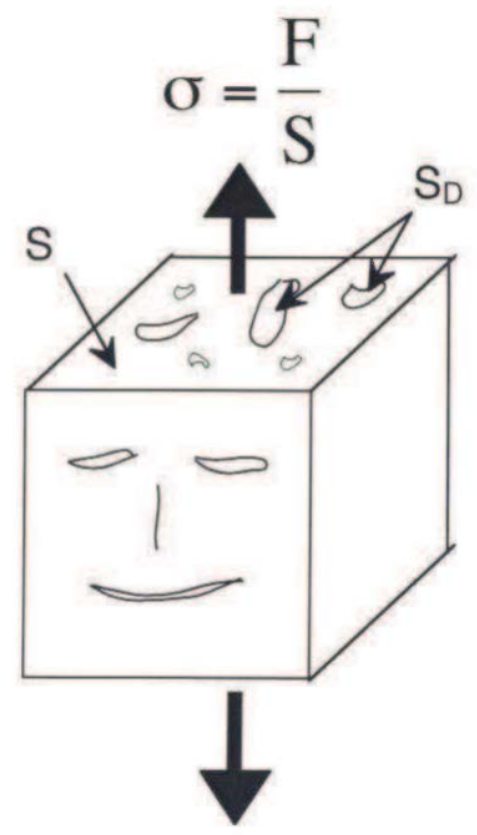

Figure 5.1: Visual Representation of a volume element, showing damage as cavities and cracks [Kondo, 2013]

This Damage variable $\left(D_{n}\right)$ in Eq. 5.1, when zero corresponds to the undamaged state of the composite, and has a maximum threshold, $\left(D_{C}\right)$, at which fracture occurs. For simplicity sake, the crack and cavity densities are assumed to be isotropic, reducing the Damage variable to a scalar quantity $(D)$.

For an undamaged sample, the stress is defined as the force divided by the area. However, in the presence of surface defects and deformities, the effective stress $\left(\sigma_{D}\right)$ is defined as,

$$
\sigma_{D}=\sigma \frac{S}{S_{D}}
$$

While the surface area can be calculated mathematically, the defects and cavities are near impossible to quantify. Therefore, to resolve this conundrum, Lemaitre [146] hypothesized that the strain behaviour of the damaged material can be defined by simply replacing the stress with the effective stress in its constituent equations. Therefore, for a uniaxial, linear elastic case, the strain for an undamaged $(\epsilon)$ and damaged $\left(\epsilon_{D}\right)$ state can be defined as:

$$
\epsilon=\frac{\sigma}{E_{0}}
$$




$$
\epsilon_{D}=\frac{\sigma_{D}}{E_{0}}
$$

Where $E_{0}$ is the Young's elastic modulus. Rearranging the equation Eq. 5.4 and substituting Eq. 5.2 and Eq. 5.1, gives the following relation,

$$
\frac{\sigma_{D}}{\epsilon_{D}}=E_{0}(1-D)
$$

The ratio of the effective stress and strain, is essentially the effective Young's elastic modulus $\left(E_{D}\right)$, which when substituted into Eq. 5.5 and rearranged in terms of D is,

$$
D=1-\frac{E_{D}}{E_{0}}
$$

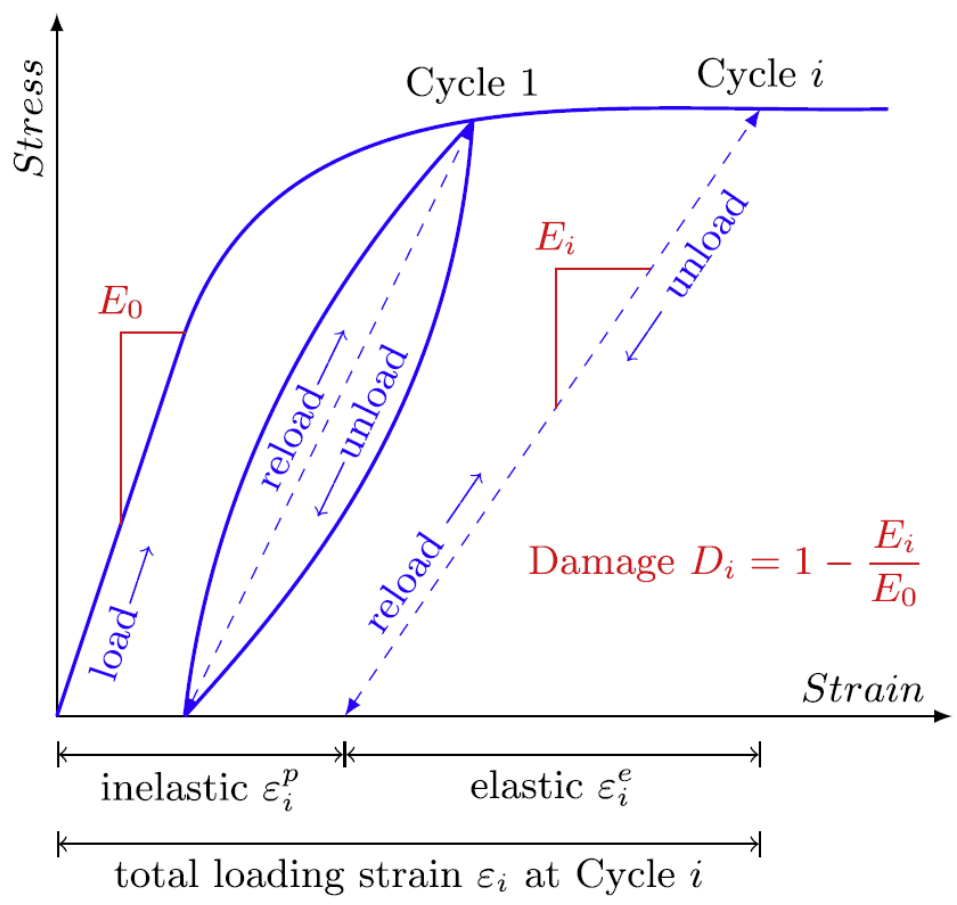

Figure 5.2: General hysteretic response curve generated during quasi-static loading [[78]

The damaged or effective elastic modulus can be determined experimentally, through progressively loading and unloading test samples as shown in Figure 5.2 . Figure 5.3 shows an example of a typical quasi static load unload test for KFE Hybrid and Kevlar/Epoxy.

It should be noted that the assumptions made earlier only apply to the damage variable. Damage accumulation in material also affects many other material properties, which can also 
be used to quantify damage in their own way.

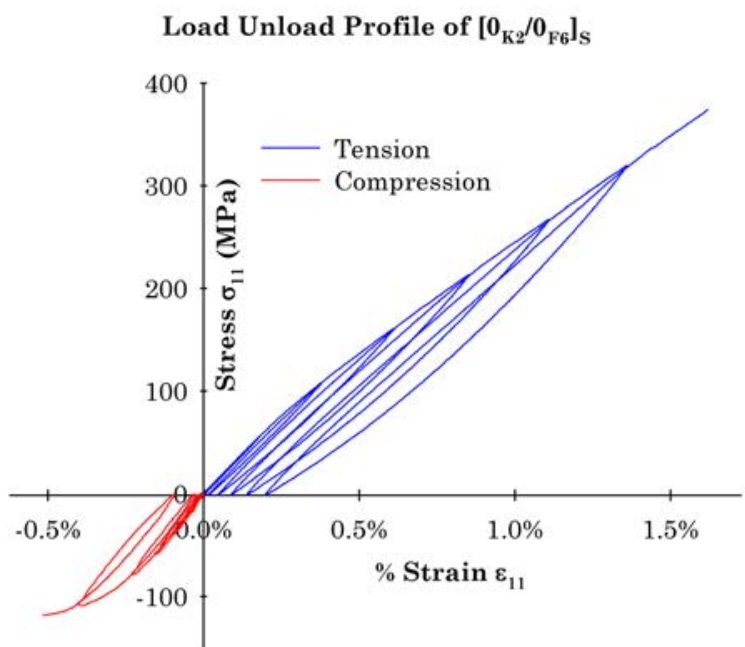

(a)

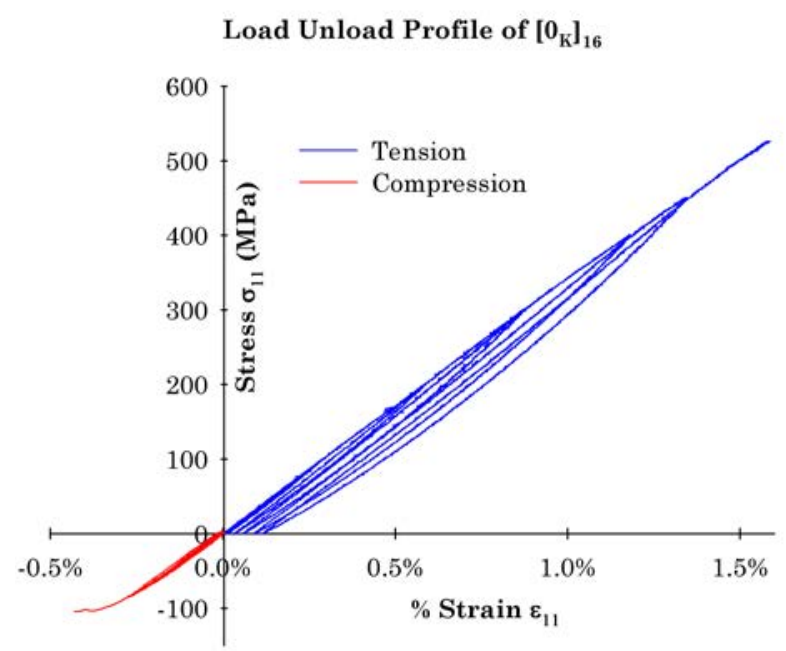

(b)

Figure 5.3: Load Unload Plot for (a) Unidirectional KFE Hybrid and (b) Kevlar/Epoxy showing hysteresis

\subsubsection{Inelasticity}

Materials undergo permanent deformation when distorted beyond their elastic limits. This plastic behaviour is also a symptom of internal structural damage. In fiber composites, this inelastic strain can be affected by many factors. The natural elementary fibers in Flax, as discussed previously, undergo reorientation under loading conditions. This permanently reorganizes the fibers, reducing their elasticity. Fiber breakage, delamination, and matrix crack all contribute to the accumulation of plastic strain. The fibers and matrix also inherently possess plasticity that can add to the strain. In order to simulate the inelastic behaviour of composites, MDT couples the plastic strain to the damage accumulation.

Similar to stiffness evolution, load-unload tests also show accumulation of plastic strain $\left(\epsilon^{P}\right)$. During unloading, samples acquire a non-zero strain, which lies at the intersection of the slope of the damaged modulus and the strain axis, [Figure 5.2]. Permanent strain tends to accumulate with each loading cycle . Consequently, developing a complete understanding of the damage behaviour in fiber composites, requires at the very least, studying the stiffness degradation and inelastic strain accumulation 


\subsection{Damage in Flax and Kevlar Composites}

As mentioned earlier, damage in a fiber composite affects many different material properties which can be used to build a damage profile. Density change, electrical resistance ,Creep, surface hardness, ultrasonic penetration etc., can all be used to quantify damage, therefore, the publications in literature also vary greatly. Published research consists of analyzing damage in the fiber-direction [147], microcrack analysis [107; 148-150], acoustic emission techniques $[119 ; 151 ; 152]$, and even damage in naked fibers $[59 ; 66 ; 120]$

Kersani et al. [151] and Romh'any et al. [120] both produced tensile strain plots using acoustic emissions. They noticed that the number of events was proportional to the fibers in the loading axis, noticing that the count of acoustic events was proportional to the number of fibers along the loading axis, and concluded via optical microscopy that most of the damage initiated after $0.5 \%$ strain was caused by the fibers, as the fiber-matrix interface developed microcracks. Shah et al. [153] showed for his tensile tests on Flax composites that permanent deformation in the fiber direction may not occur until after a threshold of $0.146 \%$.

Charlet et al. [154] studied Flax epoxy composites and concluded that the volume fraction directly correlated with the composite strength. They also found that the failure strain remained consistent after a 0.15 volume fraction, indicating that the fibers were the dominant load bearers. However, Romh'any et al. [120] showed that a fraction of the Flax fibers in the composite do not contribute to reinforcing the material, either due to manufacturing defects and/or fiber slippage.

Panamoottil et al. [148] and Romh'any et al. [120] also used optical microscopy to determine dominant damage mechanisms for tensile loading in Flax composites. They determined the damage initiated in Flax is caused by microcracks appearing inside the Flax bundles and propagating outwards. These cracks could extend between plies and initiate chained crack behaviour causing failure. It should be noted though that the authors were unable to find evidence of matrix cracking.

Mahboob et al. [155] recently published a complete characterization of the damage response in Flax fibers using MDT as a basis for analysis. The authors developed a modified MDT model, capable of simulating damage behaviour in Flax composites. They were also able to validate the model based on experiments performed, with excellent correlation.

Damage in Kevlar mostly remains in the domain of impact performance. Majority of the studies conducted optimize Kevlar and its hybrids for impact performance, and do not study the damage progression at a microscale in detail. Andrews et al. [150] used Raman spec- 
troscopy to study the micro-mechanics in Kevlar composites. They showed that fiber deformation and point to point strain distribution could be accurately measured, however, the method was very dependent on the specimen geometry and also did not work at higher strain values, especially during and after matrix yielding.

Musutova et al. [149] analyzed the growth of microcracks in Kevlar 49 weaved composites. Specimens underwent tensile loading and microscopic optical analysis was performed to study crack density. They concluded that crack distribution was spread evenly outwards from the fracture site. Microcracks were observed to run along and across the fibers and were also observed to branch out. Though, majority of the cracks terminated upon encountering the fiber-matrix interface.

Acoustic emission has also been utilized to analyze damage in Kevlar composites. Waller et al. [152] performed progressive load holding tests on Kevlar 49 composites, to analyze damage evolution. The number of damage events increased alongside each incremental load. However, very near fracture, the number of events rose exponentially, indicating fiber breakage and crack formation, prior to failure.

Damage progression in Kevlar fibers and in Flax fibers has been characterized somewhat, however, to the authors knowledge, there is no data available analyzing the damage response of natural and synthetic hybrid composites. Thus, this novel work characterizes the damage progression and identifies the damage mechanisms of three Kevlar/Flax/Epoxy composites in the fiber and transverse direction. Tests were performed under both tensile and compressive quasi static loads, by measuring the stiffness degradation and inelasticity (i.e., permanent deformation), to understand the crack propagation behaviour and material response. 


\subsection{Damage Response of Kevlar/Flax/Epoxy Composites}

\subsubsection{Unidirectional fiber Direction $\left[W_{K 2} / 0_{F 6}\right]_{S}$}

\subsubsection{Tension}

Damage in the fiber direction exhibits a sigmoidal profile for the UD [Figure 5.4(a)]. Progression starts off relatively slow, with an inflection point occurring around $0.20 \%$ strain. The damage becomes linear afterwards, levelling off at $0.7 \%$ strain. At $D_{11}=0.09$, samples stop accumulating any further damage, and the trend continues until failure at $1.60 \%$ strain. The inelasticity [Figure 5.4(b)] follows a parabolic path, accumulating a plastic strain of $0.25 \%$ before failure. It should be noted that while damage becomes constant at $1.0 \%$ strain, the samples continue to acquire inelastic strain.

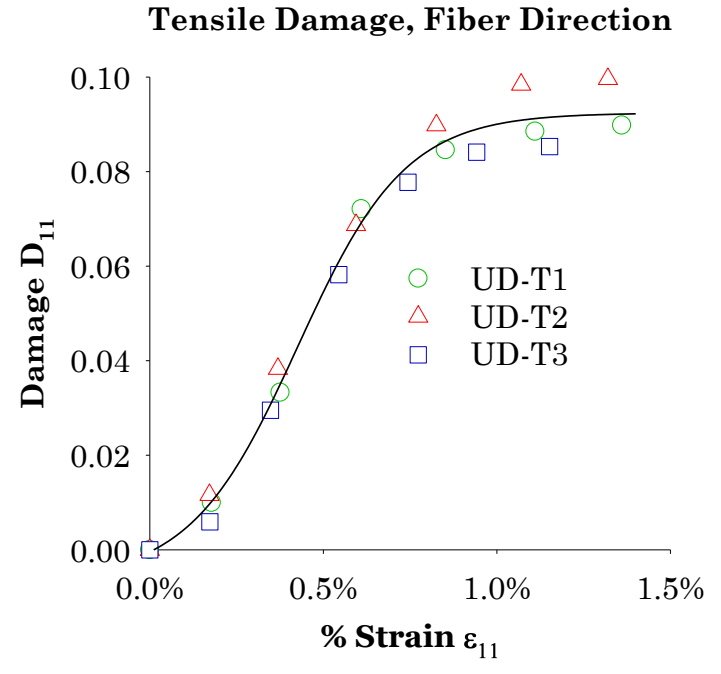

(a)

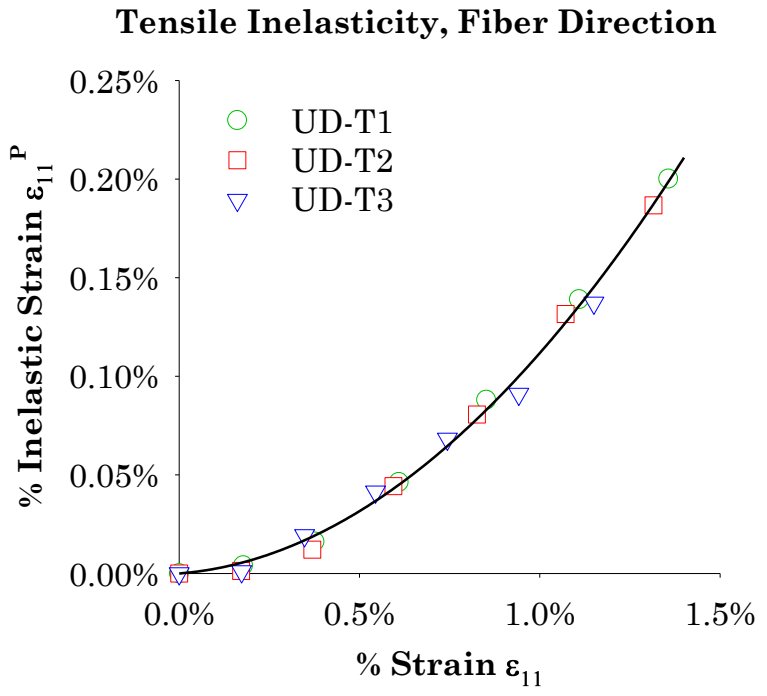

(b)

Figure 5.4: Damage [(a),(c)] and Inelasticity [(b),(d)] for Tension and Compression in Unidirectional KFE Hybrid

Figure 5.5 shows SEM images of KFE specimens cut perpendicular to fiber direction. Figure 5.5(a) and Figure 5.5(b) show specimens with a tensile load of $0.2 \sigma_{11}^{t}$ and $0.8 \sigma_{11}^{t}$ respectively. At $0.2 \sigma_{11}^{t}$, minor cracks that stem from voids and or other irregularities are seen, however, fiber and matrix integrity is intact and negligible crack development is observed in the overall specimen. At $0.8 \sigma_{11}^{t}$, micro-cracks formed are within the fiber bundles, which can be attributed to the comparatively weaker natural binding adhesive within the Flax fiber bundles. As individual Flax fibers break, they act as an initiation sites for the micro-cracks, which 
follow through the path of least resistance keeping them confined within the fiber bundles. Crack density remains low throughout the specimens, unless initiated by an irregularity. In both load levels, delamination and micro-cracks were negligible within the matrix, the interface and the Kevlar fibers themselves.
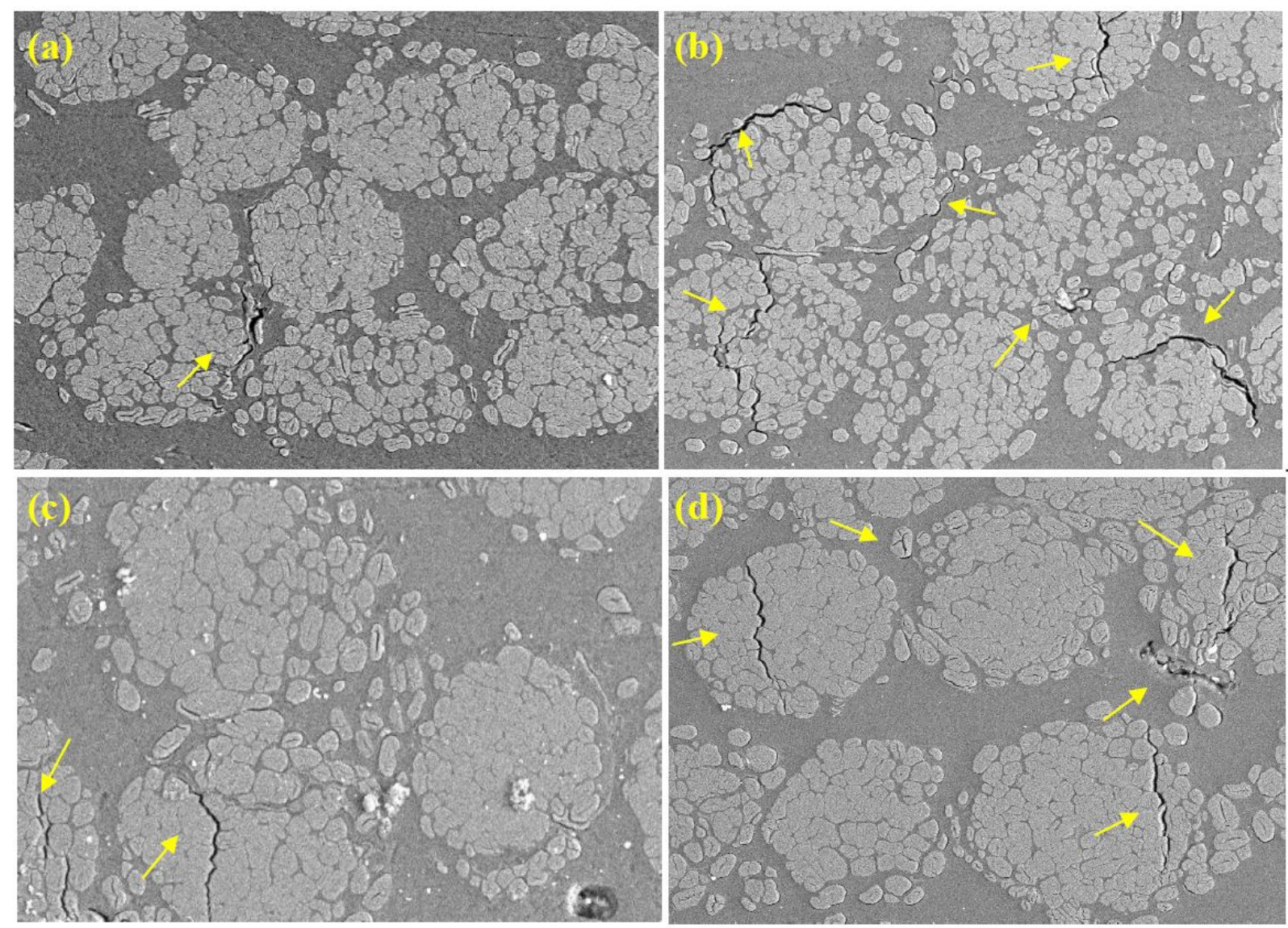

Figure 5.5: SEM Images at 100x for damage in Fiber direction for $\left[W_{K 2} / 0_{F 6}\right]_{S}$ (a)Tension at $0.2 \sigma_{11}^{t}$, (b) Tension at $0.8 \sigma_{11}^{t}$, (c) Compression at $0.2 \sigma_{11}^{c}$, and (d) Compression at $0.8 \sigma_{11}^{c}$. Arrows show intra-bundle cracks. Load applied parallel to fiber direction.

\subsubsection{Compression}

Compressive damage [Figure 5.6(a)] initiates at the origin, follows a somewhat linear path, until buckling occurs at $0.5 \%$ with a stiffness degradation of $20 \%$ near failure. Inelastic strain in Figure 5.6(b) shows a parabolic trend, similar to tensile, with the material accumulating a permanent strain of $0.08 \%$ near buckling. Figure 5.5(c) and Figure 5.5(d) are of specimens in compression at $0.2 \sigma_{11}^{c}$ and $0.8 \sigma_{11}^{c}$. Micro cracks are seen to initiate inside fiber bundles at $0.2 \sigma_{11}^{c}$, with almost no cracks observed in the matrix or the fiber matrix boundaries. At $0.8 \sigma_{11}^{c}$, 


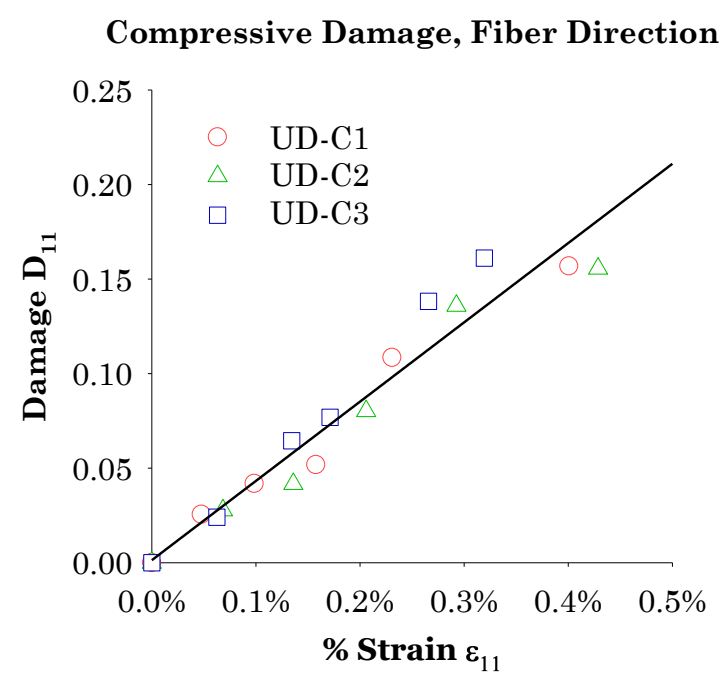

(a)

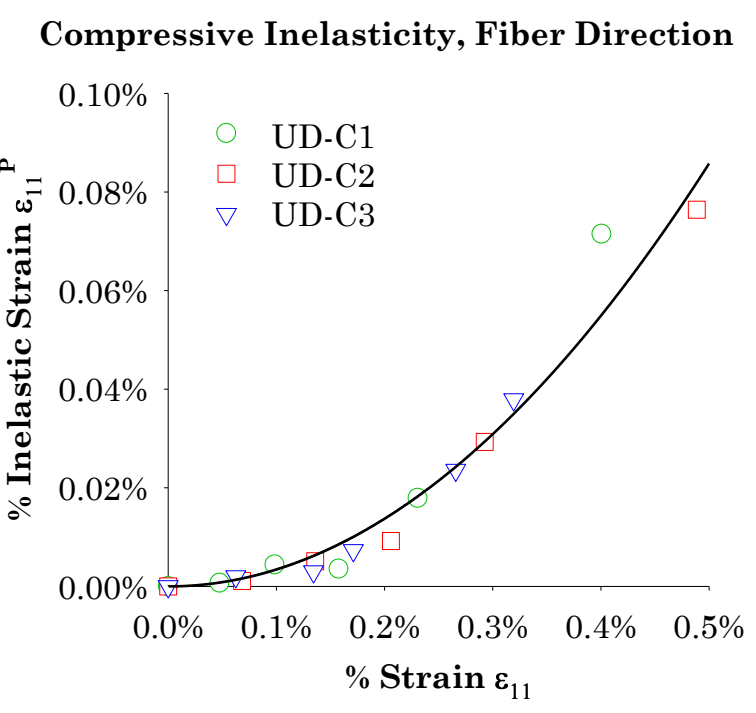

(b)

Figure 5.6: Damage [(a),(c)] and Inelasticity [(b),(d)] for Tension and Compression in $\left[W_{K 2} / 0_{F 6}\right]_{S}$

intra bundle cracks still dominate, at a higher density, however, irregularities in the matrix also cause the it to split. No cracks were observed in the Kevlar and Flax interface, similar to the tension specimens.

\subsubsection{Unidirectional Transverse $\left[W_{K 2} / 0_{F 6}\right]_{S}$}

\subsubsection{Tension}

In-plane transverse tensile damage [Figure 5.7(a)] follows the same pattern as its fiber direction counterpart, with an inflection point at $0.20 \%$ strain and a constant damage $D_{22}=0.08$, corresponding to an $8 \%$ reduction in stiffness, just before failure at $1.69 \%$ strain. The inelastic strain [Figure 5.7 (b)] shows a threshold of $0.20 \%$ strain, following a linear function afterwards. The threshold suggests that the material behaves in an elastic manner, and only acquires plastic strain, after the threshold. The total accumulation of strain just before fracture is $0.32 \%$.

SEM observations shown in Figure 5.8(a) demonstrate cracks propagating along the fiber bundles. Due to the transverse loading nature of the specimen, the matrix develops cracks, starting from the weak points i.e., intra bundle bonding and the matrix fiber boundary. The cracks coalesce over the loading period, resulting in failure. Surprisingly, even though the initiation sites for these micro-cracks were observed to be at the Flax fiber bundle boundaries, 
Tensile Damage, Transverse Direction

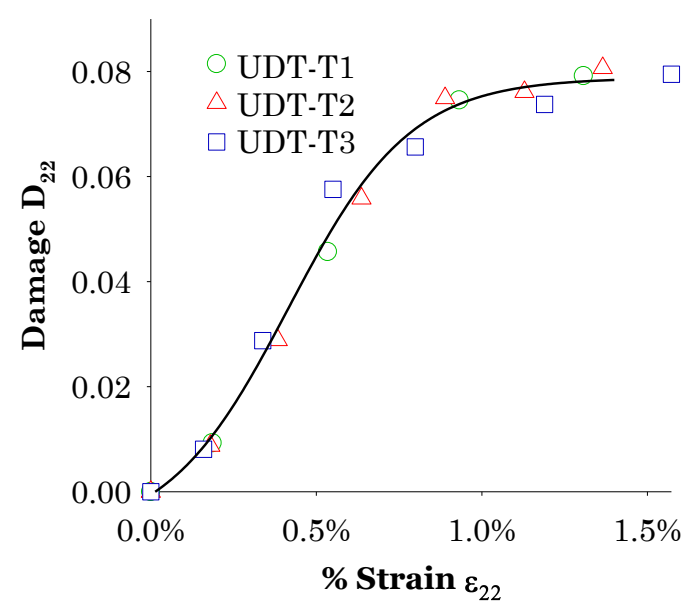

(a)
Tensile Inelasticity, Transverse Direction

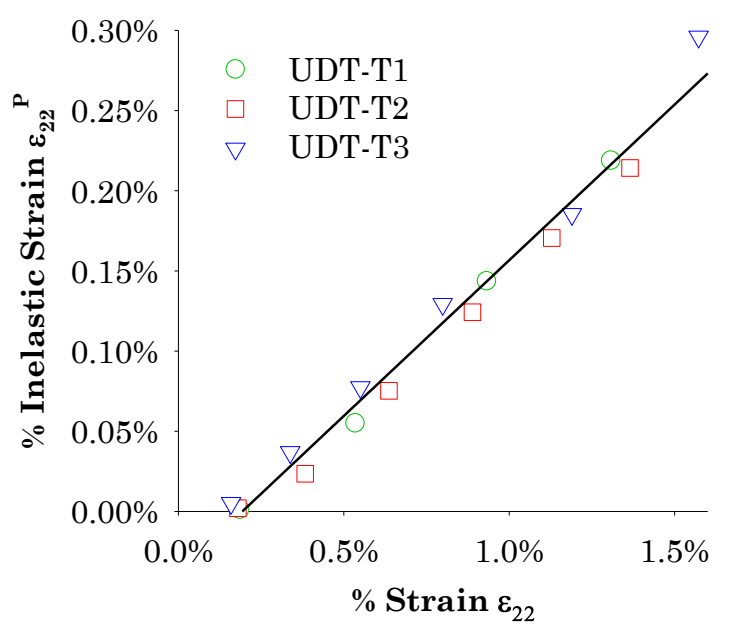

(b)

Figure 5.7: Transverse Damage [(a),(c)] and Inelasticity [(b),(d)] for Tension and Compression in Unidirectional KFE Hybrid

there was no cracking in the Kevlar matrix interface along the edges.
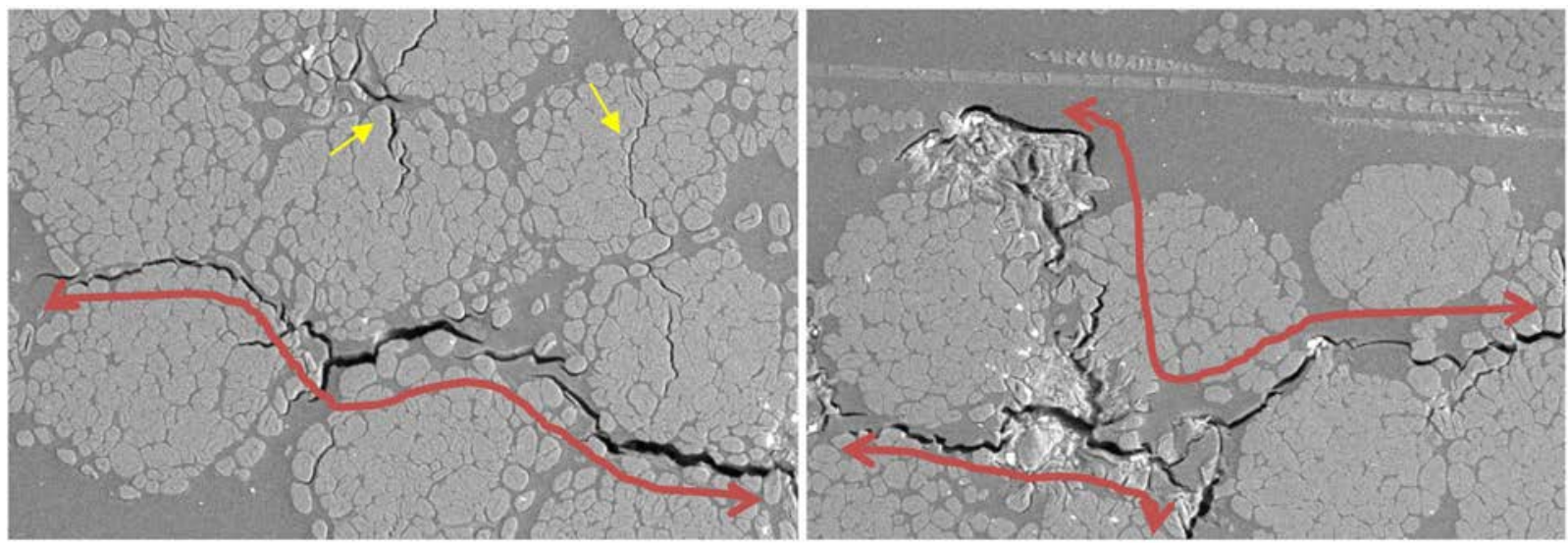

Figure 5.8: SEM Images at 100x for transverse damage for $\left[W_{K 2} / 0_{F 6}\right]_{S}$ (a)Tension at $0.8 \sigma_{22}^{t}$, and (b) Compression at $\sigma_{22}^{c}$. Small arrows show intra-bundle cracks. Load applied perpendicular to fiber direction.

\subsubsection{Compression}

Compressive transverse damage shows a logarithmic profile [Figure 5.9(a)], initiating at a threshold of $0.1 \%$. Damage increases steadily at a more or less linear fashion after $0.2 \%$ strain, 
until buckling at $1.6 \%$ with $D_{22}=0.5$. Inelastic strain [Figure 5.9(b)], similar to tensile transverse, appears to initiate at $0.2 \%$ applied strain, and continues to rise linearly until failure at $1.73 \%$ strain with an accumulating permanent strain of $0.6 \%$. In both stiffness degradation and inelasticity, while a threshold is present, it is not at the same stage. Interestingly, the samples may remain elastic and acquire damage, as in this case, however, the vice versa is also true as observed in tension loading.

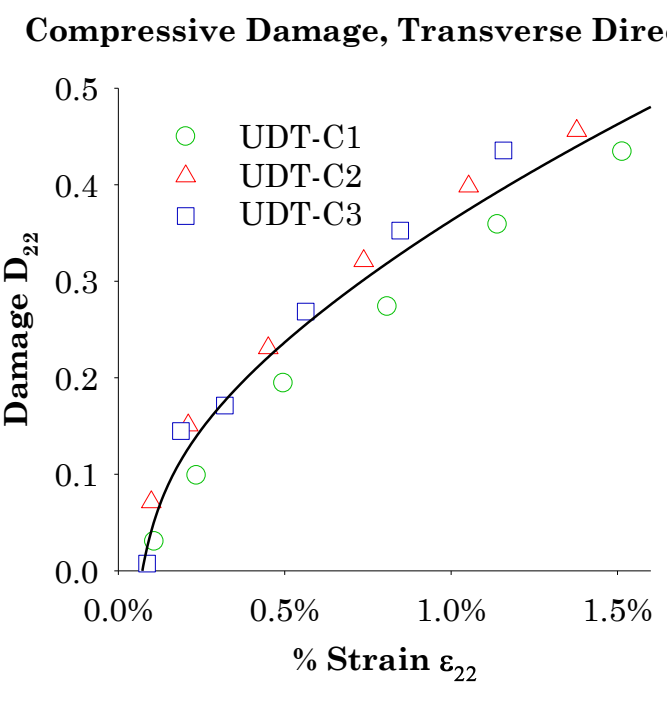

(a)
Compressive Inelasticity, Transverse Direction

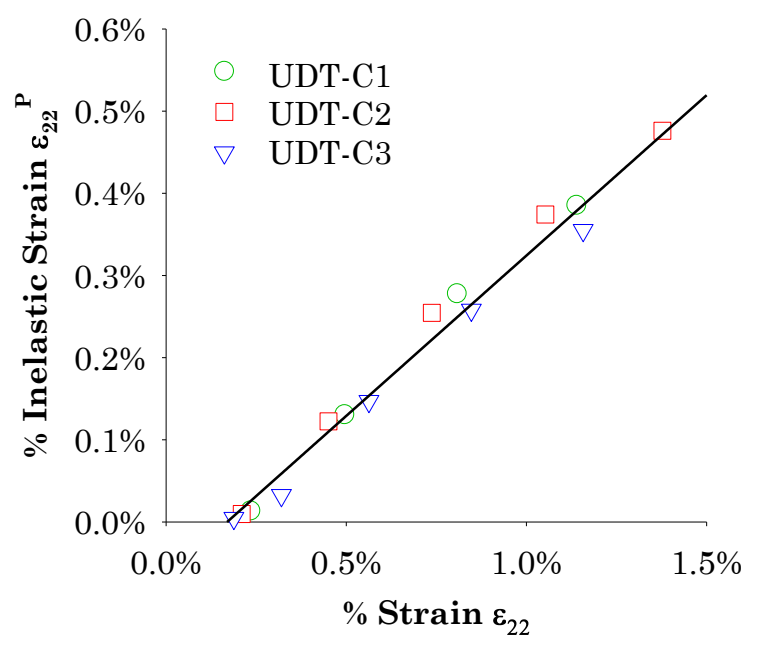

(b)

Figure 5.9: Transverse Damage [(a),(c)] and Inelasticity [(b),(d)] for Tension and Compression in Unidirectional KFE Hybrid

Similar to tension, cracks appear to form in the matrix around Flax fiber bundle as well as in the bundles themselves [Figure 5.8(b)]. Crack initiation sites were dominated by intra bundle fractures propagating outwards along the boundary of the fibers. It can be noted though, that the cracks remain absent in the Kevlar portion as well as the interface, unless initiated from the Flax bundles.

\subsubsection{Crossply $\left[W_{K 2} /(0 / 90)_{F 3}\right]_{S}$}

\subsubsection{Tension}

Damage [Figure 5.10(a)] and inelasticity [Figure 5.10(b)] in cross-ply follow the same trend as their unidirectional counterparts. An inflection point occurs at $0.20 \%$ strain, with the damage remaining constant after $1.0 \%$ at $11 \%$ stiffness degradation. Similarly, the plastic strain 
exhibits a parabolic trend, until failure at $1.56 \%$ and an inelastic strain of $0.26 \%$. It can be seen that the cross-ply accumulates more damage and inelasticity compared to UD. This can be attributed to the reduction of Flax fibers in the loading direction, as well as the addition of 0/90 interfaces between plies, thus introducing weaker bonds and higher number of crack initiation sites.

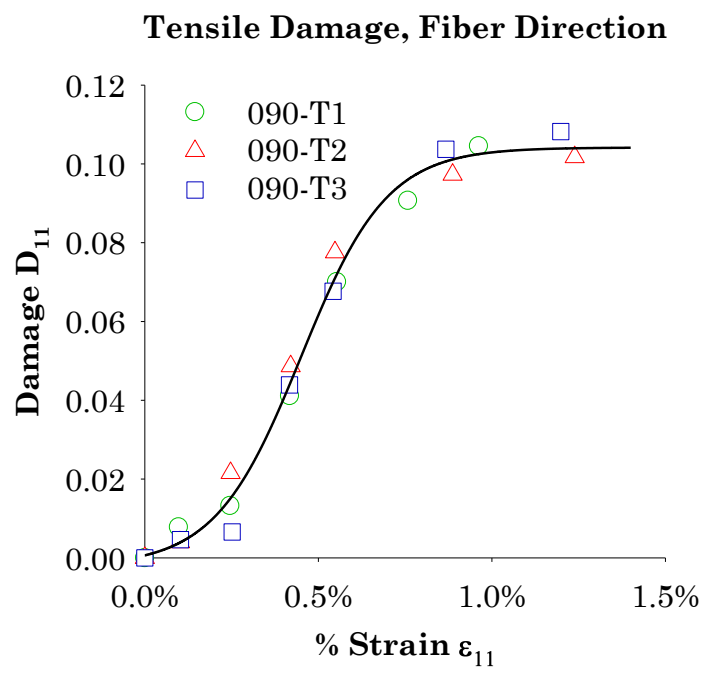

(a)
Tensile Inelasticity, Fiber Direction

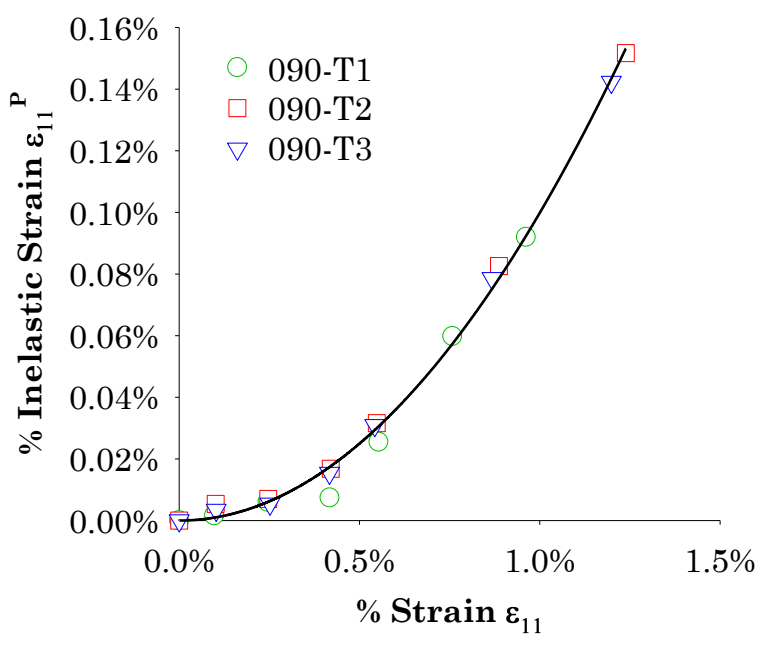

(b)

Figure 5.10: Damage [(a),(c)] and Inelasticity [(b),(d)] for Tension and Compression in Crossply KFE Hybrid

SEM images at $0.2 \sigma_{11}^{t}$ [Figure 5.11(a)] and $0.8 \sigma_{11}^{t}$ [Figure 5.11(b)], show intra bundle cracks as the dominant fracture mechanism, with inter bundle cracks appearing at higher load levels. Cracks can also be observed to originate from voids in the matrix and/or the Flax bundles. Due to the polishing incurred on the samples, it is harder to ascertain the behaviour of the transverse layers. However, certain implications can be made. The fibers with in the Flax bundles, do show some delamination throughout, suggesting intra and inter bundle crack formations. This assumption can be made based on the damage mechanisms displayed in the fiber direction.

\subsubsection{Compression}

Compressive damage [Figure 5.12(a)] follows a linear trend, with inelasticity [Figure 5.12(b)] following a parabolic path. Damage increases until failure at $2.48 \%$ strain with an extrapolated value of $D_{11}=0.85$. Similarly extrapolating the plasticity to the failure strain results in an 

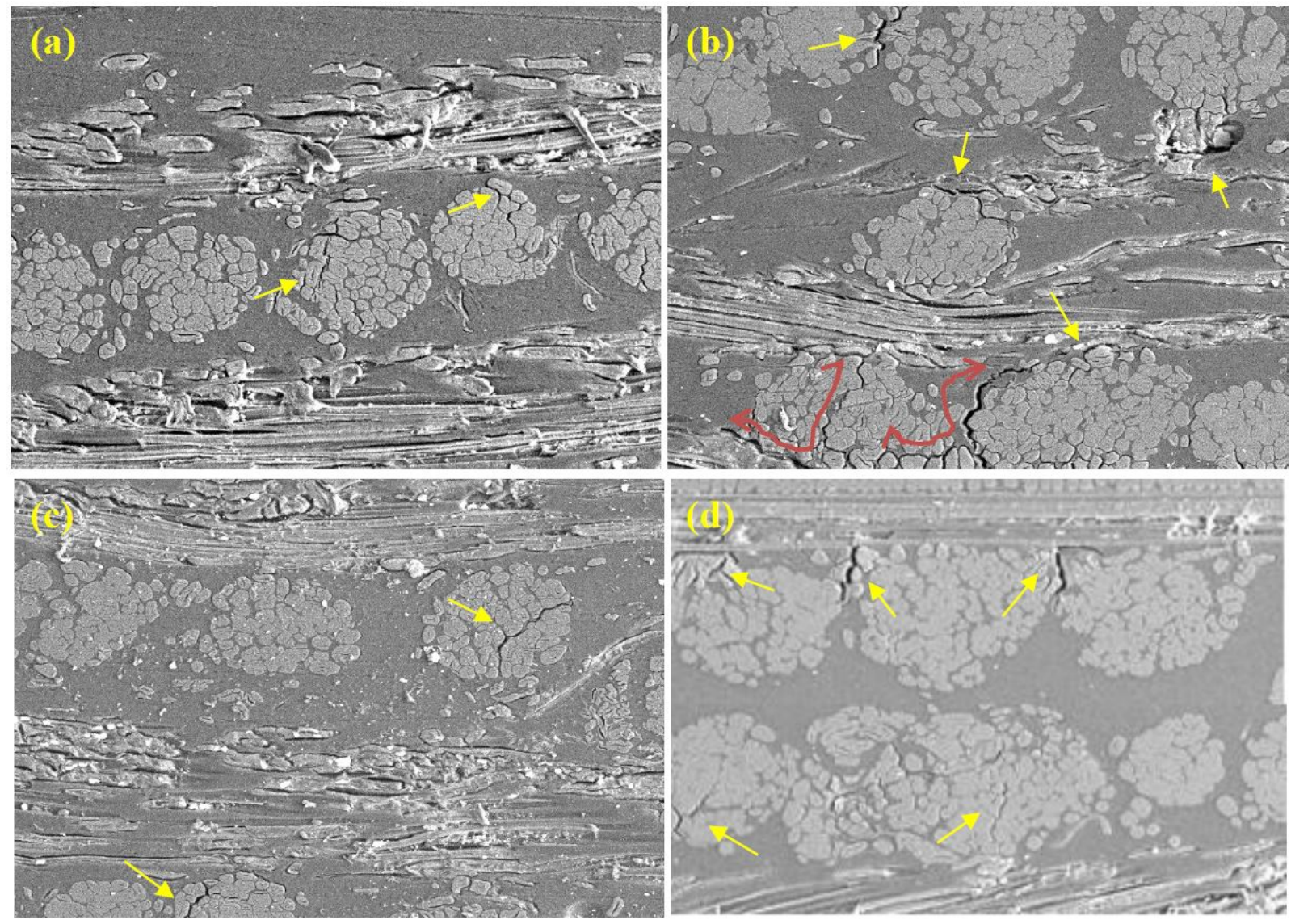

Figure 5.11: SEM Images at 100x for damage for $\left[W_{K 2} /(0 / 90)_{F 3}\right]_{S}$ (a)Tension at $0.2 \sigma_{11}^{t}$, (b) Tension at $0.8 \sigma_{11}^{t}$, (c) Compression at $0.2 \sigma_{11}^{c}$, and (d) Compression at $0.8 \sigma_{11}^{c}$. Arrows show intra-bundle cracks. Load applied parallel to fiber direction.

inelastic strain accumulation of $1.80 \%$ before failure. SEM observation of the sample at $0.2 \sigma_{11}^{c}$ [Figure 5.11(c)] shows intra bundle cracks forming like other cases. However, at $0.8 \sigma_{11}^{c}$ [Figure 5.11(d)], for the first time, cracks initiate at the Kevlar interface and move inwards towards the Flax bundles. As the density of cracks increases, the sample can be compressed further while retaining the same load. Hence, it can be implied that the interface cracking alongside the cracks in Flax bundles, results in a higher failure strain for this ply orientation.

\subsubsection{Angleply $\left[W_{K 2} / \pm 45_{F 3}\right]_{S}$}

\subsubsection{Tension}

Angle ply, with a shear oriented layup, behaves differently from other tension specimens. Damage [Figure 5.13(a)] initiates after a threshold of $0.10 \%$ strain, and increases linearly until 


\section{Compressive Damage, Fiber Direction}

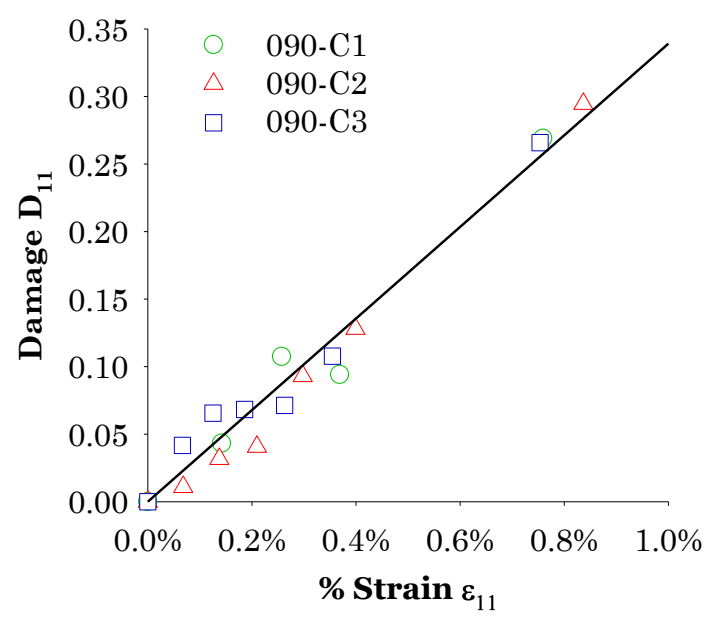

(a)

\section{Compressive Inelasticity, Fiber Direction}

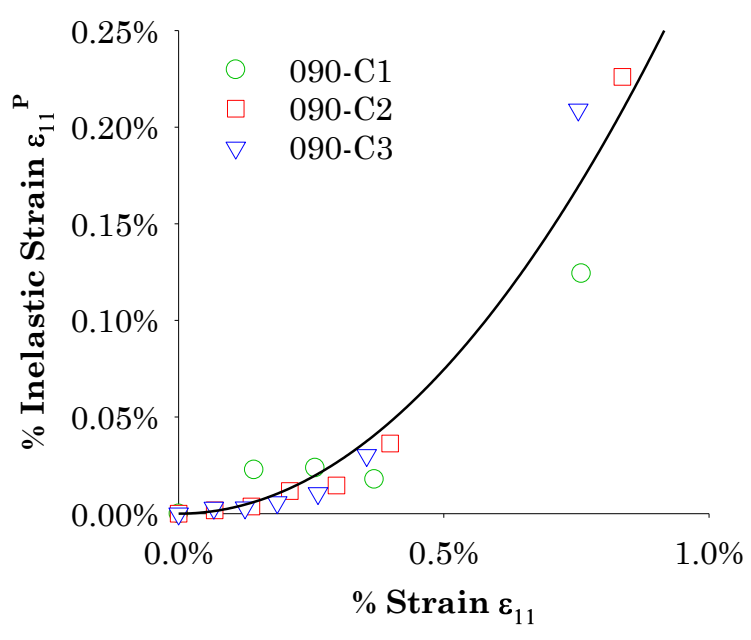

(b)

Figure 5.12: Damage [(a),(c)] and Inelasticity [(b),(d)] for Tension and Compression in Crossply KFE Hybrid

\section{Tensile Damage, Fiber Direction}

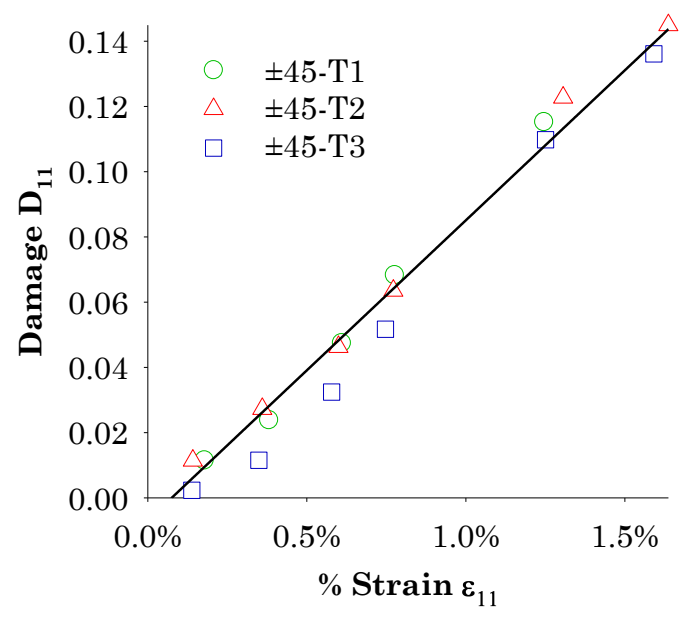

(a)
Tensile Inelasticity, Fiber Direction

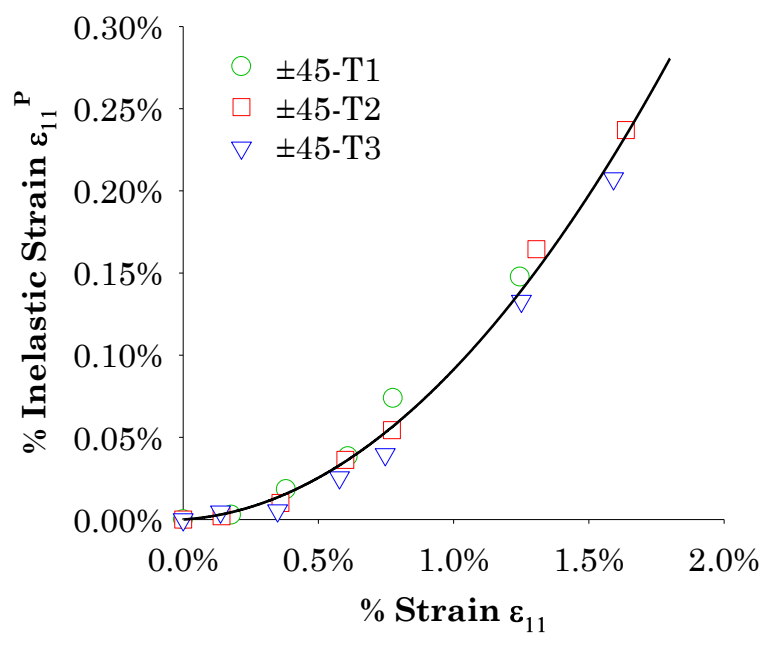

(b)

Figure 5.13: Damage [(a),(c)] and Inelasticity [(b),(d)] for Tension and Compression in Angle ply KFE hybrid

failure at $1.88 \%$ strain with a stiffness reduction of around $20 \%$. Over the loading period, an inelastic strain [Figure 5.13(b)] of $0.30 \%$ is accrued till failure. At $0.2 \sigma_{11}^{t}$ [Figure 5.14], only intra bundle cracks can be observed. Increasing the load to $0.8 \sigma_{11}^{t}$ [Figure $5.14(\mathrm{~b}, \mathrm{e})$ ], the crack density increases significantly, with cracks moving outwards and around fiber bundles. Flax 
fibers reorient along the fiber direction, causing numerous intra bundle cracks to form. The matrix rich areas do not allow the cracks to propagate between bundles, localizing the damage.
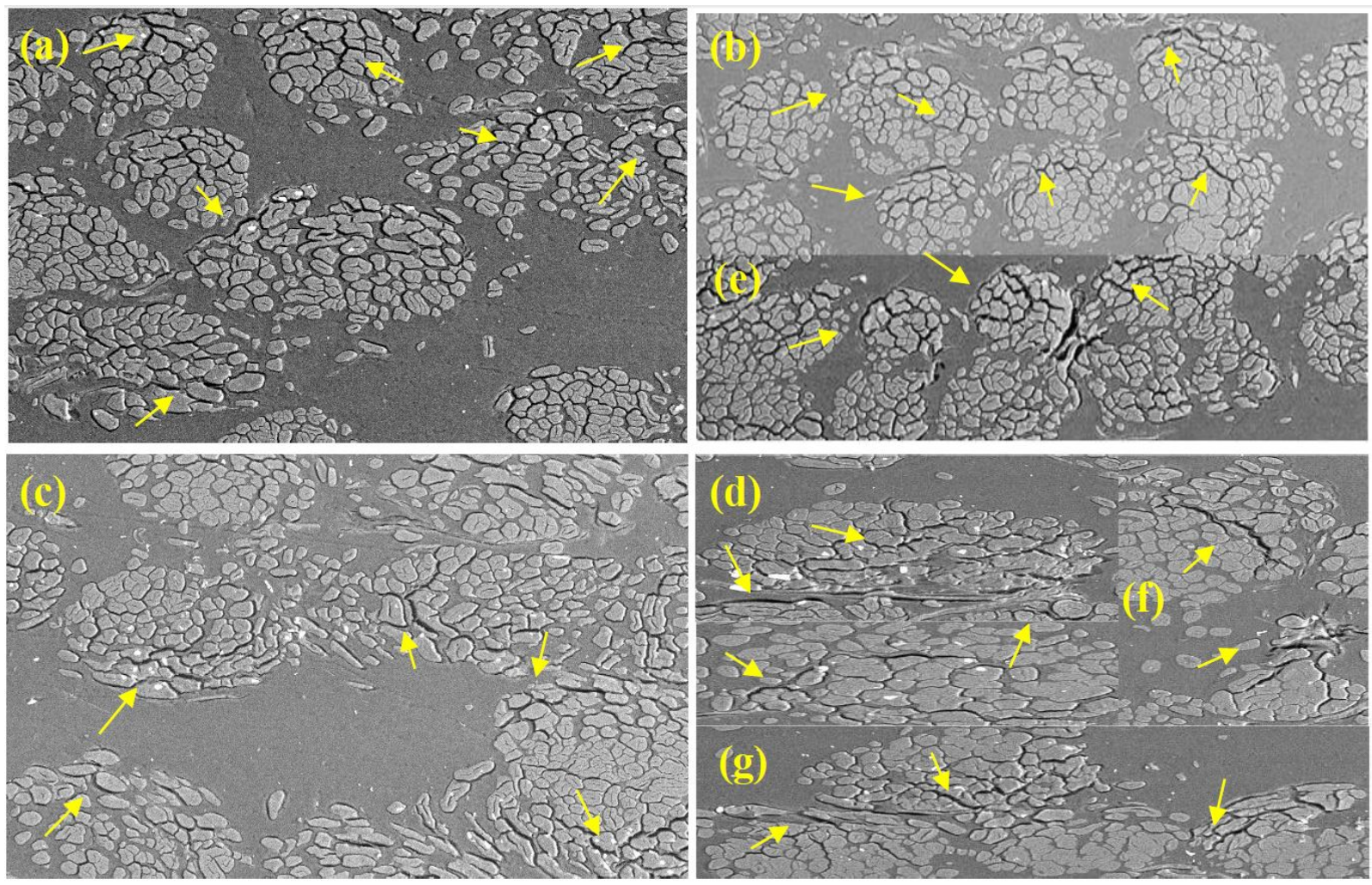

Figure 5.14: SEM Images at 100x for damage for $\left[W_{K 2} / \pm 45_{F 3}\right]_{S}$ (a)Tension at $0.2 \sigma_{11}^{t}$, (b,e) Tension at $0.8 \sigma_{11}^{t}$, (c) Compression at $0.2 \sigma_{11}^{c}$, and (d,g,f) Compression at $0.8 \sigma_{11}^{c}$. Arrows show intra-bundle cracks. Load applied parallel to fiber direction.

\subsubsection{Compression}

In compression, damage [Figure 5.15(a)] progresses linearly, similar to other fiber direction cases, until failure at $1.69 \%$ strain. Extrapolating the fit gives a $D_{11}=0.53$ near failure. Likewise, inelasticity[Figure 5.15(b)] at failure comes to be $0.8 \%$. SEM images at $0.2 \sigma_{11}^{c}$ [Figure 5.14(c)] and $0.8 \sigma_{11}^{c}$ [Figure 5.14(d,g,f)], show similar damage mannerisms as tensile. Intra bundle cracks appear in high volumes, confined inside and around the fiber bundles. 


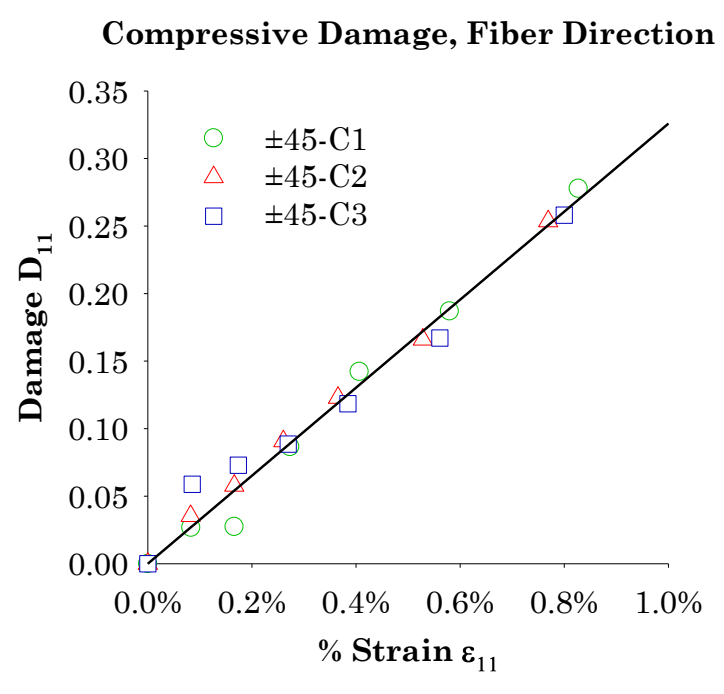

(a)
Compressive Inelasticity, Fiber Direction

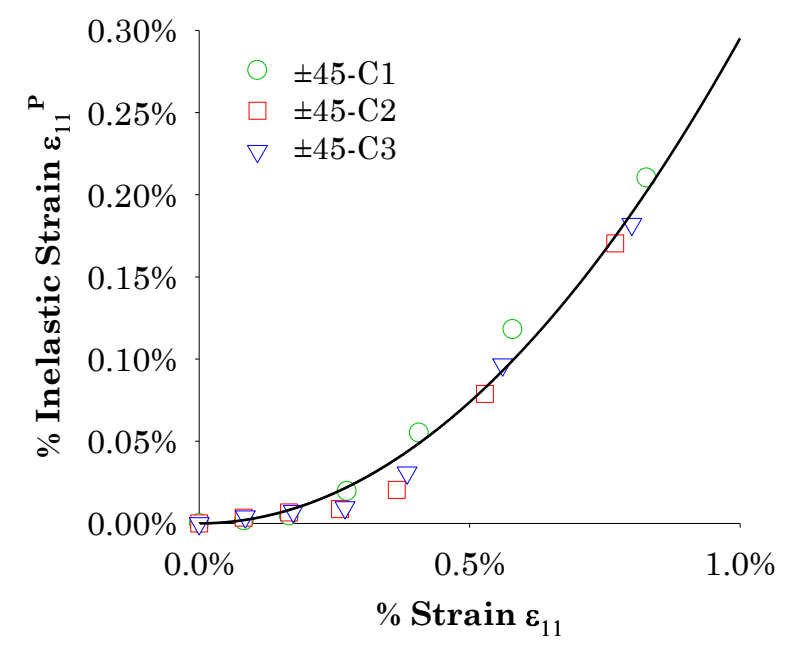

(b)

Figure 5.15: Damage [(a),(c)] and Inelasticity [(b),(d)] for Tension and Compression in Angle ply KFE hybrid

\subsubsection{Kevlar/Epoxy $\left[W_{K}\right]_{16}$}

For comparison purposes and in the absence of relevant published data, quasi static tests were also performed on a unidirectional Kevlar/epoxy composite. As the Kevlar plies remain constant in the Flax combinations, these tests were performed to understand the contribution of Kevlar in the hybrid composites. Damage in tension and compression [Figure 5.16(a) and 5.16(c)], both follow an exponential rise, stabilizing at $D_{11}=0.087$ and 0.27 respectively. Similar to Figure 5.4(a) and 5.10(a), the Kevlar in tension also plateaus as the loading approaches fracture. This can explain why the same behaviour is observed in the hybrid for tension in fiber direction and transverse.

A threshold occurs at $0.04 \%$ strain under compressive loading. As Kevlar is weak in compression, the matrix handles most of the load, which can describe the elastic nature observed here. Inelastic strain [Figure 5.16(b) and 5.16(d)] exhibit a familiar parabolic trend, amassing $0.12 \%$ and $0.04 \%$ near failure for tension and compression. The inelastic strain can be attributed to the loose nature of the weave during manufacturing. As load is applied, the fibers move within the weave, displacing the surrounding matrix and contributing to the inelastic strain. 


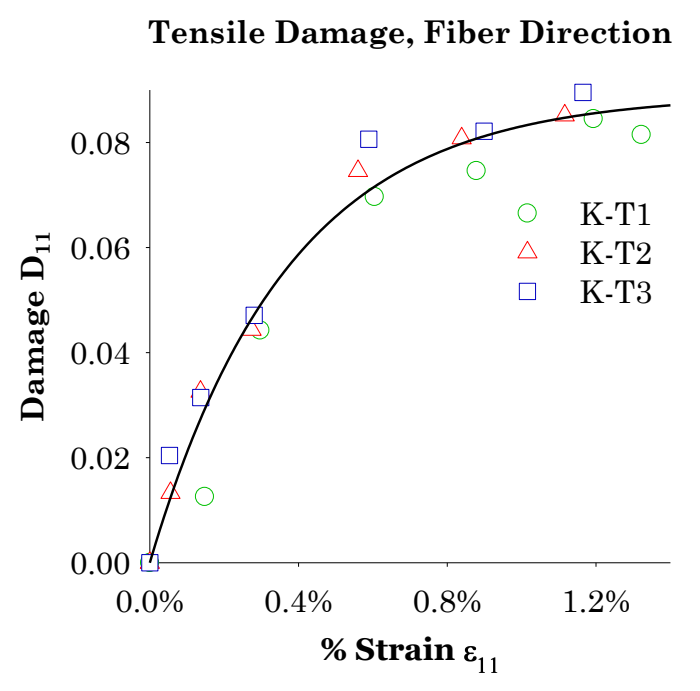

(a)

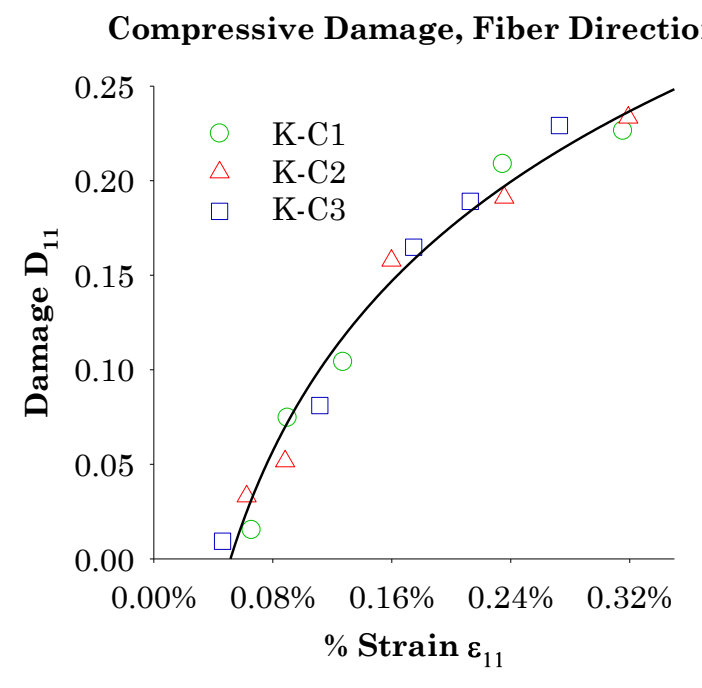

(c)
Tensile Inelasticity, Fiber Direction

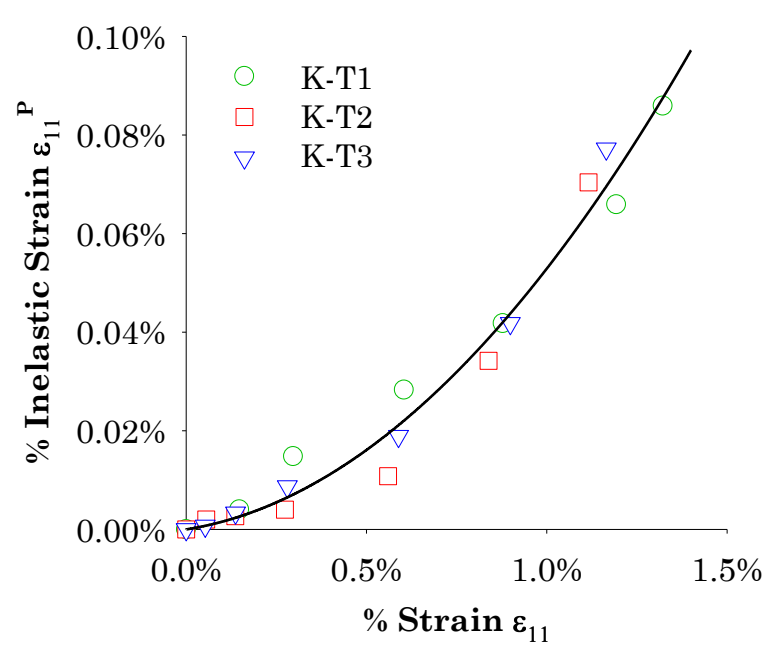

(b)

Compressive Inelasticity, Fiber Direction

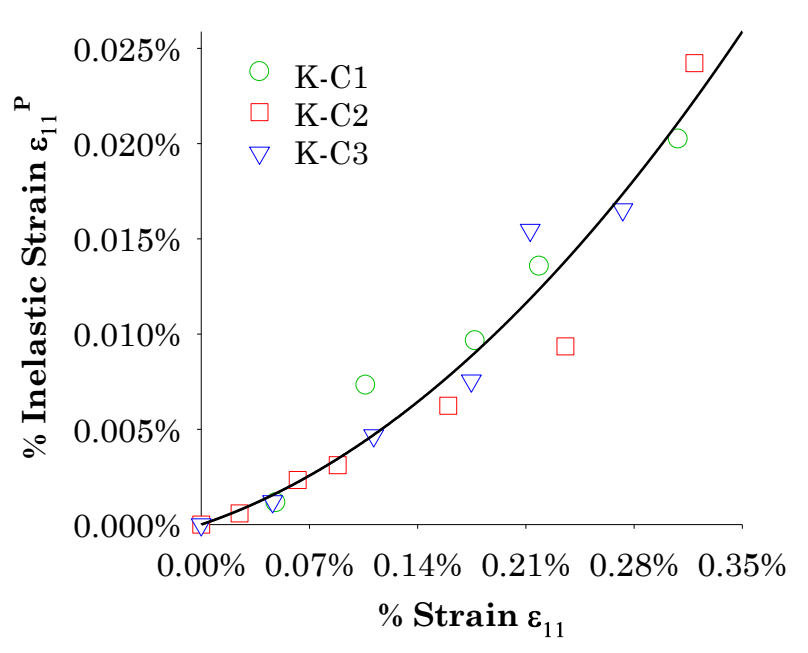

(d)

Figure 5.16: Damage and Inelasticity for Tension [(a),(b)] and Compression [(c),(d)] in Pure Kevlar/Epoxy

\subsection{Further discussion}

Load-unload tests offer an excellent method to gain insight into the internal structural damage response of composites. All tested composites exhibited behaviour where the yield stress point increased with progressive loading, accumulating permanent strain. Table 5.1 shows the damage and inelasticity across the different KFE hybrids. 
It can be seen that the between the stacking sequences, the unidirectional layup provides the best overall performance. It should also be noted that the Cross-ply and Angle-ply are symmetric across the loading direction, resulting in better isotropic behaviour in tension. However, performance suffers greatly in compression, due to lower number of fibers present in the loading direction and Kevlar's poor compression capability.

While all configurations did undergo stiffness degradation and plastic strain accumulation, it cannot be concluded that damage is perfectly proportional to loading for every case. There also exists a damage initiation threshold where materials may accumulate inelastic strain, but stiffness may remain constant. Vice-versa, an inelastic strain threshold also exists, where the material behaves elastically while damage increases. In cases, where both threshold types occur, it is also observed that they are independent of each other.

It can also be noted from the inelasticity plots for both UD and cross-ply, that the plastic strain remains relatively negligible up to the inflection point. Shah et. al [153] and Mahboob et. al [78] both observed similar behaviour in their respective Flax composites, where specimens display a threshold strain before which, elastic behaviour is observed.

In all cases, and in agreement with Kersani et.al [151], Mahboob et.al [78] and Bos et al. [66], damage initiation is not witnessed in the matrix, unless an irregularity is present. Cracks tend to form within Flax fiber bundles and propagate outwards and around the bundles themselves. In cases where the bundles are in close proximity, these cracks may transfer through, however, they do not pass through epoxy rich regions. No crack formation was observed anywhere inside the woven Kevlar, at any load level. This behaviour is surprising, considering the pure Kevlar/Epoxy samples do acquire damage during loading. It can be deduced that the stress concentrations in the hybrid find release in the weaker pectin bonds inside the Flax bundles, rather than forming cracks inside Kevlar layers.

All fiber direction damage in compression for the KFE hybrid followed a linear profile. This can be inferred from the similarly weak performance of Flax and Kevlar in compression loading. As the epoxy bears the majority of the load, the behaviour remained consistent in all orientations. Inelastic behaviour across all fiber directional loading, also remained consistent. This can be attributed to the same intra Flax bundle damage initiation behaviour observed in all orientations. Interestingly, a similar trend was also observed in the pure Kevlar composite, implying that the woven Kevlar must also be a contributing factor. Understandably, transverse loading of the KFE hybrid, did not exhibit the same behaviour, as the Flax fibers provided no contribution to the loading and the Flax's intra bundle bonding as well as the fiber surface bonding are too weak, compared to the Kevlar. 
As reported by Mahboob et. al [78], accumulated strain in pure epoxy specimens was observed to be significantly lower than the Flax composites. Pure Kevlar/epoxy samples tested also exhibited a much lower strain accumulation. Comparing with the KFE hybrid, plasticity buildup was significantly higher, indicating that damage must primarily accumulate inside or around the Flax fibers.

Many differences in behaviour were observed when comparing Flax/epoxy composites and the KFE hybrids reported in this study. As the Kevlar ply orientation was kept constant throughout the various combinations, the direct contributions of the addition of Kevlar can be compared. Comparing the damage response of Flax/Epoxy composites from Mahboob et.al [78], Table 5.1 demonstrates that a relatively minimal addition of Kevlar as a sandwich structure, reduces the stiffness degradation and plastic strain accumulation in the composite, apart from the transverse compression profile.

Studying the damage behaviour using SEM offers a meaningful insight into the composite behaviour. However, it cannot be used to quantifiably measure crack density, for evolution purposes. The SEM images taken are manually altered for optimal contrast and brightness, which causes variations in the images taken, increasing the measurement spread. Also the transverse cross-sections make it very hard to differentiate between a crack and a collapsed lumen. Therefore, the SEM images, while excellent for qualitative comparison, display huge standard deviations and are unreliable for measuring the crack density quantitatively. 
Table 5.1: Comparison of damage and inelasticity evolution in tension (T) and compression (C) for Kevlar/Flax/Epoxy (KFE), Flax/Epoxy (FE) and Kevlar/Epoxy (KE)

\begin{tabular}{|c|c|c|c|c|c|c|c|}
\hline & \multirow[b]{2}{*}{ Type } & \multicolumn{3}{|c|}{ Damage Evolution } & \multicolumn{3}{|c|}{ Inelastic Strain } \\
\hline & & $\begin{array}{l}\text { Initia- } \\
\text { tion } \\
\text { strain }\end{array}$ & behaviour & $\begin{array}{l}\text { Damage } D \\
\text { at failure }\end{array}$ & $\begin{array}{l}\text { Initia- } \\
\text { tion } \\
\text { strain }\end{array}$ & behaviour & $\begin{array}{l}\text { Permanent strain } \\
\varepsilon^{p} \text { at failure }\end{array}$ \\
\hline \multirow[t]{2}{*}{$\begin{array}{l}\mathrm{KFE} \\
11^{a}\end{array}$} & $\mathrm{~T}$ & 0 & $\begin{array}{l}\text { Sigmoidal profile with a slower rate up to } 0.2 \% \text { strain, followed by linear } \\
\text { degredation till } 1.0 \% \text { strain. Constant damage till failure after }\end{array}$ & 0.09 & $0.2 \%$ & $\begin{array}{l}\text { Increasing quadratic } \\
\text { profile }\end{array}$ & $0.25 \%$ \\
\hline & $\mathrm{C}$ & 0 & Constant Linearly increasing degredation & 0.20 & $0.07 \%$ & $\begin{array}{l}\text { Increasing quadratic } \\
\text { profile }\end{array}$ & $0.08 \%$ \\
\hline \multirow[t]{2}{*}{$\begin{array}{l}\text { FE } 11 \\
{[78]}\end{array}$} & $\mathrm{T}$ & 0 & $\begin{array}{l}\text { Sigmoidal profile. Initial rate slow followed by rapid degradation, constant until } \\
\text { failure. }\end{array}$ & 0.183 & 0 & $\begin{array}{l}\text { Increasing quadratic } \\
\text { profile }\end{array}$ & $0.40 \%$ \\
\hline & $\mathrm{C}$ & $0.09 \%$ & Logarithmic profile. & 0.378 & 0 & $\begin{array}{l}\text { Increasing quadratic } \\
\text { profile }\end{array}$ & $0.60 \%$ \\
\hline \multirow[t]{2}{*}{$\begin{array}{l}\mathrm{KFE} \\
22^{b}\end{array}$} & $\mathrm{~T}$ & 0. & $\begin{array}{l}\text { Sigmoidal profile. Damage rate inflection point at } 0.2 \% \text { with a linear increase } \\
\text { till } 1.1 \% \text {. No degradation after, till failure. }\end{array}$ & 0.08 & $0.2 \%$ & Linear increase & $0.32 \%$ \\
\hline & $\mathrm{C}$ & 0 & Logarithmic profile & 0.5 & 0 & Linear increase & $0.60 \%$ \\
\hline \multirow[t]{2}{*}{$\begin{array}{l}\text { FE } 22 \\
{[78]}\end{array}$} & $\mathrm{T}$ & $0.2 \%$ & Linearly Increasing Damage profile & 0.465 & $0.3 \%$ & $\begin{array}{l}\text { Increasing quadratic } \\
\text { profile }\end{array}$ & $0.44 \%$ \\
\hline & $\mathrm{C}$ & 0 & Linearly Increasing Damage profile & 0.493 & 0 & $\begin{array}{l}\text { Continuous, Increasing } \\
\text { quadratic profile }\end{array}$ & $0.31 \%$ \\
\hline \multirow[t]{2}{*}{ KE } & $\mathrm{T}$ & 0 & Rapid increase till stabilizing at $1.2 \%$ near failure & 0.087 & $0.1 \%$ & $\begin{array}{l}\text { Increasing quadratic } \\
\text { profile }\end{array}$ & $0.12 \%$ \\
\hline & $\mathrm{C}$ & $0.05 \%$ & Logarithmic constant increase till failure & 0.27 & 0 & $\begin{array}{l}\text { Increasing quadratic } \\
\text { profile }\end{array}$ & $0.04 \%$ \\
\hline
\end{tabular}

\footnotetext{
$a$ fiber-direction

$b$ in-plane transverse
} 


\subsection{Summary}

Damage in composites is shown to rely on the modulus degradation and accumulation of permanent or plastic strain. A complete damage response analysis of Kevlar/Flax/Epoxy hybrid composites is performed, considering both fiber and transverse directions. Three different stacking sequences, along with Kevlar/Epoxy and Flax/Epoxy were compared for optimized application specific use. Dominant damage mechanisms were identified using optimal microscopy to better understand crack progression in hybrid Flax composites. Comparison between the KFE hybrid composite and pure Flax composite showed substantial improvement in overall performance with the KFE hybrid, both in stiffness and inelasticity. 


\section{Conclusion}

Flax fibers have repeatedly been demonstrated to replace glass fibers in industrial applications. However, due to the inherent composite-like structure of plant based fibers, many disadvantages cannot be ignored(microfibril loading dependent reorientation, non-elastic behaviour etc) when compared to synthetic fibers. Therefore, their adaption in structural applications has been slow. Hybridization between natural and synthetic fibers offers a compromise, where different materials can be combined, to compliment individual weaknesses and improve over mechanical properties.

The original test data reported in this study, presents a continuous Kevlar/Flax Hybrid composite manufactured as a sandwich structure, as a potential material to replace synthetic fibers in general mechanical applications. The manufacturing process results in an average fiber volume fraction of $50 \%$ with minimal void content observed. Bonding between the Kevlar and Flax fibers also indicated excellent adhesion. The addition of the Kevlar skin also reduced water permeation, decreasing the effects of water damage. Surface hardness, tensile, compressive, bending, and shear properties were determined for three standard symmetrical stacking sequences $\left(\left[W_{K 2} / 0_{F 6}\right]_{S},\left[W_{K 2} /[0 / 90]_{F 6}\right]_{S},\left[W_{K 2} / \pm 45_{F 6}\right]_{S}\right)$. The designed hybrid composite shows improvements in all aspects, except compression, when compared with pure Flax/Epoxy composites. Overall material strength is noticeably improved in tension, bending and torsion, while maintaining similar stiffness behaviour as Flax/Epoxy. In compression, Kevlar's poor performance in compression affects the laminate performance, resulting in a decrease. Analyzing the fractured surfaces determine a variety of dominant fracture mechanisms, depending on the loading conditions. Fiber breakage and pullout were commonly observed in tensile and bending, whereas delamination was apparent for torsional and compression loading.

Damage in the hybrid composites is investigated by studying the elastic stiffness degradation and accumulation of permanent or plastic strain. Damage is defined as a reduction in the elastic modulus over the load-unload period. This damage also introduces a permanent deformation, in terms of plastic strain, which accumulates over time. The evolution 
of damage and inelastic strain was profiled in and normal to fiber-direction, under quasistatic tension and compression. Damage behaviour was generally observed to be non-linear, with the exception that, damage in fiber direction under compression appeared to be linear. Dominant damage mechanisms were identified using Scanning Electron Microscopy(SEM) to better understand crack progression in hybrid Kevlar Flax composites. Observations showed initiation of microcracks to occur within the Flax bundles. Matrix and interfacial cracking was also rare. No cracks were observed inside the Kevlar layers. Comparison between the KFE hybrid composite and pure Flax/Epoxy composite showed substantial improvement in overall performance, both in stiffness and inelasticity.

This novel study lays the groundwork necessary to evaluate the static and quasi-static mechanical behaviour for Kevlar/Flax hybrid composites. To the authors knowledge, it is the first of its kind to study the damage behaviour in Flax-Kevlar hybrid composites. It also describes and quantifies underlying damage mechanisms, responsible for failure and builds a base for future computational validation for hybrid composites. In doing so, this work introduces hybrid composites as a middle ground to replace synthetic fibers for structural engineering applications, while keeping the environmental impact at minimum.

\section{Future Work}

While the mechanical and damage response of the Kevlar/Flax/Epoxy composites tested do provide enough data to understand the general behaviour, it is necessary to extensively research more variables and avenues, to build a complete behavioural profile for Natural-Synthetic hybrid composites.

As the number of Kevlar layers, their position and orientation were kept constant throughout, its contribution to the hybrid remained consistent. Studying the interfacial interactions between two different materials with respect to the variations in these variables will add to the knowledge of hybrid composites.

The three most commonly used stacking sequences were tested for the Flax core, however, the behaviour of composites is highly dependent on the fiber orientation and the material properties. Therefore, different material composites can have different optimal orientations, and a study understanding this relationship for hybrids will be greatly beneficial.

After understanding the damage behaviour, it is necessary to quantify the behaviour of a composite under fatigue. It is essential to determine the high cyclic fatigue strength and 
fatigue life for structural applications. Previous studies $[41 ; 78]$ have stated that the fatigue life of flax is comparable to Glass fibers and its hybrids can exceed 5 million cycles at $50-60 \%$ of the Ultimate Strength with negligible fatigue damage. Understanding the toughness of Kevlar and its damage response, it can be insightful to perform a tension and compression fatigue study on different ply orientations.

With the established baseline for the Mesoscale Damage theory in this study, the experimental data can be used to develop and verify a Ladeveze based damage and fatigue model for hybrid composites. In its current state, the MDT model developed by Mahboob et. al [155] only simulates the behaviour of Natural fiber composites. One of the major hurdles is analytically predicting the behaviour at the interface of different materials. An interfacial layer can be inserted to simulate the shear response of the boundary Though, in-depth research is required for full-scale adaptation. 



\section{Appendices}

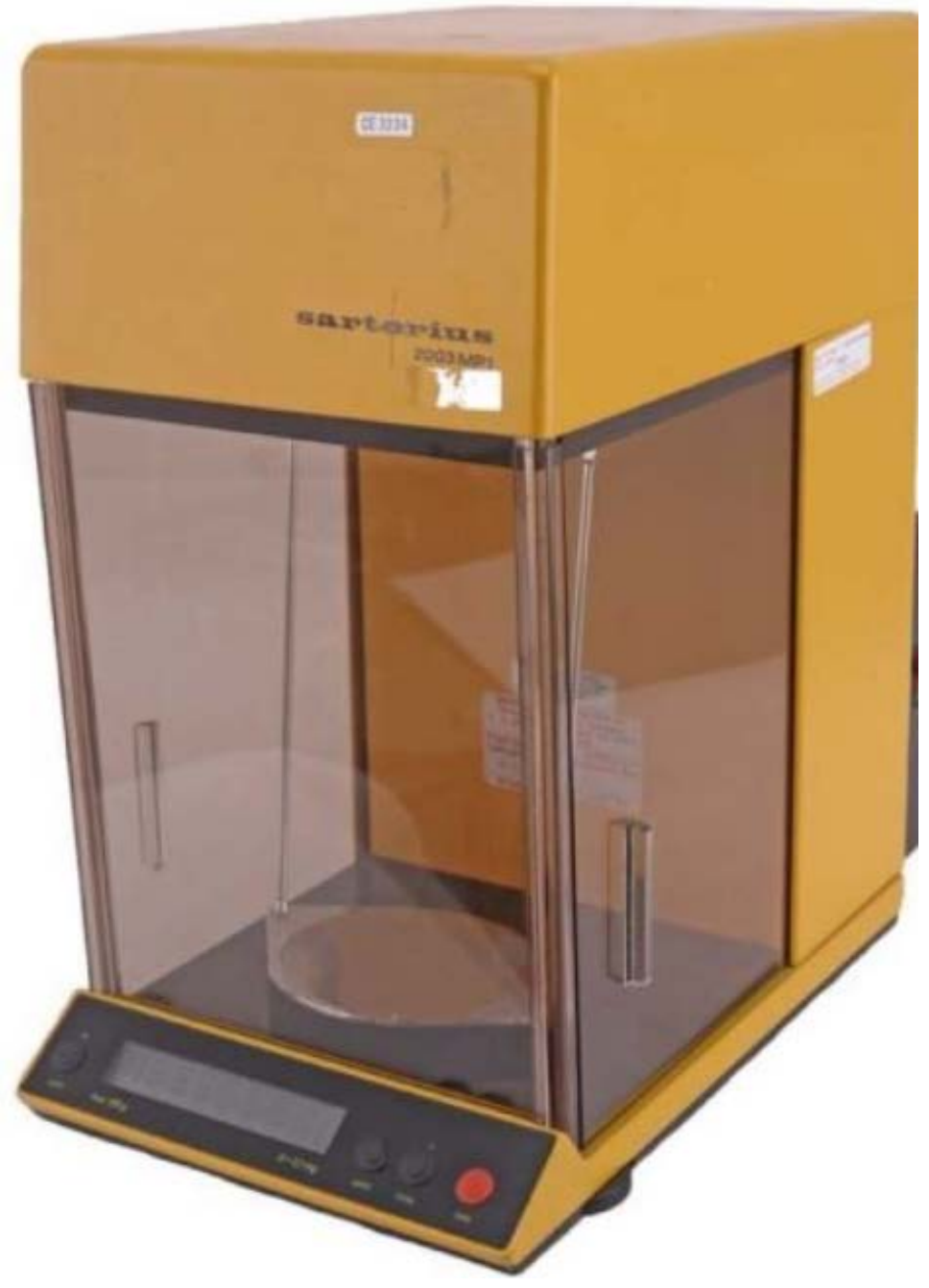

Figure A.1: Sartorius Lab 2000 Series (Sartorius Inc., NY, USA) 


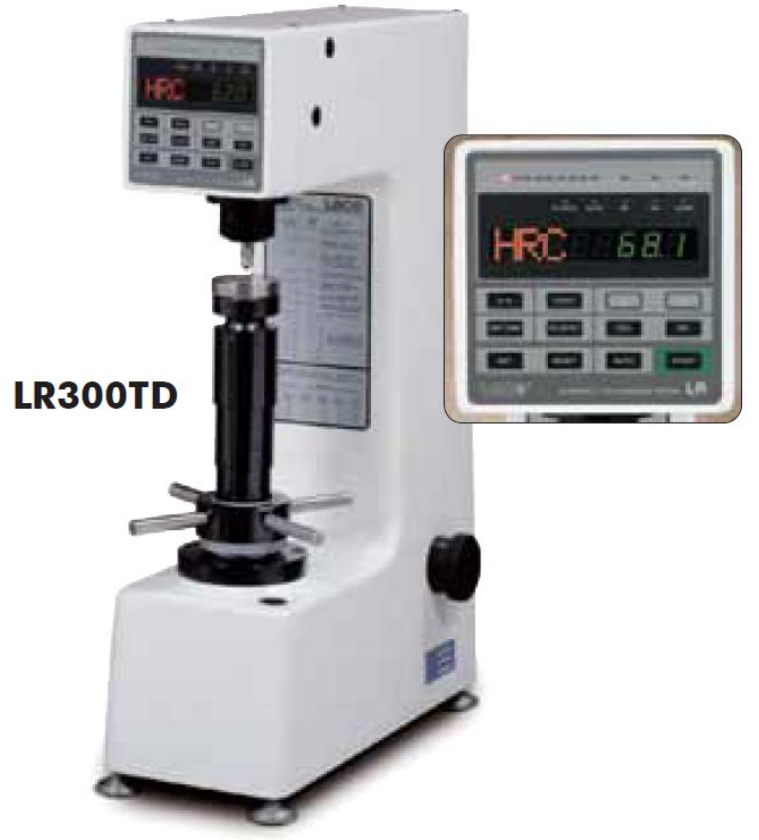

Figure A.2: LR300TD Rockwell Hardness tester (LECO Corporation, St. Joseph, MI, USA) 


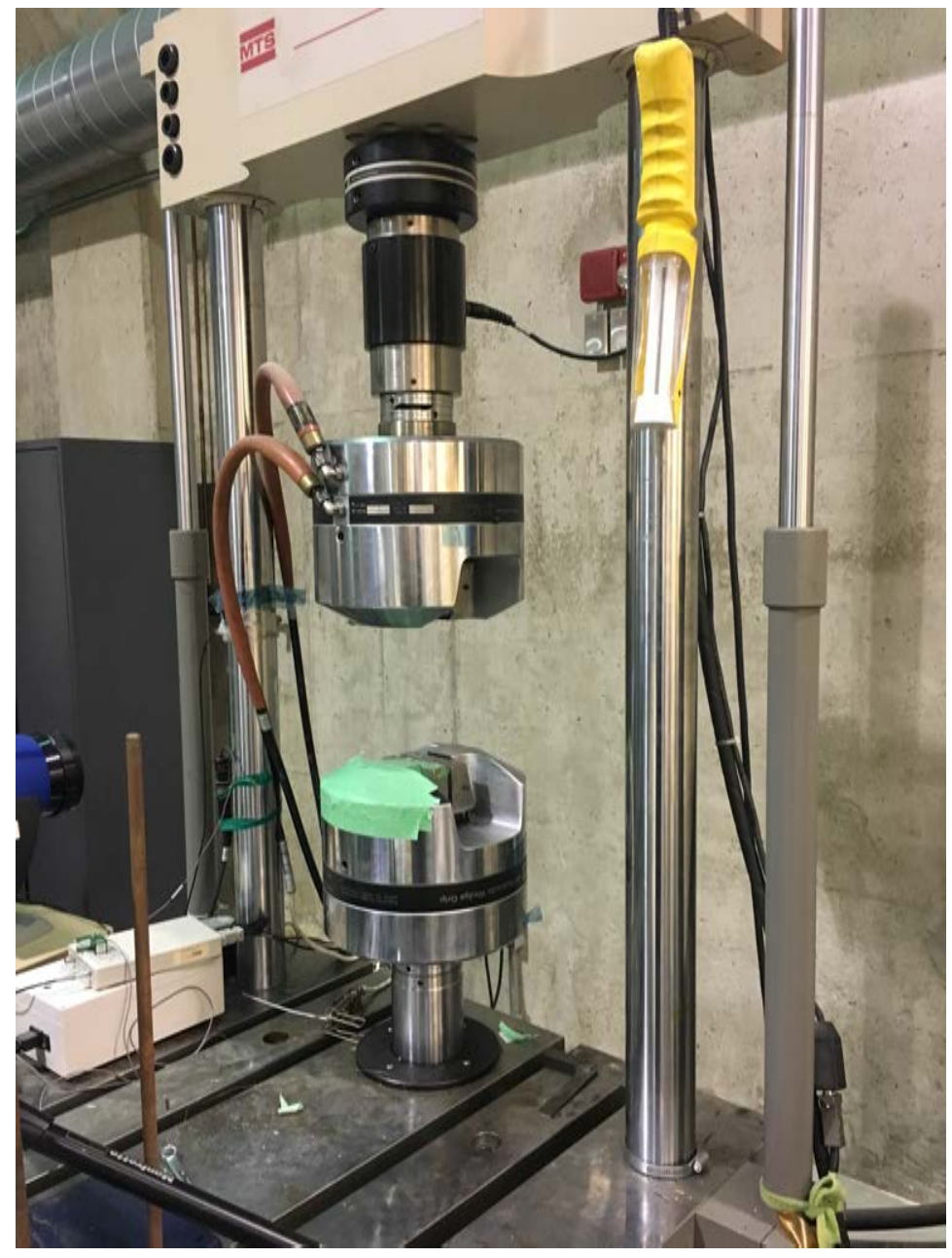

Figure A.3: MTS 322 (Eden Prairie, MN, USA) Hydraulic Test Frame 


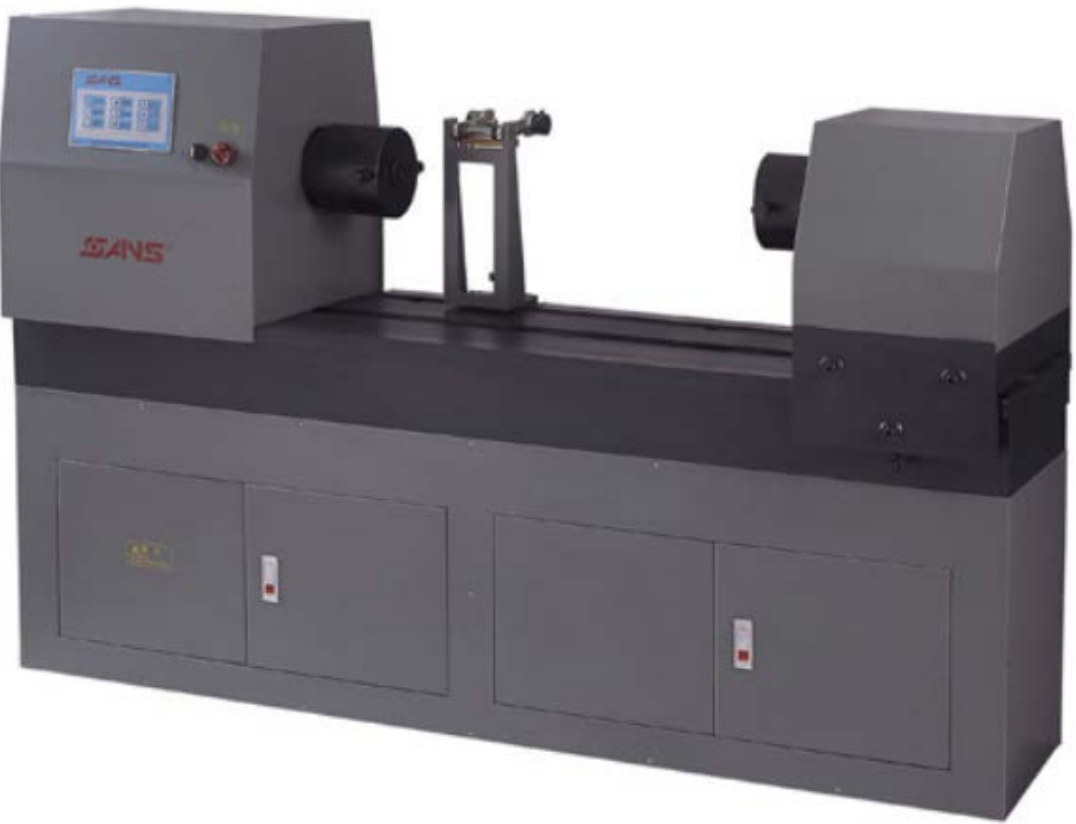

Figure A.4: CTT series torque testing machine (Shenzhen Sans Testing Machine Co. Ltd., Shen-zhen, China) 


\section{References}

[1] D. U. Shah, Developing plant fibre composites for structural applications by optimising composite parameters: a critical review, Journal of Materials Science 48 (18) (2013) 6083-6107. doi:10.1007/s10853-013-7458-7.

[2] D. U. Shah, Natural fibre composites: Comprehensive ashby-type materials selection charts, Materials Design (1980-2015) 62 (2014) 21-31. doi:10.1016/j .matdes . 2014. 05.002 .

[3] P. Wambua, J. Ivens, I. Verpoest, Natural fibres: can they replace glass in fibre reinforced plastics?, Composites Science and Technology 63 (9) (2003) 1259-1264. doi : 10.1016/ s0266-3538(03) 00096-4.

[4] S. Joshi, L. Drzal, A. Mohanty, S. Arora, Are natural fiber composites environmentally superior to glass fiber reinforced composites?, Composites Part A: Applied Science and Manufacturing 35 (3) (2004) 371-376. doi :10.1016/j. compositesa. 2003.09.016.

[5] K. G. Satyanarayana, G. G. Arizaga, F. Wypych, Biodegradable composites based on lignocellulosic fibers-an overview, Progress in Polymer Science 34 (9) (2009) 982-1021. doi:10.1016/j.progpolymsci.2008.12.002.

[6] K. Pickering, M. A. Efendy, T. Le, A review of recent developments in natural fibre composites and their mechanical performance, Composites Part A: Applied Science and Manufacturing 83 (2016) 98-112. doi :10.1016/j . compositesa.2015.08.038.

[7] H. Hamada, J. Denault, A. K. Mohanty, Y. Li, M. S. Aly-Hassan, Natural fiber composites, Advances in Mechanical Engineering 5 (2013) 569020. doi : 10.1155/2013/569020.

[8] E. A. Elbadry, M. S. Aly-Hassan, H. Hamada, Tensile and bending properties of jute fiber mat reinforced unsaturated polyester matrix composites, Volume 3: Design and Manufacturingdoi:10.1115/imece2011-62409.

[9] S. González-García, A. Hospido, G. Feijoo, M. Moreira, Life cycle assessment of raw materials for non-wood pulp mills: Hemp and flax, Resources, Conservation and Recycling 54 (11) (2010) 923-930. doi:10.1016/j.resconrec.2010.01.011.

[10] A. L. Duigou, P. Davies, C. Baley, Environmental impact analysis of the production of flax fibres to be used as composite material reinforcement, Journal of Biobased Materials and Bioenergy 5 (1) (2011) 153-165. doi :10.1166/jbmb .2011.1116. 
[11] A. Stamboulis, C. Baillie, T. Peijs, Effects of environmental conditions on mechanical and physical properties of flax fibers, Composites Part A: Applied Science and Manufacturing 32 (8) (2001) 1105-1115. doi :10.1016/s1359-835x(01) 00032-x.

[12] N. Sgriccia, M. Hawley, M. Misra, Characterization of natural fiber surfaces and natural fiber composites, Composites Part A: Applied Science and Manufacturing 39 (10) (2008) 1632-1637. doi:10.1016/j.compositesa.2008.07.007.

[13] D. B. Dittenber, H. V. Gangarao, Critical review of recent publications on use of natural composites in infrastructure, Composites Part A: Applied Science and Manufacturing 43 (8) (2012) 1419-1429. doi:10.1016/j .compositesa.2011.11.019.

[14] K. M. M. Rao, K. M. Rao, A. R. Prasad, Fabrication and testing of natural fibre composites: Vakka, sisal, bamboo and banana, Materials Design 31 (1) (2010) 508-513. doi: $10.1016 /$ j.matdes. 2009.06.023.

[15] H. M. V. D. Werf, L. Turunen, The environmental impacts of the production of hemp and flax textile yarn, Industrial Crops and Products 27 (1) (2008) 1-10. doi:10.1016/ j. indcrop. 2007.05.003.

[16] D. N. Saheb, J. P. Jog, Natural fiber polymer composites: A review, Advances in Polymer Technology 18 (4) (1999) 351-363. doi:10.1002/ (sici) 1098-2329 (199924)18: 4<351: : aid-adv6>3.3.co;2-o.

[17] J. Summerscales, N. P. Dissanayake, A. S. Virk, W. Hall, A review of bast fibres and their composites. part 1 - fibres as reinforcements, Composites Part A: Applied Science and Manufacturing 41 (10) (2010) 1329-1335. doi:10.1016/j.compositesa.2010.06. 001.

[18] M.-P. Ho, H. Wang, J.-H. Lee, C.-K. Ho, K.-T. Lau, J. Leng, D. Hui, Critical factors on manufacturing processes of natural fibre composites, Composites Part B: Engineering 43 (8) (2012) 3549-3562. doi:10.1016/j . compositesb.2011.10.001.

[19] D. U. Shah, D. Porter, F. Vollrath, Can silk become an effective reinforcing fibre? a property comparison with flax and glass reinforced composites, Composites Science and Technology 101 (2014) 173-183. doi:10.1016/j . compscitech.2014.07.015.

[20] F. Ahmad, H. S. Choi, M. K. Park, A review: Natural fiber composites selection in view of mechanical, light weight, and economic properties, Macromolecular Materials and Engineering 300 (1) (2014) 10-24. doi:10.1002/mame. 201400089.

[21] L. Yan, N. Chouw, K. Jayaraman, Flax fibre and its composites - a review, Composites Part B: Engineering 56 (2014) 296-317. doi :10 .1016/j . compositesb. 2013.08. 014.

[22] J. Flynn, A. Amiri, C. Ulven, Hybridized carbon and flax fiber composites for tailored performance, Materials Design 102 (2016) 21-29. doi:10.1016/j.matdes.2016.03. 164. 
[23] S. L. Valença, S. Griza, V. G. D. Oliveira, E. M. Sussuchi, F. G. C. D. Cunha, Evaluation of the mechanical behavior of epoxy composite reinforced with kevlar plain fabric and glass/kevlar hybrid fabric, Composites Part B: Engineering 70 (2015) 1-8. doi:10.1016/j.compositesb.2014.09.040.

[24] P. Priyanka, A. Dixit, H. S. Mali, High-strength hybrid textile composites with carbon, kevlar, and e-glass fibers for impact-resistant structures. a review., Mechanics of Composite Materials 53 (5) (2017) 685-704. doi:10.1007/s11029-017-9696-2.

[25] Y. Z. Wan, J. J. Lian, Y. Huang, F. He, Y. L. Wang, H. J. Jiang, J. Y. Xin, Preparation and characterization of three-dimensional braided carbon/kevlar/epoxy hybrid composites, Journal of Materials Science 42 (4) (2006) 1343-1350. doi:10.1007/ s10853-006-1215-0.

[26] S. Liang, P. Gning, L. Guillaumat, A comparative study of fatigue behaviour of flax/epoxy and glass/epoxy composites, Composites Science and Technology 72 (5) (2012) 535-543. doi:10.1016/j.compscitech.2012.01.011.

[27] A. Shahzad, D. Isaac, Fatigue properties of hemp and glass fiber composites, Polymer Composites 35 (10) (2014) 1926-1934. doi : 10.1002/pc . 22851.

[28] K. Oksman, L. Wallström, L. A. Berglund, R. D. T. Filho, Morphology and mechanical properties of unidirectional sisal- epoxy composites, Journal of Applied Polymer Science 84 (13) (2002) 2358-2365. doi : 10.1002/app. 10475.

[29] C. Bonnafous, F. Touchard, L. Chocinski-Arnault, Multi scale analysis by acoustic emission of damage mechanisms in natural fibre woven fabrics/epoxy composites., EPJ Web of Conferences 6 (2010) 20009. doi : 10.1051/epjconf/20100620009.

[30] D. U. Shah, P. J. Schubel, M. J. Clifford, Can flax replace e-glass in structural composites? a small wind turbine blade case study, Composites Part B: Engineering 52 (2013) 172-181. doi:10.1016/j.compositesb. 2013.04.027.

[31] N. Saba, M. Jawaid, O. Y. Alothman, M. Paridah, A review on dynamic mechanical properties of natural fibre reinforced polymer composites, Construction and Building Materials 106 (2016) 149-159. doi:10.1016/j . conbuildmat. 2015.12.075.

[32] B. D. Agarwal, L. J. Broutman, K. Chandrashekhara, Analysis and performance of fiber composites, Wiley, 2018.

[33] M. N. Gururaja, A. N. Harirao, Influence of angle ply orientation on tensile properties of carbon/glass hybrid composite, Journal of Minerals and Materials Characterization and Engineering 01 (05) (2013) 231-235. doi : 10.4236/jmmce.2013.15036.

[34] G. Czél, M. Jalalvand, M. R. Wisnom, Design and characterisation of advanced pseudoductile unidirectional thin-ply carbon/epoxy-glass/epoxy hybrid composites, Composite Structures 143 (2016) 362-370. doi:10.1016/j . compstruct.2016.02.010. 
[35] Y. Swolfs, Perspective for fibre-hybrid composites in wind energy applications, Materials 10 (12) (2017) 1281. doi :10.3390/ma10111281.

[36] A. Dorigato, A. Pegoretti, Flexural and impact behaviour of carbon/basalt fibers hybrid laminates, Journal of Composite Materials 48 (9) (2013) 1121-1130. doi : 10.1177/ 0021998313482158.

[37] H. Sezgin, O. B. Berkalp, The effect of hybridization on significant characteristics of jute/glass and jute/carbon-reinforced composites, Journal of Industrial Textiles 47 (3) (2016) 283-296. doi : 10.1177/1528083716644290.

[38] M. DUBRAVCIK, Testing of hybrid composites, ACTA TEHNICA CORVINIENSIS - Bulletin of Engineering.

[39] H. Dhakal, Z. Zhang, R. Guthrie, J. Macmullen, N. Bennett, Development of flax/carbon fibre hybrid composites for enhanced properties, Carbohydrate Polymers 96 (1) (2013) 1-8. doi:10.1016/j. carbpol.2013.03.074.

[40] Z. S. Bagheri, P. T. Avval, H. Bougherara, M. S. R. Aziz, E. H. Schemitsch, R. Zdero, Biomechanical analysis of a new carbon fiber/flax/epoxy bone fracture plate shows less stress shielding compared to a standard clinical metal plate, Journal of Biomechanical Engineering 136 (9) (2014) 091002. doi:10.1115/1.4027669.

[41] S. Manteghi, Z. Mahboob, Z. Fawaz, H. Bougherara, Investigation of the mechanical properties and failure modes of hybrid natural fiber composites for potential bone fracture fixation plates, Journal of the Mechanical Behavior of Biomedical Materials 65 (2017) 306-316. doi:10.1016/j . jmbbm.2016.08.035.

[42] R. Yahaya, S. Sapuan, M. Jawaid, Z. Leman, E. Zainudin, Mechanical performance of woven kenaf-kevlar hybrid composites, Journal of Reinforced Plastics and Composites 33 (24) (2014) 2242-2254. doi : 10 .1177/0731684414559864.

[43] E. Nisini, C. Santulli, A. Liverani, Mechanical and impact characterization of hybrid composite laminates with carbon, basalt and flax fibres, Composites Part B: Engineering 127 (2017) 92-99. doi :10.1016/j . compositesb.2016.06.071.

[44] C. Cerbu, Practical solution for improving the mechanical behaviour of the composite materials reinforced with flax woven fabric, Advances in Mechanical Engineering 7 (2) (2015) 168781401558208. doi:10.1177/1687814015582084.

[45] S. K. Nayak, S. Mohanty, S. K. Samal, Influence of short bamboo/glass fiber on the thermal, dynamic mechanical and rheological properties of polypropylene hybrid composites, Materials Science and Engineering: A 523 (1-2) (2009) 32-38. doi:10.1016/j . msea.2009.06.020.

[46] M. A. Alam, K. Alriyami, Z. C. Muda, M. Z. Jumaat, Hybrid kenaf fibre composite plates for potential application in shear strengthening of reinforced concrete structure, Indian Journal of Science and Technology 9 (6). doi :10.17485/i jst/2016/v9i6/77483. 
[47] C. Dong, Review of natural fibre-reinforced hybrid composites, Journal of Reinforced Plastics and Composites 37 (5) (2017) 331-348. doi : 10.1177/0731684417745368.

[48] M. Jawaid, H. A. Khalil, Cellulosic/synthetic fibre reinforced polymer hybrid composites: A review, Carbohydrate Polymers 86 (1) (2011) 1-18. doi:10.1016/j . carbpol. 2011.04 .043$.

[49] CARBIO, Carbio - carbon-flax hybrid structures for automotive applications. URL http://carbioproject.com/

[50] G. Cicala, G. Cristaldi, G. Recca, G. Ziegmann, A. El-Sabbagh, M. Dickert, Properties and performances of various hybrid glass/natural fibre composites for curved pipes, Materials Design 30 (7) (2009) 2538-2542. doi:10.1016/j.matdes.2008.09.044.

[51] V. Fiore, A. Valenza, G. D. Bella, Mechanical behavior of carbon/flax hybrid composites for structural applications, Journal of Composite Materials 46 (17) (2012) 2089-2096. doi:10.1177/0021998311429884.

[52] V. K. Thakur, M. K. Thakur, R. K. Gupta, Review: Raw natural fiber-based polymer composites, International Journal of Polymer Analysis and Characterization 19 (3) (2014) 256-271. doi : 10.1080/1023666x.2014.880016.

[53] M. A. Fuqua, S. Huo, C. A. Ulven, Natural fiber reinforced composites, Polymer Reviews 52 (3) (2012) 259-320. doi : 10.1080/15583724.2012.705409.

[54] D. D. Stokke, Introduction to Wood and Natural Fiber Composites, Wiley.

[55] T. Sathishkumar, P. Navaneethakrishnan, S. Shankar, R. Rajasekar, N. Rajini, Characterization of natural fiber and composites - a review, Journal of Reinforced Plastics and Composites 32 (19) (2013) 1457-1476. doi : 10.1177/0731684413495322.

[56] T. Peijs, S. Garkhail, R. Heijenrath, M. V. D. Oever, H. Bos, Thermoplastic composites based on flax fibres and polypropylene: Influence of fibre length and fibre volume fraction on mechanical properties, Macromolecular Symposia 127 (1) (1998) 193-203. doi:10.1002/masy. 19981270126.

[57] T. Corbière-Nicollier, B. G. Laban, L. Lundquist, Y. Leterrier, J.-A. Månson, O. Jolliet, Life cycle assessment of biofibres replacing glass fibres as reinforcement in plastics, Resources, Conservation and Recycling 33 (4) (2001) 267-287. doi:10.1016/ s0921-3449(01)00089-1.

[58] W. Kim, A. Argento, High strain rate testing of natural fiber composites, Natural Fibre Composites (2014) 303-322doi : 10.1533/9780857099228.3.303.

[59] H. L. Bos, M. J. A. Van Den Oever, O. C. J. J. Peters, Tensile and compressive properties of flax fibres for natural fibre reinforced composites, Journal of Materials Science 37 (8) (2002) 1683-1692. doi:10.1023/A:1014925621252.

URL https : / /doi.org/10.1023/A : 1014925621252 
[60] B. Lamy, C. Baley, Journal of materials science letters, Journal of Materials Science Letters 19 (11) (2000) 979-980. doi :10.1023/a:1006776423764.

[61] B. Lamy, C. Pomel, Journal of materials science letters, Journal of Materials Science Letters 21 (15) (2002) 1211-1213. doi : 10.1023/a:1016524619867.

[62] B. Madsen, H. Lilholt, Physical and mechanical properties of unidirectional plant fibre composites-an evaluation of the influence of porosity, Composites Science and Technology 63 (9) (2003) 1265-1272. doi : 10.1016/s0266-3538(03) 00097-6.

[63] B. Madsen, A. Thygesen, H. Lilholt, Plant fibre composites - porosity and volumetric interaction, Composites Science and Technology 67 (7-8) (2007) 1584-1600. doi:10. 1016/j. compscitech. 2006.07.009.

[64] B. Madsen, A. Thygesen, H. Lilholt, Plant fibre composites - porosity and stiffness, Composites Science and Technology 69 (7-8) (2009) 1057-1069. doi:10.1016/j. compscitech.2009.01.016.

[65] C. Baley, Analysis of the flax fibres tensile behaviour and analysis of the tensile stiffness increase, Composites Part A: Applied Science and Manufacturing 33 (7) (2002) 939-948. doi:10.1016/s1359-835x(02)00040-4.

[66] H. L. Bos, A. M. Donald, In situ esem study of the deformation of elementary flax fibres, Journal of Materials Science 34 (13) (1999) 3029-3034. doi:10.1023/A: 1004650126890.

URL https://doi .org/10.1023/A:1004650126890

[67] M. Assarar, D. Scida, A. E. Mahi, C. Poilâne, R. Ayad, Influence of water ageing on mechanical properties and damage events of two reinforced composite materials: Flax-fibres and glass-fibres, Materials Design 32 (2) (2011) 788-795. doi:10.1016/ j.matdes. 2010.07 .024 .

[68] R. H. Newman, Auto-accelerative water damage in an epoxy composite reinforced with plain-weave flax fabric, Composites Part A: Applied Science and Manufacturing 40 (10) (2009) 1615-1620. doi:10.1016/j.compositesa.2009.07.010.

[69] D. Scida, M. Assarar, C. Poilâne, R. Ayad, Influence of hygrothermal ageing on the damage mechanisms of flax-fibre reinforced epoxy composite, Composites Part B: Engineering 48 (2013) 51-58. doi : 10.1016/j . compositesb. 2012.12.010.

[70] M. Wróbel-Kwiatkowska, M. Czemplik, A. Kulma, M. Żuk, J. Kaczmar, L. Dymińska, J. Hanuza, M. Ptak, J. Szopa, New biocomposites based on bioplastic flax fibers and biodegradable polymers, Biotechnology Progress 28 (5) (2012) 1336-1346. doi:10. 1002/btpr. 1599.

[71] M. Karus, M. Kaup, Natural fibres in the european automotive industry, Journal of Industrial Hemp 7 (1) (2002) 119-131. doi : 10.1300/j237v07n01_10. 
[72] S. Kalia, B. S. Kaith, I. Kaur, Cellulose Fibers: Bio- and Nano-Polymer Composites Green Chemistry and Technology, Springer-Verlag Berlin Heidelberg, 2011.

[73] M. J. John, S. Thomas, Natural polymers, Royal Society of Chemistry, 2012.

[74] O. L. Friec, Flaxpregtm wins jec europe 2015 innovation award in the semi-products category.

URL http://www .faurecia.com/en/faurecia-flaxpregtm-wins-jec-europe-2015-innovatio

[75] Stemergy, products: stemergy renewable bio fiber (london, ontario, canada). URL http://www . stemergy.com/products/flaxfibre/flaxfibercomposites/

[76] P.-O. Hagstrand, K. Oksman, Mechanical properties and morphology of flax fiber reinforced melamine-formaldehyde composites, Polymer Composites 22 (4) (2001) 568-578. doi : 10.1002/pc. 10560.

[77] B. A. Muralidhar, Tensile and compressive properties of flax-plain weave preform reinforced epoxy composites, Journal of Reinforced Plastics and Composites 32 (3) (2012) 207-213. doi : 10.1177/0731684412469136.

[78] Z. Mahboob, I. E. Sawi, R. Zdero, Z. Fawaz, H. Bougherara, Tensile and compressive damaged response in flax fibre reinforced epoxy composites, Composites Part A: Applied Science and Manufacturing 92 (2017) 118-133. doi:10.1016/j.compositesa. 2016.11 .007$.

[79] Biotex, biotex flax used to improve impact performance for bamboo bike).

URLhttps://compositesevolution.com/news/biotex-flax-used-to-improve-impact-perfo

[80] A. Bourmaud, C. Morvan, A. Bouali, V. Placet, P. Perré, C. Baley, Relationships between micro-fibrillar angle, mechanical properties and biochemical composition of flax fibers, Industrial Crops and Products 44 (2013) 343-351. doi:10.1016/j.indcrop. 2012.11 .031$.

[81] J. Zhu, K. Immonen, C. Avril, J. Brighton, H. Zhu, H. Abhyankar, Novel hybrid flax reinforced supersap composites in automotive applications, Fibers 3 (4) (2015) 76-89. doi:10.3390/fib3010076.

[82] H. L. Bos, J. Müssig, M. J. van den Oever, Mechanical properties of short-flax-fibre reinforced compounds, Composites Part A: Applied Science and Manufacturing 37 (10) (2006) 1591 - 1604. doi :https ://doi .org/10.1016/j . compositesa.2005.10.011. URL http://www.sciencedirect.com/science/article/pii/ S1359835X05003982

[83] About flax fibers (linen).

URL http://flaxcomposites.com/?page_id=2

[84] A. K. Kaw, Mechanics of composite materials, Taylor Francis, 2006. 
[85] F. Campbell, Thermoplastic composites: An unfulfilled promise, Manufacturing Processes for Advanced Composites (2004) 357-397doi:10.1016/b978-185617415-2/ 50011-3.

[86] F. Larsson, The effect of ultraviolet light on mechanical properties of kevlar 49 composites, Journal of Reinforced Plastics and Composites 5 (1) (1986) 19-22. doi : 10.1177/ 073168448600500103.

[87] F. Aird, Fiberglass other composite materials: a guide to high performance non-metallic materials for race cars, street rods, body shops, boats and aircraft, Penguin, 2006.

[88] M. E. Tuttle, Structural analysis of polymeric composite materials, CRC, 2013.

[89] S. M. Lee, Handbook of composite reinforcements, VCH., 1993.

[90] S. Dutton, D. Kelly, A. Baker, Composite materials for aircraft structures, second editiondoi : 10.2514/4.861680.

[91] M. F. Ashby, P. J. Ferreira, D. L. Schodek, Nanomaterials and nanotechnologies in health and the environment, Nanomaterials, Nanotechnologies and Design (2009) 467-500doi : 10.1016/b978-0-7506-8149-0.00013-1.

[92] B. T. ASTROM, MANUFACTURING OF POLYMER COMPOSITES, CRC PRESS, 2017.

[93] A. P. Mouritz, Introduction to aerospace materials, Woodhead Pub., 2012.

[94] Y. Swolfs, I. Verpoest, L. Gorbatikh, Maximising the hybrid effect in unidirectional hybrid composites, Materials Design 93 (2016) 39-45. doi:10.1016/j.matdes. 2015. 12.137.

[95] A. P. Vassilopoulos, T. Keller, Fatigue of fiber-reinforced composites, Engineering Materials and Processesdoi : 10.1007/978-1-84996-181-3.

[96] K. Oksman, M. Skrifvars, J.-F. Selin, Natural fibres as reinforcement in polylactic acid (pla) composites, Composites Science and Technology 63 (9) (2003) 1317-1324. doi: $10.1016 / \mathrm{s} 0266-3538(03) 00103-9$.

[97] J. Andersons, R. Joffe, Estimation of the tensile strength of an oriented flax fiberreinforced polymer composite, Composites Part A: Applied Science and Manufacturing 42 (9) (2011) 1229-1235. doi:10.1016/j . compositesa.2011.05.005.

[98] J. Gassan, A study of fibre and interface parameters affecting the fatigue behaviour of natural fibre composites, Composites Part A: Applied Science and Manufacturing 33 (3) (2002) 369-374. doi:10.1016/s1359-835x(01)00116-6.

[99] P. B. Gning, S. Liang, L. Guillaumat, W. J. Pui, Influence of process and test parameters on the mechanical properties of flax/epoxy composites using response surface methodology, Journal of Materials Science 46 (21) (2011) 6801-6811. doi:10.1007/ s10853-011-5639-9. 
[100] LINEO NV, Advanced Flax - FlaxPly (2014).

URL http://lineo.eu/products

[101] M. Jawaid, H. A. Khalil, A. A. Bakar, Woven hybrid composites: Tensile and flexural properties of oil palm-woven jute fibres based epoxy composites, Materials Science and Engineering: A 528 (15) (2011) 5190-5195. doi :10.1016/j.msea. 2011.03 .047$.

[102] M. Idicula, N. R. Neelakantan, Z. Oommen, K. Joseph, S. Thomas, A study of the mechanical properties of randomly oriented short banana and sisal hybrid fiber reinforced polyester composites, Journal of Applied Polymer Science 96 (5) (2005) 1699-1709. doi:10.1002/app. 21636.

[103] R. Gujjala, S. Ojha, S. Acharya, S. Pal, Mechanical properties of woven jute-glass hybridreinforced epoxy composite, Journal of Composite Materials 48 (28) (2013) 3445-3455. doi:10.1177/0021998313501924.

[104] L. Pothan, Y. Mai, S. Thomas, R. Li, Tensile and flexural behavior of sisal fabric/polyester textile composites prepared by resin transfer molding technique, Journal of Reinforced Plastics and Composites 27 (16-17) (2008) 1847-1866. doi : 10.1177/ 0731684408090342.

[105] G. A. Khan, M. Terano, M. Gafur, M. S. Alam, Studies on the mechanical properties of woven jute fabric reinforced poly(l-lactic acid) composites, Journal of King Saud University - Engineering Sciences 28 (1) (2016) 69-74. doi:10.1016/j . jksues . 2013.12. 002.

[106] D. Zhu, B. Mobasher, S. D. Rajan, Characterization of mechanical behavior of kevlar 49 fabrics, Experimental and Applied Mechanics, Volume 6 Conference Proceedings of the Society for Experimental Mechanics Series (2011) 377-384doi : 10.1007/ 978-1-4614-0222-0_46.

[107] I. E. Sawi, Z. Fawaz, R. Zitoune, H. Bougherara, An investigation of the damage mechanisms and fatigue life diagrams of flax fiber-reinforced polymer laminates, Journal of Materials Science 49 (5) (2013) 2338-2346. doi : 10.1007/s10853-013-7934-0.

[108] I. E. Sawi, H. Bougherara, R. Zitoune, Z. Fawaz, Influence of the manufacturing process on the mechanical properties of flax/epoxy composites, Journal of Biobased Materials and Bioenergy 8 (1) (2014) 69-76. doi : 10.1166/jbmb.2014.1410.

[109] E. Bodros, I. Pillin, N. Montrelay, C. Baley, Could biopolymers reinforced by randomly scattered flax fibre be used in structural applications?, Composites Science and Technology 67 (3-4) (2007) 462-470. doi :10.1016/j . compscitech.2006.08.024.

[110] N. Pan, Theoretical determination of the optimal fiber volume fraction and fiber-matrix property compatibility of short fiber composites, Polymer Composites 14 (2) (1993) 85-93. doi:10.1002/pc.750140202. 
[111] R. F. Gibson, Principles of composite material mechanics, CRC Press, Taylor Francis Group, 2016.

[112] ASTM D3171, Test Methods for Constituent Content of Composite Materials, Tech. Rep. ASTM D3171-15, ASTM International, West Conshohocken, PA (2011). doi : 10.1520/ D3171- 15.

URL https: //www . astm.org/Standards/D3171.htm

[113] S. Phillips, J. Baets, L. Lessard, P. Hubert, I. Verpoest, Characterization of flax/epoxy prepregs before and after cure, Journal of Reinforced Plastics and Composites 32 (11) (2013) 777-785. doi:10.1177/0731684412473359.

[114] J.-M. Berthelot, Composite materials: mechanical behavior and structural analysis, Springer-Verlag New York, 2013.

[115] A. Corigliano, Damage and fracture mechanics techniques for composite structures, Comprehensive Structural Integrity (2003) 459-539doi:10.1016/b0-08-043749-4/ $03041-\mathrm{x}$.

[116] A. Fotouh, J. D. Wolodko, M. G. Lipsett, Fatigue of natural fiber thermoplastic composites, Composites Part B: Engineering 62 (2014) 175-182. doi:10.1016/j. compositesb.2014.02.023.

[117] C. Bathias, An engineering point of view about fatigue of polymer matrix composite materials, International Journal of Fatigue 28 (10) (2006) 1094-1099. doi :10.1016/j. ijfatigue.2006.02.008.

[118] W. W. Stinchcomb, N. E. Ashbaugh, Composite materials: Fatigue and fracture, fourth volume, American Society for Testing and Materialsdoi : 10.1520/stp1156-eb.

[119] M. Hughes, J. Carpenter, C. Hill, Deformation and fracture behaviour of flax fibre reinforced thermosetting polymer matrix composites, Journal of Materials Science 42 (7) (2007) 2499-2511. doi : 10.1007/s10853-006-1027-2.

[120] G. Romhány, J. Karger-Kocsis, T. Czigány, Tensile fracture and failure behavior of thermoplastic starch with unidirectional and cross-ply flax fiber reinforcements, Macromolecular Materials and Engineering 288 (9) (2003) 699-707. doi:10.1002/mame. 200300040.

[121] A. D5229-14, Standard test method for moisture absorption properties and equilibrium conditioning of polymer matrix composite materials, Tech. rep., ASTM (2014).

[122] W. Wang, M. Sain, P. Cooper, Study of moisture absorption in natural fiber plastic composites, Composites Science and Technology 66 (3-4) (2006) 379-386. doi : 10 .1016/j . compscitech.2005.07.027. 
[123] M. Sreekala, S. Thomas, Effect of fibre surface modification on water-sorption characteristics of oil palm fibres, Composites Science and Technology 63 (6) (2003) 861-869. doi : 10.1016/s0266-3538(02)00270-1.

[124] H. Alamri, I. Low, Mechanical properties and water absorption behaviour of recycled cellulose fibre reinforced epoxy composites, Polymer Testing 31 (5) (2012) 620-628. doi:10.1016/j.polymertesting.2012.04.002.

[125] G. Marom, The role of water transport in composite materials, Polymer Permeability (1985) 341-374doi : 10.1007/978-94-009-4858-7_9.

[126] A. D785-08, Standard test method for rockwell hardness of plastics and electrical insulating materials, Tech. rep., ASTM (2015).

[127] A. D3039-17, Standard test method for tensile properties of polymer matrix composite materials, Tech. rep., ASTM (2017).

[128] K. Charlet, S. Eve, J. Jernot, M. Gomina, J. Breard, Tensile deformation of a flax fiber, Procedia Engineering 1 (1) (2009) 233-236. doi : 10.1016/j . proeng . 2009.06. 055.

[129] S. Alix, E. Philippe, A. Bessadok, L. Lebrun, C. Morvan, S. Marais, Effect of chemical treatments on water sorption and mechanical properties of flax fibres, Bioresource Technology 100 (20) (2009) 4742-4749. doi:10.1016/j.biortech.2009.04.067.

[130] A. D695-15, Standard test method for compressive properties of rigid plastics, Tech. rep., ASTM (2015).

[131] A. D7264-15, Standard test method for flexural properties of polymer matrix composite materials, Tech. rep., ASTM (2015).

[132] C. Claudio, I. M. Rosa, F. Sarasini, Acoustic emission monitoring of flexurally loaded aramid/epoxy composites by embedded pvdf sensors, Journal of Acoustic Emission 25 (2007) 80.

URL http://link.galegroup.com.ezproxy.lib.ryerson.ca/apps/doc/ A254015067/AONE?u=rpu_main\&sid=AONE\&xid=c470777a

[133] A. E143-13, Standard test method for shear modulus at room temperature, Tech. rep., ASTM (2013).

[134] R. L. Huston, H. Josephs, Practical stress analysis in engineering design, CRC Press, 2009.

[135] C. T. Herakovich, Mechanics of composites: A historical review, Mechanics Research Communications 41 (2012) 1-20. doi:10.1016/j.mechrescom.2012.01.006.

[136] G. Z. Voyiadjis, J. W. Ju, J.-L. Chaboche, Damage mechanics in engineering materials, Elsevier, 1998. 
[137] A. K. Gupta, B. P. Patel, Y. Nath, Nonlinear static analysis of composite laminated plates with evolving damage, Acta Mechanica 224 (6) (2013) 1285-1298. doi : 10.1007/ s00707-013-0875-5.

[138] P. Ladeveze, E. Ledantec, Damage modelling of the elementary ply for laminated composites, Composites Science and Technology 43 (3) (1992) 257-267. doi:10.1016/ 0266-3538(92) 90097-m.

[139] P. Ladevèze, A damage computational method for composite structures, Computers and Structures 44 (1-2) (1992) 79-87. doi :10.1016/0045-7949(92)90226-P.

[140] P. Ladevèze, E. Le Dantec, Damage modelling of the elementary ply for laminated composites, Composites Science and Technology 43 (3) (1992) 257-267. doi:10.1016/ 0266-3538 (92) 90097-M.

[141] O. Allix, P. Ladevèze, E. Vittecoq, Modelling and identification of the mechanical behaviour of composite laminates in compression, Composites Science and Technology 51 (1) (1994) 35-42. doi : 10.1016/0266-3538(94)90154-6.

[142] O. Allix, P. Ladevèze, A. Corigliano, Damage analysis of interlaminar fracture specimens, Composites Structures 31 (1) (1995) 61-74. doi : 10 .1016/0263-8223 (95)00002-X.

[143] L. Daudeville, P. Ladevèze, A damage mechanics tool for laminate delamination, Composites Structures 25 (1) (1993) 547-555. doi : 10.1016/0263-8223(93) 90203-3.

[144] A. Gasser, P. Ladevèze, M. Poss, Damage mechanisms of a woven SiC/SiC composite: Modelling and identification, Composites Science and Technology 56 (7) (1996) 779784. doi : 10 .1016/0266-3538(96)00020-6.

[145] F. Daghia, P. Ladevèze, Identification and validation of an enhanced mesomodel for laminated composites within the WWFE-III, Journal of Composite Materials 47 (20-21) (2013) 2675-2693. doi : 10.1177/0021998313494095.

[146] J. Lemaitre, How to use damage mechanics, Nuclear Engineering and Design 80 (2) (1984) 233-245. doi : 10.1016/0029-5493(84)90169-9.

[147] S. Liang, P.-B. Gning, L. Guillaumat, Quasi-static behaviour and damage assessment of flax/epoxy composites, Materials Design 67 (2015) 344-353. doi:10.1016/j.matdes. 2014.11 .048$.

[148] S. M. Panamoottil, R. Das, K. Jayaraman, Anisotropic continuum damage model for prediction of failure in flax/polypropylene fabric composites, Polymer Composites 37 (8) (2015) 2588-2597. doi : 10.1002/pc. 23453.

[149] V. Mušutova, P. Tej, J. Kolísko, M. Černý, Analysis of the geometry and microcracks of kevlar/epoxy composites, Advanced Materials Research 1095 (2015) 3-7. doi:10. 4028/www.scientific.net/amr.1095.3. 
[150] M. Andrews, R. Day, A. Patrikis, R. Young, Deformation micromechanics in aramid/epoxy composites, Composites 25 (7) (1994) 745-751. doi:10.1016/ 0010-4361 (94)90210-0.

[151] M. Kersani, S. V. Lomov, A. W. V. Vuure, A. Bouabdallah, I. Verpoest, Damage in flax/epoxy quasi-unidirectional woven laminates under quasi-static tension, Journal of Composite Materials 49 (4) (2014) 403-413. doi : 10.1177/0021998313519282.

[152] J. M. Waller, E. Andrade, R. L. Saulsberry, D. O. Thompson, D. E. Chimenti, Use of acoustic emission to monitor progressive damage accumulation in kevlar® 49 compositesdoi:10.1063/1.3362168.

[153] D. U. Shah, P. J. Schubel, M. J. Clifford, P. Licence, The tensile behavior of off-axis loaded plant fiber composites: An insight on the nonlinear stress-strain response, Polymer Composites 33 (9) (2012) 1494-1504. doi:10.1002/pc. 22279.

[154] K. Charlet, C. Baley, C. Morvan, J. Jernot, M. Gomina, J. Bréard, Characteristics of hermès flax fibres as a function of their location in the stem and properties of the derived unidirectional composites, Composites Part A: Applied Science and Manufacturing 38 (8) (2007) 1912-1921. doi:10.1016/j .compositesa.2007.03.006.

[155] Z. Mahboob, Y. Chemisky, F. MERAGHNI, H. Bougherara, Mesoscale modelling of tensile response and damage evolution in natural fibre reinforced laminates 119. 